\title{
Use of non-pathogenic bacteria as vectors for targeted gene expression cancer gene therapy
}

Citation for published version (APA):

Mengesha Woldemicael, A. (2009). Use of non-pathogenic bacteria as vectors for targeted gene expression cancer gene therapy. [Doctoral Thesis, Maastricht University]. Maastricht University. https://doi.org/10.26481/dis.20090401am

Document status and date:

Published: 01/01/2009

DOI:

10.26481/dis.20090401am

Document Version:

Publisher's PDF, also known as Version of record

\section{Please check the document version of this publication:}

- A submitted manuscript is the version of the article upon submission and before peer-review. There can be important differences between the submitted version and the official published version of record.

People interested in the research are advised to contact the author for the final version of the publication, or visit the DOI to the publisher's website.

- The final author version and the galley proof are versions of the publication after peer review.

- The final published version features the final layout of the paper including the volume, issue and page numbers.

Link to publication

\footnotetext{
General rights rights.

- You may freely distribute the URL identifying the publication in the public portal. please follow below link for the End User Agreement:

www.umlib.nl/taverne-license

Take down policy

If you believe that this document breaches copyright please contact us at:

repository@maastrichtuniversity.nl

providing details and we will investigate your claim.
}

Copyright and moral rights for the publications made accessible in the public portal are retained by the authors and/or other copyright owners and it is a condition of accessing publications that users recognise and abide by the legal requirements associated with these

- Users may download and print one copy of any publication from the public portal for the purpose of private study or research.

- You may not further distribute the material or use it for any profit-making activity or commercial gain

If the publication is distributed under the terms of Article $25 \mathrm{fa}$ of the Dutch Copyright Act, indicated by the "Taverne" license above, 


\section{Use of Non-Pathogenic Bacteria as Vectors for Targeted Gene Expression in Cancer Gene Therapy}

Asferd Mengesha 
The study presented in this thesis was performed at the Department of Radiation Oncology (Maastro Lab), School for Oncology \& Developmental Biology (GROW), Maastricht University, Maastricht, The Netherlands

Printed by Procopia

(C) Asferd Mengesha Woldemicael, Maastricht, 2009

No part of this thesis may be reproduced in any form without prior written approval from the author 


\title{
Use of non-pathogenic bacteria as vectors for targeted gene expression in cancer gene therapy
}

\author{
PROEFSCHRIFT \\ ter verkrijging van de graad van doctor aan de Universiteit Maastricht, \\ op gezag van de Rector Magnificus, Prof. mr. G.P.M.F. Mols \\ volgens het besluit van het College van Decanen, \\ in het openbaar te verdedigen \\ op wensdag 1 April 2009 om 14.00 uur
}

door

Asferd Mengesha Woldemicael 
Promoter:

Prof. dr. P. Lambin

\section{Copromotor:}

Dr. Jan Theys

Beoordelingscommissie:

Prof. dr. F.C.S. Ramaekers (Voorzitter)

Prof. dr. C.A. Bruggeman

Prof. dr. V. Tjan-Heijnen

Prof. dr. M. Vooijs, Molecular Research Lab, UMC Utrecht. 
This thesis is dedicated to

My wife Dr. Netsanet Shiferaw And

My sons Ammanuel and Bereket 


\section{TABLE OF CONTENTS:}

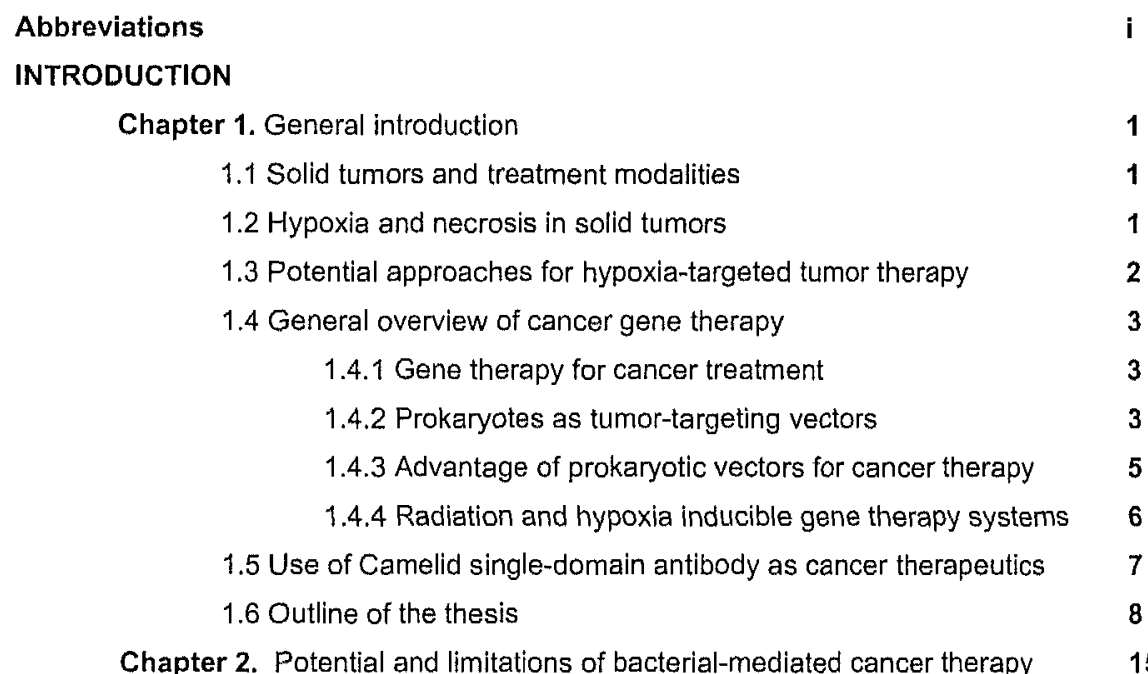

\section{SALMONELLA}

Chapter 3. Efficacy of gene therapy-delivered cytosine deaminase is determined by enzymatic activity but not expression

Chapter 4. Development of a Flexible and Potent Hypoxia-Inducible Promoter for Tumor-Targeted Gene Expression in Attenuated Salmonella

Chapter 5. Identification of highly induced Salmonella genes to increase the specificity of Salmonella mediated cancer therapy

\section{CLOSTRIDIUM}

Chapter 6 . Repeated cycles of Clostridium-directed enzyme prodrug therapy result in sustained antitumour effects in vivo

Chapter 8. General discussion and future perspectives 125

REFERENCE 
Abbreviations

Abbreviations:

\begin{tabular}{|c|c|}
\hline $5-\mathrm{FC}$ & 5-fluorocytosine \\
\hline $5-\mathrm{FU}$ & 5-fluorouracil \\
\hline aa & amino acid(s) \\
\hline Ap & ampicillin \\
\hline BCG & Bacille Calmette-Guérin \\
\hline $\mathrm{BHI}$ & brain heart infusion \\
\hline $\mathrm{bp}$ & base pair(s) \\
\hline CD & cytosine deaminase \\
\hline CDNA & complementary deoxyribonucleic acid \\
\hline cfu & colony forming units \\
\hline $\mathrm{CmR}$ & chloramphenicol resistance gene \\
\hline COBALT & combination bacteriolytic therapy \\
\hline $\operatorname{codA}$ & cytosine deaminase gene \\
\hline DNA & deoxyribonucleic acid \\
\hline DNase & deoxyribonuclease \\
\hline ds & double-stranded \\
\hline EDTA & ethylenediaminetetraacetate \\
\hline ELISA & enzyme-linked immunosorbent assay \\
\hline $\mathrm{Em}$ & erythromycin \\
\hline FNR & fumerate nitrate reductase \\
\hline GFP & green fluorescent protein \\
\hline Gy & Gray \\
\hline HIF & hypoxia-inducible factor \\
\hline HRE & hypoxia responsive element \\
\hline HSV1-TK & herpes simplex virus type 1 thymidine kinase \\
\hline i.p. & intraperitoneal \\
\hline i.t. & intratumoural(ly) \\
\hline I.v & intravenous \\
\hline IFN & interferon \\
\hline IL2 & interleukin-2 \\
\hline $\mathrm{kb}$ & kilo base pair(s) \\
\hline $\mathrm{kDa}$ & kilo Dalton \\
\hline LB & Luria Bertani \\
\hline LPS & lipopolysaccharides \\
\hline mRNA & messenger ribonucleic acid \\
\hline MRS & magnetic resonance spectroscopy \\
\hline$m s b B$ & myristoyl transferase in lipid A biosynthesis, \\
\hline $\mathrm{mTNFa}$ & murine tumour necrosis factor a \\
\hline $\mathrm{nt}$ & nucleotide(s) \\
\hline OD600 & optical density at wavelength $600 \mathrm{~nm}$ \\
\hline PAGE & polyacrylamide gel electrophoresis \\
\hline PBS & phosphate buffered saline \\
\hline PCR & polymerase chain reaction \\
\hline PET & positron emitting tomography \\
\hline RLUU & relative light units \\
\hline RNA & ribonucleic acid \\
\hline Rpm & rotations per minute \\
\hline RT & room temperature \\
\hline S.c. & subcutaneous \\
\hline s.d. & standard deviation \\
\hline SD & Shine Dalgarno \\
\hline SDS & sodium dodecyl sulphate \\
\hline SDS-PAGE & sodium dodecyl sulphate polyacrylamide gel electrophoresis \\
\hline SPI & Salmonella pathogenicity island \\
\hline Spp. & Subspecies \\
\hline tk & thymidine kinase; \\
\hline TK & thymidine kinase \\
\hline tlc & thin layer chromatography \\
\hline
\end{tabular}


Abbreviations

TNFa

UV

$v / V$

$w / v$

wt

tumour necrosis factor $\alpha$

ultraviolet

volume per volume

weight per volume

wild-type 


\section{CHAPTER 1}

\section{GENERAL INTRODUCTION}




\section{GENERAL INTRODUCTION}

\subsection{Solid tumors and treatment modalities}

Cancer is a disease with a high incidence in the western world. It is a molecularly heterogeneous disease that can result from a multitude of genetic alterations [1]. The use of conventional treatment modalities results in $-50 \%$ cure of cancer patients, whereas failure to control the tumor locally and metastasis result in treatment failure in the rest. Although many patients can be successfully treated with conventional therapies, such as surgery, radiotherapy and chemotherapy, the efficacy of these therapies is limited by various factors [2]. For instance, the effectiveness of surgical removal may be restricted by the accessibility of the tumor, inadequate removal and the presence of distant metastases. Chemotherapy can be impaired by the development of drug resistance malignant cells and the occurrence of undesired systemic side effects [3]. Furthermore, the efficacy of both radio- and chemotherapy is hindered by the presence of hypoxic/necrotic regions (see below) in the majority of solid tumors. Thus, for many patients, current treatments are ineffective and consequently overall survival rates often remain low. As a result the therapeutic potential of alternative innovative approaches is being evaluated. Included amongst these new approaches is gene therapy, with a wide variety of proposed delivery vectors and therapeutic genes (see section 1.3.1)

\subsection{Hypoxia and necrosis in solid tumors}

Cancer cells are characterized by an aberrantly accelerated metabolism and an exponential proliferation. This results in an imbalance of "oxygen-supply" and "oxygen-consumption" leading to heterogeneity in regional oxygenation. This disequilibrium is a major causative factor of tumor hypoxia [4]. Similarly, necrotic regions are a common, if not a universal, feature of solid tumors. These necrotic regions typically develop at a distance from functioning blood vessels beyond the diffusion gradient of oxygen.

The importance of hypoxia in solid tumors is linked to the fact that hypoxic cells are intrinsically more resistant to current cancer therapies. Tumor hypoxia is a major factor contributing to the failure of radiotherapy. This is largely because DNA damage produced by ionizing radiation, which would otherwise become flxed and lethal to cells by reacting with $\mathrm{O}_{2}$ in well oxygenated conditions, can be restored to its undamaged form under hypoxic conditions [5]. Tumor hypoxia may also compromise the outcome of conventional chemotherapy. Since the hypoxic tumor cells are distant from functional biood vessels, inherently lower concentration of chemotherapeutic agents can reach them [6]. Furthermore, hypoxic tumor cells may demonstrate an inhibition of cell cycle progression and proliferation, and hence may be relatively resistant to many anticancer drugs that target rapidly dividing cells [3,7-10]. Hypoxia-induced modifications of gene expression may also contribute to this poor prognostic outcome, giving rise to a more aggressive loco-regional disease and an enhanced invasive capacity [11]. In addition hypoxia also regulates mRNA translation through 
a variety of mechanisms, each with important contributions to hypoxic gene expression [12]. Thus, there is a lot of clinical evidence that hypoxia interferes with the therapy efficacy of solid tumors and also contributes to a more malignant phenotype [10]. On the other hand, since hypoxia and necrosis are unique to tumor, these features may be exploited to develop tumor specific treatment strategies as such therapies that target hypoxic/necrotic regions may have the potential to specifically kill malignant tumor cells while sparing the surrounding normal tissues.

\subsection{Potential approaches for hypoxia-targeted cancer therapy}

The fact that hypoxia negatively impacts on therapy is well established, effective therapy requires to overcome the observed radio- and chemoresistance. Many attempts have been made, most of these focused on trying to restore normal oxygenation to the tumor. Examples of this approach include the use of recombinant erythropoletin (EPO) to increase hemoglobin levels [13], accelerated radiotherapy in combination with carbogen breathing and nicotinamide administration (ARCON) [14] or the use of radiation modifying drugs like nimorazoles [15]. Despite some success of these approaches, the concept of improving tumor oxygenation ignores in part the biological effects of hypoxia that may be important in malignancy and treatment response outside of therapy resistance. The increased understandings of the biology of hypoxic cells have led to new ideas for treating hypoxic tumors. Instead of attempting to rid tumors of hypoxia; approaches have been developed to exploit hypoxia for therapeutic advantage. This can be established by using a pharmaceutical approach, as shown by the use of bioreductive drugs $[16,17]$. These are compounds that are reduced by enzymes to their toxic, active metabolites only or preferentially in the absence of oxygen. Importantly, therapeutic interventions to counteract the biological responses of cells towards hypoxia have also been developed. These include the use of angiogenesis inhibitors and targeting of the important transcription factor -"Hypoxia inducible factor-1 (HIF-1)" [2]. HIF-1 plays pivotal roles in the cellular adaptive response to hypoxic microenvironment [18]. HIF-1 is a heterodimeric transcription factor composed of $\alpha-(H I F-1 \alpha)$ and $\beta$-subunit (HIF-1 $\beta$ ). Its activity is mainly dependent on the stability of the complex. The resulting complex promotes the expression of numerous genes by interacting with their hypoxia-responsive elements (HRE). These genes are involved in crucial aspects of cancer biology, including angiogenesis, cell survival, glucose metabolism and invasion. The importance of HIF-1 as a transcription factor, suggests that HIF-1 and its regulators could be tumor-specific targets for anticancer therapy [19]. Another possibility to exploit the microenvironment of hypoxic/necrotic tumor cells is the application of gene therapy. A recent approach uses the concept of targeting (facultative) anaerobic bacteria to the hypoxic/necrotic areas of the tumor. This concept will be described in detail in the subsequent section. 


\subsection{General overview}

\subsubsection{Gene therapy for cancer treatment}

Cancer gene therapy involves the transfer of genetic material to individual cells or the microenvironment aiming at cancer cell eradication. This can be accomplished directly by transferring genetic material into the cancer cells themselves or indirectly by e.g. stimulating the immune system to recognize and eliminate tumor cells. One of the most important problems in the development and use of gene therapy is the safe and specific delivery of genes to the tumor. A variety of viral delivery vectors and a number of non-viral mechanisms have been developed. Many different approaches have been conceived to produce more selective vector systems [20]. Delivery can be targeted to tumor-specific and tissue-specific antigens, and targeted gene expression has been analyzed using tissue-specific, diseasespecific and/or inducible promoter systems. Successful gene therapy requires not only the discovery of an appropriate therapeutic gene for treatment, but also a selective vector system by which the gene can be delivered to the desired site both efficiently and accurately [21]. A fundamental requirement of these strategies is that only tumor cells should be exposed as much as possible to the toxic agent, while normal healthy tissues are not affected. Over the past decade, many strategies using both viral and non-viral methods to deliver therapeutic genes have been explored $[22,23]$. Vehicles such as retro- and adenoviruses, liposomes and naked DNA injection or electroporation are currently being evaluated in clinical trials and new delivery systems like gene-attenuated adenoviruses, lentiviruses, polylysine constructs and leukocytes are being developed [24]. Although so far, clinical trials have met with only little success, they did serve to highlight some deficiencies of the applied approaches and as such, have led to a reassessment of the field. Most importantly, preclinical and clinical data suggest that strategies need to focus less on the choice of the therapeutic gene than on the means of dellvering it. Therefore, when making choices regarding suitable vectors for gene therapy for cancer, it is important to recognize both the factors that distinguish a tumor from its surrounding normal tissue as well as the factors that limit successful therapy with available treatments. Tumor hypoxia is a good example. Since this micro-environmental condition arises due to the chaotic organization and irregularity of blood vessels, sufficient delivery of oxygen, nutrients and accordingly also therapeutic agents to all cells within the tumor is prevented [25]. On the other hand, it also represents a unique environment not found elsewhere in the body. This environment encourages the growth of strictly anaerobic and facultative anaerobic bacteria [26-29].

\subsubsection{Prokaryotes as tumor-targeting vectors}

An alternative to viral delivery that has been proposed is the use of bacteria as gene delivery vehicles. Several strains have been genetically engineered to deliver a therapeutic gene into tumors. As such, it can be considered a gene therapy approach. If on the other hand, gene therapy is to be defined as the introduction of a gene, or part of a gene, into the cancer cells (or normal cells) then using recombinant bacteria as anticancer vectors is not gene therapy. 
Bacteria are not vectors for the introduction of genes into mammalian cells. However, they can and do concentrate in tumors and can carry a gene of interest to produce a protein of choice in tumors.

Live bacteria were first associated with cancers almost two centuries ago when tumor regression was observed in patients who contracted gas gangrene [30]. Today, interest in microbe-based approaches to cancer therapy has reemerged with the discovery of strains that specifically and preferentially target solid tumors, and with the development of techniques to engineer them, reducing their toxicity and arming them with genes encoding therapeutic proteins. Although several species of bacteria have been investigated as anti-cancer agents, most of the current approaches are focused on non-pathogenic strictly anaerobic Clostridium and Bifidobacteria strains and facultative anaerobic strains such as Salmonella [28,31-33]. Although, the precise molecular mechanisms underling bacterial tumor colonization are not fully understood, the presence of hypoxic/necrotic areas within solid tumors provide the necessary anaerobic microenvironment for bacterial proliferation [34]. It is also believed that areas of necrosis provide nutrients to further promote the growth of facultative anaerobes. In addition, these areas with low oxygen and high interstitial pressure are considered to be an immunological sanctuary, where bacterial clearance mechanisms are greatly inhibited [35] (Figure 1).

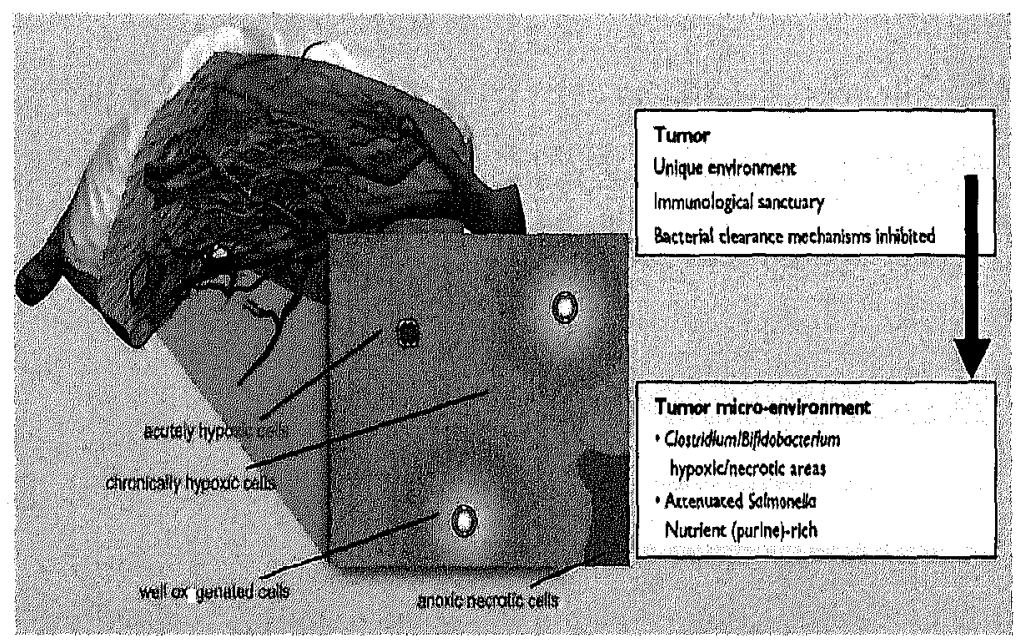

Figure 1.1. Acute and chronic hypoxia in solid tumors. An imbalance of oxygen-supply and consumption leading to heterogeneity in regional oxygenation. This will lead to the development of tumor hypoxla. Hypoxic/necrotic areas within tumor provide the necessary anaerobic m/croenvironment for bacterial proliferation. Areas of necrosis also provide nutrients to promote the growth of facultalive anaerobes. Furthermore, these areas with low oxygen and high Interstitial pressure are considered to be an immunological sanctuary, where bacterial clearance mechanisms are greatly inhibited [36].

For the last decades, preclinical studies clearly demonstrated the success of prokaryotic based therapy with respect to their specificity, efficacy in controlling tumor growth and delivering effector genes coding for therapeutic proteins [37-40] (Figure 2). Current research 
have been focusing to determine the best colonizing host, testing different therapeutic proteins and assessing the therapeutic efficacy of different strategies either as a single treatment or in combination with other treatment modalities. The potential and limitations of prokaryotic-based cancer therapy will be discussed in chapter 2 .

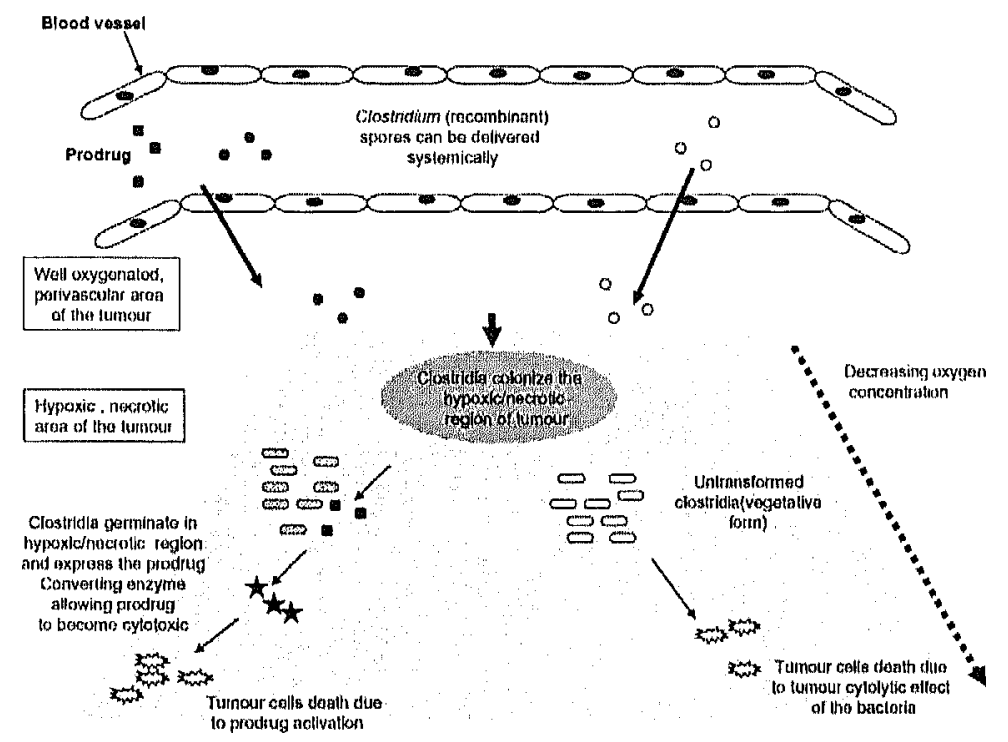

Figure 1.2. Use of clostridia to target the hypoxic/necrotic regions of solid tumors. Wild-type or recombinant clostridia carrying a therapeutic gene (e.g. encoding prodrug converting enzyme such as CD or NTR, or a cytotoxic drug such as TNFa or IL-2) can be administered systemically. Upon arrival to the hypoxic/necrotic part of the tumor, clostridia germinate and proliferate thereby expressing the transgene, leading to tumor cell death.

\subsubsection{Advantages of prokaryotic vectors for cancer gene therapy}

The application of prokaryotic-based vectors as gene therapy delivery vehicles offers several advantages:

(1) The approach is safe: safety is obviously an important issue when live vector systems are used for clinical use. Some of the hurdles of using viral vectors include the expression of viral antigenes that may subsequently lead to an increased toxicity and immunogenicity. Moreover, viral particles are sequestered within the target cells or secreted into body fluid with subsequent spread into the environment $[41,42]$. On the other hand, clinical trials in which non-pathogenic bacterial strains were used have demonstrated to be safe. In the event of an adverse effect the prokaryotic vector can always be eliminated from the blood stream with the use of readily available antibiotics. This not only allows control over bacterial presence in the tumor but also to maintain control over therapeutic gene expression, as the gene is expressed in the bacterial host $[39,43]$.

(2) The system exhibits a high degree of tumor selectivity: since hypoxic/necrotic regions are not present in normal tissues and thus represent a unique feature of solid tumors. Most solid 
tumors investigated have been shown to contain hypoxic/necrotic regions, even in tumors as small as $1 \mathrm{~mm}^{3}$.

(3) The approach is feasible and easy to implement: The production of spores or prokaryotic stock solutions is straightforward. Importantly, in the case of Clostridium vectors, the therapeutic spore formulation is oxygen insensitive, they can subsequentiy be easily handled, stored and administrated [30].

(4) Systemic administration is possible: While most viral vectors have to be intratumorally injected, prokaryotic vectors can be delivered by intravenous (iv), or intraperitoneal (ip). This is a major advantage over many viral vectors, which largely or completely lack efficacy following systemic delivery $[35,36]$.

(5) Broad and high degree of tumor specificity: prokaryotic vectors have been shown to target a broad range of solid tumors, including melanoma, lung, colon, breast, renal, hepatic, and prostate tumors, independent of $p 53$ mutations $[35,44]$.

(6) Delivery capacity: One of the primary limitations of most viral vectors has been the small size of the virion, which only permits the packaging of very limited sizes (usually a few kilobases) of exogenous DNA. However, in theory such limitation doesn't exist when the foreign gene is integrated in the bacterial host genome resulting in almost unlimited capacity for insertion of therapeutic genes. Furthermore, live bacteria are metabolically active and continuously produce active proteins while infecting tumors [45].

\subsubsection{Radiation and hypoxia inducible gene therapy systems}

Studies over the past decade have sought to incorporate ionizing radiation and hypoxia responsive gene promoters to conditionally activate cancer gene therapy vectors [46-49]. The murine early growth response (Egr1) gene has been used as the predominant model of a radiation-inducible promoter in this context [50]. Furthermore, the identification of the radiation-responsive sequences or CArG elements has enabled the construction of Improved, synthetic promoters [47]. Gene therapy vectors that express therapeutic genes following Irradiation have been produced [51]. Delivery of such vectors to the tumor allows temporal and spatial expression of the transgenes within the radiation field [52].

Analogues to mammalian system, the potential use of radiation-induced promoters to control gene expression in prokaryotic vector system has been investigated [53]. In an attempt to enhance the tumor targeting and efficacy of Clostridium-based gene therapy, a therapeutic gene encoding mouse tumor necrosis factor a (TNF- a) was placed under the regulatory control of the recA promoter [54]. RecA is involved in the SOS repair system and its expression is activated by single-strand breaks in DNA. lonizing radiation (IR) at the clinically relevant dose of 2 gray resulted in significantly enhanced gene expression [55].

Similarly, hypoxia has been exploited to drive therapeutic gene expression from gene therapy vectors delivered to solid tumors [52]. Hypoxia-responsive elements (HREs), present in promoters of various HIF-responsive genes driving genes have been used to control heterologous gene expression [56]. 
Analogous to the eukaryotic context in which the hypoxia response element (HRE) is the recognition site for the HIF-1, an oxygen-responsive global transcription factor (FNR) induces the expression of a number of bacterial genes during anaerobic growth following binding to a consensus FNR recognition site at the promoter of target genes [57]. FNR is a bifunctional protein that acts both as a hypoxic sensor and a hypoxia-responsive transcription factor. FNR-regulated promoters are thus considered to be attractive candidates that can be exploited for hypoxia-inducible gene expression in prokaryotes [58].

\subsection{Use of Camelid single-domain antibody for cancer therapy}

Camelids produce functional antibodies devoid of light chains of which the single $\mathrm{N}$-terminal domain is fully capable of antigen binding. The variable domains of this heavy-chain subclass are still capable of binding an antigen. This Variable domain of the Heavy chain of a Heavychain subclass antibody is referred to as VHH. These VHHs have several advantages for biotechnological applications [59]. They are well expressed in microorganisms and have a high stability and solubility. The field of recombinant antibody technology has rapidly progressed during the last two decades, mainly because of the interest in their human therapeutic use. The ability to select specific human antibodies by display technologies and to improve their affinity, stability, and expression level by molecular evolution has further boosted the field. The discovery that camelids (bactrian camels, dromedaries, and llamas) produce functional antibodies devoid of light chains formed a further breakthrough because their single $\mathrm{N}$-terminal domain binds antigen without requiring domain pairing. These heavychain antibodies also lack the $\mathrm{CH} 1$ domain, which in a conventional antibody associates with the light chain and to a lesser degree interacts with the VH domain. Most research on the biotechnological application of single domain antibodies was done using camelids because of their ease of handling, including immunization. Methods to isolate antigen-specific VHHs from immune, nonimmune, or semisynthetic libraries using phage, yeast, or ribosome display are now well established [59].

These heavy-chain antibodies provided a natural solution for size reduction of an antibody fragment. In contrast to $\mathrm{VH}$ fragments of conventional antibodies, these small molecules (VHH) are well expressed and were shown to overcome, to a large extent, the stability, aggregation and degradation problems often encountered with Single Chain Variable Fragments (ScFvs) [59]. Several VHHs are now being studied for use in various disease areas, including oncology, inflammatory and neurodegenerative diseases. Several studies have identified cell surface antigens that are tumor or lineage specific (e.g. CD20 in lymphoma), receptors that are mutated in cancer cells (e.g. mutated EGFR) [60], or receptors that are over expressed on cancer cells relative to normal cells (e.g. EGFR) [61]. VHHs binding to epidermal growth factor receptor (EGFR) can block epidermal growth factor (EGF) binding to its receptor, which can be used to treat solid tumors [60-62]. 


\subsection{Outline of the thesis}

Each of the sections describes the work focused on the use of two different prokaryotic protein delivery vectors for cancer therapy. As such, the work presented in this thesis can be divided in two sections. The first part deals with the use of attenuated salmonella as a protein delivery vehicle while the second portion of the thesis deals with clostridium.

\section{Salmonella}

The first two chapters give an overview about the importance of hypoxia in the current status of gene therapy for cancer treatment. Chapter 1 contains the general introduction, whereas in chapter 2 a review is given of the use of prokaryotic-based vector systems as alternative approaches for cancer treatment.

In the first part of this work described in chapter 3 , we aimed to assess the value of in vivo ${ }^{19} \mathrm{~F}$-MRS to predict the success of the Salmonella-mediated cytosine deaminase (CD)/5fluorocytosine (5-FC) cancer therapy system and to evaluate the method as a tool to allow individualized treatment.

Chapters 4 and 5 describe our approach to make the delivery vector a real therapeutic option with increased tumor specificity. In that context we sought to develop a $2^{\text {nd }}$ generation clinically relevant attenuated Salmonella strain expressing a therapeutic protein under the regulatory control of an inducible promoter, thereby increasing temporal and spatial control of gene expression. To this end our specific objectives were (1) To determine the best promoter in terms of induction following exposure to hypoxia or lonizing radiation and, (2) To find the best inducible tumor-specific Salmonella promoter.

\section{Clostridium}

The Clostridium-mediated transfer of therapeutic proteins to solid tumors has been extensively studied. Until now however, limited successes have been achieved in terms of clostridia engineered to express therapeutic proteins in preclinical models. One of the hurdles was the lack of efficient and reliable gene transfer methods in proteolytic clostridial strains.

As a result we developed a reproducible gene transfer protocol in these clostridial strains with best tumor colonizing properties. Secondly, we assessed the therapeutic efficacy of nitroreductase recombinant $C$. sporagenous delivered in multiple cycles. The results are described in chapter 6 .

In chapter 7, we describe our studies in which we use this novel gene transfer protocol. We have generated a recombinant clostridia expressing camelids single chain antibody (VHH) directed against HIF-1 $\alpha$ as an extension to the already existing anticancer therapeutics used in clostridial vectors. Finally, in chapter 8 , the results of this thesis are summarized and discussed. 


\section{References:}

1. Croce, C.M. (2008) Oncogenes and cancer. N Engl J Med, 358, 502-11.

2. Wouters, B.G., Weppler, S.A., Koritzinsky, M., Landuyt, W., Nuyts, S., Theys, J., Chiu, R.K. and Lambin, P. (2002) Hypoxia as a target for combined modality treatments. Eur J Cancer, 38, 240-57.

3. Janssen, H.L., Haustermans, K.M., Balm, A.J. and Begg, A.C. (2005) Hypoxia in head and neck cancer: how much, how important? Head Neck, 27, 622-38.

4. Vaupel, P. and Mayer, A. (2007) Hypoxia in cancer: significance and impact on clinical outcome. Cancer Metastasis Rev, 26, 225-39.

5. Brown, J.M. and Wilson, W.R. (2004) Exploiting tumour hypoxia in cancer treatment. Nat Rev Cancer, 4, 437-47.

6. Durand, R.E. (1994) The influence of microenvironmental factors during cancer therapy. In Vivo, 8, 691-702.

7. Kizaka-Kondoh, S., Inoue, M., Harada, H. and Hiraoka, M. (2003) Tumor hypoxia: a target for selective cancer therapy. Cancer Sci, 94, 1021-8.

8. Nordsmark, M., Alsner, J., Keller, J., Nielsen, O.S., Jensen, O.M., Horsman, M.R. and Overgaard, J. (2001) Hypoxia in human soft tissue sarcomas: adverse impact on survival and no association with p53 mutations. Br J Cancer, 84, 1070-5.

9. Nordsmark, M., Loncaster, J., Aquino-Parsons, C., Chou, S.C., Gebski, V., West, C., Lindegaard, J.C., Havsteen, H., Davidson, S.E., Hunter, R., Raleigh, J.A. and Overgaard, J. (2006) The prognostic value of pimonidazole and tumour pO2 in human cervix carcinomas after radiation therapy: a prospective international multicenter study. Radiother Oncol, 80, 123-31.

10. Hockel, M., Schlenger, K., Hockel, S. and Vaupel, P. (1999) Hypoxic cervical cancers with low apoptotic index are highly aggressive. Cancer Res, 59, 4525-8.

11. Graeber, T.G., Osmanian, C., Jacks, T., Housman, D.E., Koch, C.J., Lowe, S.W. and Giaccia, A.J. (1996) Hypoxia-mediated selection of cells with diminished apoptotic potential in solid tumours. Nature, 379, 88-91.

12. Koritzinsky, M., Magagnin, M.G., van den Beucken, T., Seigneuric, R., Savelkouls, K. Dostie, J., Pyronnet, S., Kaufman, R.J., Weppler, S.A., Voncken, J.W., Lambin, P., Koumenis, C., Sonenberg, N. and Wouters, B.G. (2006) Gene expression during acute and prolonged hypoxia is regulated by distinct mechanisms of translational control. Embo J, 25, 1114-25.

13. Henke, M. and Guttenberger, R. (2000) Erythropoietin in radiation oncology - A review. 1st international conference, Freiburg, June 11-12, 1999. Oncology, 58, 17582.

14. Kaanders, J.H., Bussink, J. and van der Kogel, A.J. (2002) ARCON: a novel biologybased approach in radiotherapy, Lancet Oncol, 3, 728-37.

15. Brown, J.M. (2000) Exploiting the hypoxic cancer cell: mechanisms and therapeutic strategies. Mol Med Today, 6, 157-62.

16. Koch, C.J. (1993) Unusual oxygen concentration dependence of toxicity of SR-4233, a hypoxic cell toxin. Cancer Res, 53, 3992-7.

17. Rischin, D., Peters, L., Fisher, R., Macann, A., Denham, J., Poulsen, M., Jackson, M., Kenny, L., Penniment, M., Corry, J., Lamb, D. and McClure, B. (2005) Tirapazamine, Cisplatin, and Radiation versus Fluorouracil, Cisplatin, and Radiation in patients with locally advanced head and neck cancer: a randomized phase II trial of the TransTasman Radiation Oncology Group (TROG 98.02). J Clin Oncol, 23, 79-87.

18. Semenza, G.L. (2001) HIF-1, O(2), and the 3 PHDs: how animal cells signal hypoxia to the nucleus. Cell, 107, 1-3.

19. Harris, A.L. (2002) Hypoxia--a key regulatory factor in tumour growth. Nat Rev Cancer, 2, 38-47.

20. Waehler, R., Russell, S.J. and Curiel, D.T. (2007) Engineering targeted viral vectors for gene therapy. Nat Rev Genet, 8, 573-87.

21. Lambin, P., Theys, J., Landuyt, W., Rijken, P., van der Kogel, A., van der Schueren, E., Hodgkiss, R., Fowler, J., Nuyts, S., de Bruijn, E., Van Mellaert, L. and Anne, J. (1998) Colonisation of Clostridium in the body is restricted to hypoxic and necrotic areas of tumours. Anaerobe, 4, 183-8.

22. Seth, P. (2005) Vector-mediated cancer gene therapy: an overview. Cancer Biol Ther, 4, 512-7. 
23. Wolff, J., Lewis, D.L., Herweljer, H., Hegge, J. and Hagstrom, J. (2005) Non-viral approaches for gene transfer. Acta Myol, 24, 202-8.

24. Greco, O., Patterson, A.V. and Dachs, G.U. (2000) Can gene therapy overcome the problem of hypoxia in radiotherapy? J Radiat Res (Tokyo), 41, 201-12.

25. Dreher, M.R., Liu, W., Michelich, C.R., Dewhirst, M.W., Yuan, F. and Chilkoti, A. (2006) Tumor vascular permeability, accumulation, and penetration of macromolecular drug carriers. J Natl Cancer Inst, 98, 335-44.

26. Dang, L.H., Bettegowda, C., Huso, D.L., Kinzler, K.W. and Vogelstein, B. (2001) Combination bacteriolytic therapy for the treatment of experimental tumors. Proc Natl Acad Sci U S A, 98, 15155-60.

27. Liu, S.C., Minton, N.P., Giaccia, A.J. and Brown, J.M. (2002) Anticancer efficacy of systemically delivered anaerobic bacteria as gene therapy vectors targeting tumor hypoxia/necrosis. Gene Ther, 9, 291-6.

28. Minton, N.P., Mauchline, M.L., Lemmon, M.J., Brehm, J.K., Fox, M., Michael, N.P., Giaccia, A. and Brown, J.M. (1995) Chemotherapeutic tumour targeting using clostridial spores. FEMS Microbiol Rev, 17, 357-64.

29. Theys, J., Landuyt, W., Nuyts, S., Van Mellaert, L., Bosmans, E., Rijnders, A., Van Den Bogaert, W., van Oosterom, A., Anne, J. and Lambin, P. (2001) Improvement of Clostridium tumour targeting vectors evaluated in rat rhabdomyosarcomas. FEMS Immunol Med Microbiol, 30, 37-41.

30. Minton, N.P. (2003) Clostridia in cancer therapy. Nat Rev Microbiol, 1, 237-42.

31. Pawelek, J.M., Low, K.B. and Bermudes, D. (1997) Tumor-targeted Salmonella as a novel anticancer vector. Cancer Res, 57, 4537-44.

32. Lee, C.H., Wu, C.L. and Shiau, A.L. (2004) Endostatin gene therapy delivered by Salmonella choleraesuis in murine tumor models. J Gene Med, 6, 1382-93.

33. Yazawa, K., Fujimori, M., Amano, J., Kano, Y. and Taniguchi, S. (2000) Bifidobacterium longum as a delivery system for cancer gene therapy: selective localization and growth in hypoxic tumors. Cancer Gene Ther, 7, 269-74.

34. Mengesha, A., Dubois, L., Chiu, R.K., Paesmans, K., Wouters, B.G., Lambin, P. and Theys, J. (2007) Potential and limitations of bacterial-mediated cancer therapy. Front Biosci, 12, 3880-91.

35. Pawelek, J.M., Low, K.B. and Bermudes, D. (2003) Bacteria as tumour-targeting vectors. Lancet Oncol, 4, 548-56.

36. Theys, J., Barbe, S., Landuyt, W., Nuyts, S., Van Mellaert, L., Wouters, B., Anne, J. and Lambin, P. (2003) Tumor-specific gene delivery using genetically engineered bacteria. Curr Gene Ther, 3, 207-21.

37. Forbes, N.S., Munn, L.L., Fukumura, D. and Jain, R.K. (2003) Sparse initial entrapment of systemically injected Salmonella typhimurium leads to heterogeneous accumulation within tumors. Cancer Res, 63, 5188-93.

38. Clairmont, C., Lee, K.C., Pike, J., Ittensohn, M., Low, K.B., Pawelek, J., Bermudes, D., Brecher, S.M., Margitich, D., Turnier, J., Li, Z., Luo, X., King, I. and Zheng, L.M (2000) Biodistribution and genetic stability of the novel antitumor agent VNP20009, a genetically modified strain of Salmonella typhimurium. J Infect Dis, 181, 1996-2002.

39. Theys, J., Landuyt, A.W., Nuyts, S., Van Mellaert, L., Lambin, P. and Anne, J. (2001) Clostridium as a tumor-specific delivery system of therapeutic proteins. Cancer Detect Prev, 25, 548-57.

40. Theys, J., Pennington, O., Dubois, L., Anlezark, G., Vaughan, T., Mengesha, A. Landuyt, W., Anne, J., Burke, P.J., Durre, P., Wouters, B.G., Minton, N.P. and Lambin, P. (2006) Repeated cycles of Clostridium-directed enzyme prodrug therapy result in sustained antitumour effects in vivo. $B r J$ Cancer, 95, 1212-9.

41. Raper, S.E., Chirmule, N., Lee, F.S., Wivel, N.A., Bagg, A., Gao, G.P., Wilson, J.M. and Batshaw, M.L. (2003) Fatal systemic inflammatory response syndrome in a ornithine transcarbamylase deficient patient following adenoviral gene transfer. $\mathrm{Mol}$ Genet Metab, 80, 148-58.

42. Yang, Y., Li, Q., Ertl, H.C. and Wilson, J.M. (1995) Cellular and humoral immune responses to viral antigens create barriers to lung-directed gene therapy with recombinant adenoviruses. $J$ Virol, 69, 2004-15.

43. Van Mellaert, L., Barbe, S. and Anne, J. (2006) Clostridilum spores as anti-tumour agents. Trends Microbiol, 14, 190-6. 
44. Ryan, R.M., Green, J. and Lewis, C.E. (2006) Use of bacteria in anti-cancer therapies. Bioessays, 28, 84-94.

45. Wei, M.Q., Ellem, K.A., Dunn, P., West, M.J., Bai, C.X. and Vogelstein, B. (2007) Facultative or obligate anaerobic bacteria have the potential for multimodality therapy of solid tumours. Eur J Cancer, 43, 490-6.

46. Lipnik, K., Greco, O., Scott, S., Knapp, E., Mayrhofer, E., Rosenfellner, D., Gunzburg W.H., Salmons, B. and Hohenadl, C. (2006) Hypoxia- and radiation-inducible, breast cell-specific targeting of retroviral vectors. Virology, 349, 121-33.

47. Greco, O., Marples, B., Wilson, G.D., Joiner, M.C. and Scott, S.D. (2005) Radiationinduced gene therapy. Radiat Res, 163, 707-8.

48. Greco, O., Marples, B., Dachs, G.U., Williams, K.J., Patterson, A.V. and Scott, S.D. (2002) Novel chimeric gene promoters responsive to hypoxia and ionizing radiation. Gene Ther, 9, 1403-11.

49. Scott, S.D. and Greco, O. (2004) Radiation and hypoxia inducible gene therapy systems. Cancer Metastasis Rev, 23, 269-76.

50. Greco, O., Powell, T.M., Marples, B., Joiner, M.C. and Scott, S.D. (2005) Gene therapy vectors containing CArG elements from the Egr1 gene are activated by neutron irradiation, cisplatin and doxorubicin. Cancer Gene Ther, 12, 655-62.

51. Greco, O., Joiner, M.C., Doleh, A., Powell, A.D., Hillman, G.G. and Scott, S.D. (2006) Hypoxia- and radiation-activated Cre/loxP 'molecular switch' vectors for gene therapy of cancer. Gene Ther, 13, 206-15.

52. Greco, O., Marples, B., Joiner, M.C. and Scott, S.D. (2003) How to overcome (and exploit) tumor hypoxia for targeted gene therapy. J Cell Physiol, 197, 312-25.

53. Nuyts, S., Van Mellaert, L., Theys, J., Landuyt, W., Lambin, P. and Anne, J. (2001) The use of radiation-induced bacterial promoters in anaerobic conditions: a means to control gene expression in clostridium-mediated therapy for cancer. Radiat Res, 155 , 716-23.

54. Nuyts, S., Van Mellaert, L., Theys, J., Landuyt, W., Bosmans, E., Anne, J. and Lambin, P. (2001) Radio-responsive recA promoter significantly increases TNFalpha production in recombinant clostridia after 2 Gy irradiation. Gene Ther, 8, 1197-201.

55. Nuyts, S., Van Mellaert, L., Barbe, S., Lammertyn, E., Theys, J., Landuyt, W., Bosmans, E., Lambin, P. and Anne, J. (2001) Insertion or deletion of the Cheo box modifies radiation inducibility of Clostridium promoters. Appl Environ Microblol, 67, 4464-70.

56. Marples, B., Greco, O., Joiner, M.C. and Scott, S.D. (2002) Molecular approaches to chemo-radiotherapy. Eur J Cancer, 38, 231-9.

57. Kiley, P.J, and Beinert, H. (1998) Oxygen sensing by the global regulator, FNR: the role of the iron-sulfur cluster. FEMS Microbiol Rev, 22, 341-52.

58. Sutton, V.R., Mettert, E.L., Beinert, H. and Kiley, P.J. (2004) Kinetic analysis of the oxidative conversion of the $[4 \mathrm{Fe}-4 \mathrm{~S}] 2+$ cluster of FNR to a $[2 \mathrm{Fe}-2 \mathrm{~S}] 2+$ Cluster. J Bacteriol, 186, 8018-25.

59. Harmsen, M.M. and De Haard, H.J. (2007) Properties, production, and applications of camelid single-domain antibody fragments. Appl Microbiol Biotechnol, 77, 13-22.

60. Omidfar, K., Rasaee, M.J., Modjtahedl, H., Forouzandeh, M., Taghikhani, M. and Golmakani, N. (2004) Production of a novel camel single-domain antibody specific for the type III mutant EGFR. Tumour Biol, 25, 296-305.

61. Omidfar, K., Rasaee, M.J., Modjtahedi, H., Forouzandeh, M., Taghikhanl, M., Bakhtiari, A., Paknejad, M. and Kashanian, S. (2004) Production and characterization of a new antibody specific for the mutant EGF receptor, EGFRvIll, in Camelus bactrianus. Tumour Biol, 25, 179-87.

62. Coppieters, K., Dreier, T., Silence, K., de Haard, H., Lauwereys, M., Casteels, P., Beirnaert, E., Jonckheere, H., Van de Wiele, C., Staelens, L., Hostens, J., Revets, H., Remaut, E., Elewaut, D. and Rottiers, P. (2006) Formatted anti-tumor necrosis factor alpha $\mathrm{VHH}$ proteins derived from camelids show superior potency and targeting to inflamed joints in a murine model of collagen-induced arthritis. Arthritis Rheum, 54, 1856-66 


\section{CHAPTER 2}

\section{Bacterial-mediated cancer therapy: Potential and limitations}

Adapted from:

- Asferd Mengesha, Ludwig Dubois, Roland K. Chiu, Kim Paesmans, Bradly G.

Wouters, Philippe Lambin, Jan Theys. Potential and limitations of bacterial-mediated cancer therapy.

Front Blosci. 2007 May 1;12:3880-91.

AND

Ming Q Wei, Asferd Mengesha, David Good, Jozef Anné. Bacterial targeted tumor therapy-dawn of a new era.

Cancer Lett. 2008 Jan 18;259(1):16-27 
TABLE OF CONTENTS

1. Abstract

2. Bacterial Delivery Systems

3. What lessons have we learned?

3.1. Which vehicle should we choose as a host?

3.1.1. Clostridium

3.1.2. Salmonella

3.2. Which therapeutic protein should be delivered?

3.3. Group II intron-based genetic modifications

3.4. Should we combine Bacterial-Mediated Therapy with other treatment options?

3.4.1. Radiotherapy

3.4.2. Vascular Targeting Agents

3.5. Clinical experience so far

4. What lessons are yet to be learned?

4.1. Clostridium

4.2. Salmonella

5. Concluding Remarks

6. Acknowledgments

7. References 


\section{ABSTRACT}

Bacterial-based tumor-targeted therapy is an area of growing interest and holds promise for the treatment of solid tumors. Upon systemic administration, various types of non-pathogenic obligate anaerobes and facultative anaerobes have been shown to infiltrate and selectively replicate within solid tumors. The tumor specificity is based upon the unique physiology of solid tumors, which is often characterized by regions of hypoxia and necrosis. Prokaryotic vectors can be safely administered and their potential to deliver therapeutic proteins has been demonstrated in a variety of preclinical models. New genetic engineering tool, such as the group II intron has shown promise for genetic manipulation of bacteria and forecast the dawn of a new era for a tumor-targeted prokaryotic vector system for gene therapy of solid tumors. Although the amount of clinical experience with bacterial vectors is limited to date, the available data clearly demonstrated the feasibility of bacterial-mediated therapy in humans. There are several issues however that are still unknown and remain major challenges. In this review, using Clostridium and modified Salmonella as prototypical agents, we will discuss the major advantages, challenges and shortcomings of bacterial systems for tumor-specific therapy. In addition, we will highlight the requirements needed to advance the approach into clinical trials.

\section{BACTERIAL DELIVERY SYSTEMS}

Major advances have been made in the understanding of the genetic basis of cancer and this knowledge drives intensive activity worldwide to develop alternative treatment approaches. One of these is the use of gene therapy to selectively target and destroy tumor cells $[1,2]$. Over the past decade, many strategies have been devised, and even more vehicles to deliver therapeutic genes have been constructed [3-5]. However, one of the major drawbacks of most of these vectors is still the lack of tumor specificity. Therefore, when making choices regarding suitable vectors for gene therapy for cancer, it is important to recognize both the factors that distinguish a tumor from its surrounding normal tissue as well as the factors that limit successful therapy with currently available treatments. A good example of this is tumor hypoxia. The majority of solid tumors investigated to date have been shown to contain hypoxic and/or necrotic regions [6]. This microenvironmental condition arises due to the chaotic organization and irregularity of blood vessels preventing sufficient delivery of oxygen, nutrients and consequently also therapeutic agents (i.c. gene delivery vectors) to all cells within the tumor [7]. Although hypoxia causes resistance to radiotherapy and chemotherapy, it also represents a unique environment not found elsewhere in the body $[8,9]$. This environment supports the growth of anaerobic bacteria and provides the nutrients that allow the growth of attenuated facultative anaerobes [10,11]. The concept of using anaerobic bacteria as a single agent to treat tumors has been around for a long time (Figure 1). Live bacteria were first associated with cancers almost two centuries ago when tumor regression was observed in patients who suffered gas gangrene [12]. 
A) Clostridium

1813: Clostrifium associaled with cancer

1800

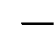

1925

\section{5: Use of Clostriaitun filrate for}

cancer treament

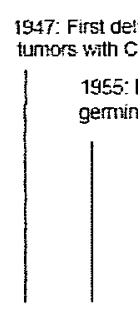

1950

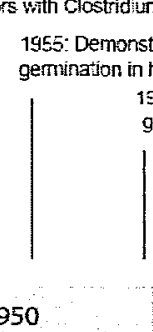

B) Salmonella

$\cdot(2-25$


Today, interest in prokaryote-based approaches to cancer therapy has reemerged with the discovery of non-pathogenic strains that specifically and preferentially target solid tumors. This method has drawn further attention with the development of techniques to genetically modify the bacteria, thereby enabling the expression of anti-cancer therapeutic genes in these hosts $[13,14]$. Numerous publications provide convincing evidence that several genera of bacteria, including Clostridium, Bifidobacterium, and attenuated Salmonella, have potential in cancer therapy [15-19] (Table1). Their therapeutic efficacy is due not only to the high selectivity of the bacteria for hypoxic tumor areas, but also because these hypoxic areas are considered one of the most important barriers to current cancer therapy [20]. Interestingly, the bacteria can be removed simply by using suitable antibiotics, thus allowing the control of bacterial presence and therapeutic gene expression levels in the tumor [21]. In addition, the bacteria can be easily stored and handled, making implementation straightforward [10].

During the last decade, research has focused on determining the best tumor colonizing bacterial host, testing different therapeutic proteins and assessing the therapeutic efficacy of different strategies either as a single treatment or in combination with other therapies [22-27]. So far, clinical experience with prokaryotic vectors is limited to early study with Clostridium and non-extensive Phase I clinical trials with attenuated Salmonella vectors $[28,29]$. Although the information gathered from these studies is restricted, these trials showed that bacterial treatment was safe and well tolerated by patients.

Here, we discuss the achievements made in this research area during the last decade and highlight the limitations and hence areas that need further investigation in order to move on to extended clinical evaluation. 
Table 2.1. Three classes of anaerobic and facultative anaerobes tested for anticancer therapy.

\begin{tabular}{|c|c|c|c|c|}
\hline Class & Species & Features & Advantages & Disadvantages \\
\hline $\begin{array}{l}\text { Class I. } \\
\text { Bifidobacteria }\end{array}$ & $\begin{array}{l}\text { Bifidobacter } \\
\text { Jum } \\
\text { B. longum } \\
\text { B. } \\
\text { adolescentis } \\
\text { B. infantis }\end{array}$ & $\begin{array}{l}\text { Gram }^{+} \text {noni- } \\
\text { motile obligate } \\
\text { anaerobes }\end{array}$ & $\begin{array}{l}\text { Non-pathogenic present } \\
\text { in common intestinal } \\
\text { flora, } \\
\text { Have been used in } \\
\text { human for many years } \\
\text { Probiotic bacteria } \\
\text { Can be used for } \\
\text { intravenous or oral } \\
\text { administration } \\
\text { Expression of } \\
\text { recombinant protein }\end{array}$ & $\begin{array}{l}\text { No obvious oncolytic } \\
\text { effect } \\
\text { Non-spore former } \\
\text { More susceptible to } \\
\text { non-permissive } \\
\text { conditions } \\
\text { More difficult to store } \\
\text { and handle }\end{array}$ \\
\hline $\begin{array}{l}\text { Class II. } \\
\text { Facultative } \\
\text { intracellular } \\
\text { Bacteria }\end{array}$ & $\begin{array}{l}\text { Salmonella } \\
\text { S. } \\
\text { typhimurium } \\
\text { S. } \\
\text { choleraesuis } \\
\text { Listeria } \\
\text { L. } \\
\text { monocytoge } \\
\text { nes } \\
\text { E. coll }\end{array}$ & $\begin{array}{l}\text { Gram facultative } \\
\text { anaerobes } \\
\text { Agent for } \\
\text { intestine } \\
\text { infection } \\
\text { Gram }{ }^{+} \\
\text {facultative } \\
\text { anaerobes } \\
\text { Gramं } \\
\text { facultative } \\
\text { anaerobes }\end{array}$ & $\begin{array}{l}\text { Attenuated vaccine } \\
\text { strain has been proved } \\
\text { safe clinically in human, } \\
\text { Blochemistry pathways } \\
\text { and genomes are well } \\
\text { characterized } \\
\text { Auxotrophic isolates for } \\
\text { solid tumors have } \\
\text { intrinsic anti-tumour } \\
\text { activity } \\
\text { Grow under aerobic and } \\
\text { anaerobic conditions, } \\
\text { thus can target both } \\
\text { large and small tumors, } \\
\text { enter professional } \\
\text { antigen presenting cells } \\
\text { and induce strong innate } \\
\text { immune response } \\
\text { Have the potential as a } \\
\text { veccine vector for } \\
\text { tumour therapy } \\
\text { Blology is well studled } \\
\text { and known }\end{array}$ & $\begin{array}{l}\text { Have a tumor to normal } \\
\text { tissue ratio of } 1000: 1 \text {, } \\
\text { therefore a significant } \\
\text { number of bacteria } \\
\text { colonize normal organs } \\
\text { Cell wall components } \\
\text { are immunogenic } \\
\text { Virulence factors exist, } \\
\text { especially LPS in the } \\
\text { bacterial cell wall, thus } \\
\text { safety is an issue when } \\
\text { large amount of } \\
\text { bacteria are delivered } \\
\text { Virulence factors exist, } \\
\text { such as LPS }\end{array}$ \\
\hline $\begin{array}{l}\text { Class } 111 . \\
\text { Strictly } \\
\text { Anaerobic } \\
\text { bacteria }\end{array}$ & $\begin{array}{l}\text { Clostridlum } \\
\text { Proteolytic } \\
\text { C. sporogenes } \\
\text { C.novyl } \\
\text { Saccharolytio } \\
\text { C. butyricum } \\
\text { C. } \\
\text { acetobutylicum } \\
\text { C. oncolyticum } \\
\text { C. beljerinckii }\end{array}$ & $\begin{array}{l}\text { Gram, strictly } \\
\text { anaerobes } \\
\text { normal habitat in } \\
\text { the soil, aquatic } \\
\text { sediments, and } \\
\text { Intestinal tract of } \\
\text { both animals and } \\
\text { humans }\end{array}$ & $\begin{array}{l}\text { Spore former } \\
\text { Spores are stable, easy } \\
\text { to produce and } \\
\text { economic to use } \\
\text { Clostridial spores can be } \\
\text { delivered non-Invaslvely } \\
\text { and systemically, le. } \\
\text { intravenous injectlon } \\
\text { Have shown extensive } \\
\text { oncolytic abllity } \\
\text { Spores are non- } \\
\text { Immuinagenlc and can be } \\
\text { repeatedly doliverod } \\
\text { Oncolysis occurs } \\
\text { irrespective of lumor cells' } \\
\text { heterogenelty or growth } \\
\text { status }\end{array}$ & $\begin{array}{l}\text { Only colonize In large } \\
\text { tumors with area of } \\
\text { hypoxlainecrosis }\end{array}$ \\
\hline
\end{tabular}




\section{WHAT LESSONS HAVE WE LEARNED?}

\subsection{Which vehicle should we choose as a host?}

\subsubsection{Clostridium}

The concept of using bacteria as tumor vectors has been most vigorously pursued using several Clostridium species. The genus Clostridium is one of the largest prokaryotic genera consisting of anaerobic, Gram-positive rods that are unified by their ability to form spores. Although they have probably achieved greatest prominence as a consequence of pathogenic representatives such as $C$. botulinum or $C$. tetani, most of the members are non-pathogenic. As early as 1813 , it was reported that tumors from patients who suffered gas gangrene regressed following clostridial infection [10] (Figure 1). In 1935, Connell used sterile filtrates from $C$. histolyticum to treat advanced cancers [30]. The observed tumor regression was attributed to the production of proteolytic enzymes and thus Parker and colleagues [31] were the first to deliberately infect tumor-bearing mice with clostridial spores. These studies indicated the potential using clostridial spores for inducing tumor lysis. The exquisite tumor selectivity of the system was further demonstrated by Malmgren and Flanigan [32] who intravenously administered $C$. tetani spores to tumor-bearing mice resulting in death from tetanus poisoning within 48 hours while being entirely benign to healthy control animals. This indicated that the spores germinated exclusively within the tumors, thereby causing release of the tetanus toxins that resulted in death. Möse and Möse demonstrated the nondetrimental effect of this group of bacteria using C. butyricum M55 (later named C. oncolyticum, and now classified as $C$. sporogenes ATCC 13732) by self injecting a spore suspension [33]. Intravenous administration of these bacteria into mice bearing Ehrlich ascites tumors resulted in tumor colonization and extensive oncolysis. These results were confirmed in other studies using a variety of rodent tumor models and non-pathogenic strains. Overall, growth of wildtype clostridial species was well tolerated and frequently resulted in destruction of a significant portion of the tumor, Invariably however, regrowth occurred from a remaining outer viable rim. This occurred even if done in combination with other therapies, such as the administration of drugs or decreasing the oxygen level in respiratory air of animals [11]. Although the development of gene transfer methods for Clostridium in the 90's allowed the generation of recombinant strains (see below), the use of unmodified clostridia for treatment of tumors has gained new interest due to the recent work performed in the laboratory of Dr. Vogelstein [34]. Screening a number of anaerobic bacterial species (bifidobacteria, lactobacilli and pathogenic clostridia) for their ability to accumulate In experimental tumors in animals, has led to the isolation of a superior tumor colonizing strain, C. novyi. Upon removal of a lethal toxin expressed by this strain, a non-toxic variant named $C$. novyi-NT (in which NT stands for non-toxic) is produced. Dang et al demonstrated that $C$. novyi-NT can efficiently infiltrate and extensively spread throughout the necrotic tumor regions. Similar to the observations initially made with $C$. butyricum M55, germination of the spores led to enlargement of the necrotic regions and to tumor growth delay. The therapeutic effects increased further when a combination bacteriolytic therapy (COBALT) was set up in order to 
increase the therapeutic effect (see below). Althought these results are certainly very promising, it should also be noted that the observations made were tumor-type dependent and that some combinations led to severe toxicity as a consequence of the so-called 'tumor lysis' syndrome [34].

Alternatively, one can choose to use less aggressive tumor colonizing strains, but instead enhance their therapeutic properties through genotypic changes. in this concept, put forward a decade ago by Brown and colleagues [35], the Clostridium host is used as a tumor specific gene delivery systern. Advances made in the development of clostridial gene transfer systems in the early 90's have allowed for the reproducible generation of recombinant strains [36]. As these gene systems were only applicable for saccharolytic strains, the initial experiments were undertaken with $C$. acetobutylicum and $C$. beijerinckii [37]. Unfortunately, these strains have been shown to have limited suboptimal tumor colonization properties. Indeed, upon systemic administration of spores, colonization levels of the saccharolytic $C$. acetobutylicum and $C$. beijerinckii were shown to be 1000 -fold lower compared to proteolytic $C$. sporogenes strains [38]. Despite their suboptimal tumor colonization properties, studies with recombinant saccharolytic strains have provided invaluable information with regards to heterologous gene expression in Clostridium (see below). The use of saccharolytic strains instead of a proteolytic host may even be beneficial if the secretion of the desired therapeutic gene is required, as degradation of extracellular therapeutic protein might be enhanced when using the latter [39]. The superior tumor colonizing strains have very long been refractory to genetic engineering. Although Liu et al [40] described a protocol for their transformation in 2002, this protocol has been shown to be highly inefficient. Fortunately, the very recent development of a gene transfer protocol based on conjugation now allows the construction of recombinant $C$. sporogenes strains. Consequently, it is now possible to use the strain with the highest tumor colonization (i.c. C. sporogenes) and thus the highest therapeutic gene expression levels. Not surprisingly, preclinical experiments with recombinant $C$. sporogenes have shown increased anti-tumor efficacy in comparison with $C$. acetobutylicum or $C$. beijerinckii (see below). Besides Clostridium, other anaerobic bacterial species such as Bifidobacterium can be used to deliver a variety of effector genes to tumors [19]. However, the rather low colonization efficiency and the tendency to clump rather that distribute within nectrotic areas [34], would appear to make Bifidobacterium inferior to the optimum strain of clostridia.

\subsubsection{Salmonella}

Genetically engineered strains of Salmonella have also been proposed for tumor selective therapy [41]. In contrast to clostridia, Salmonella are Gram-negative motile bacteria that grow well in both oxygenated and hypoxic tumor areas. To overcome its pathogenicity, $S$. typhimurium was attenuated by genetically stable chromosomal deletion of the purl and $m s b B$ genes [25,41-43]. The $m s b B$ deletion alters the lipid $A$ component of lipopolysaccharide (LPS), resulting in a strongly reduced induction of proinflammatory cytokines, thereby 
reducing the risk for a subsequent septic shock. The deletion of purl created a requirement for an external source of adenine. The low toxicity profile of the pur $r, m_{s b B^{-}}$strain (which was designated VNP20009) has been demonstrated in rodents, pigs and monkeys [44-46]. The potential of this strain to function as anti-tumor vector was reported in 1997, in a study where VNP20009 injected into tumor-bearing animals were shown to replicate preferentially in tumors [41]. Tumor-to-normal tissue ranged from 250:1 to 10.000:1 at 2 days post-injection. In addition to this selective tumor accumulation, VNP20009 have been shown to have inherent anti-tumor activity in a number of tumor models [47]. The exact mechanism for this innate anti-tumor effect is unknown, although it has been suggested that the major Salmonella virulence regulon, SPI-2, might play a role [48]. Another double auxotroph mutant strain of Salmonella (S. typhimurium A1), which has a requirement for amino acids Leu and Arg, has also been shown to be successful at tumor inhibition and regression [49]. Recently, Lee and colleagues [50] reported the use of attenuated $S$. choleraesuis as an anti-tumor agent, capable of preferentially accumulating and amplifying within tumors. This vaccine strain of $S$. choleraesuis is capable of delaying tumor growth and enhancing survival in both subcutaneous tumor and experimental metastasis models. Similar to VNP20009, tumor-tonormal tissue ratios ranged from 1000:1 to $10.000: 1$.

Despite the preferential tumor colonization following the administration of attenuated Salmonella to tumor-bearing animals, also the normal tissues are colonized, albeit transiently and to a lesser extent. Obviously this biodistribution pattern can cause undesired side effects and negatively influence the specificity of this gene transfer system. As the main potential of attenuated Salmonella in anti-cancer therapy does not lie within the use of the vector as such but 'armed' with a therapeutic protein, this is especially true for therapeutic genes controlled by strong constitutive promoters. One way to address this issue and to obtain controlled gene expression is to use inducible promoter systems (see below).

\subsection{Which therapeutic protein should be delivered?}

The main advantage of therapeutic proteins produced in situ by prokaryotic vectors directly in the tumor is that high local levels can be achieved, while concurrently avoiding the toxicity that occurs when delivery of these agents would be systemic $[17,51]$. To date, the introduction of two classes of recombinant protein has been explored: (1) proteins that have a direct cytotoxic effect, such as toxins and cytokines [52,53]; and (2) enzymes that convert a nontoxic prodrug into a toxic agent, the so-called prodrug converting enzymes (13, 17). An overview is depicted in Figure 2.

Both Clostridium and attenuated Salmonella strains have been genetically engineered to express cytotoxic agents and cytokines. C. acetobutylicum DSM792 has been genetically engineered to express and secrete murine tumor necrosis factor-alpha (TNF-alpha) and rat interleukin-2 (IL-2) (Figure 2A). Although both cytokines could be efficiently secreted and were shown to be biologically active, the therapeutic benefit has yet to be demonstrated. It can be anticipated that this might be difficult, as levels of recombinant $C$. acetobutylicum in 
tumors are low. TNF has also been expressed in VNP20009 [54]. In vivo experiments with TNF-recombinant VNP20009 showed promising anti-tumor responses in mice bearing colon C38 carcinomas and M27 lung carcinomas.

A slightly different approach has been used with attenuated $S$. choleraesuis as this strain was engineered to carry a eukaryotic expression plasmid, coding for the anti-angiogenic agent endostatin, and administered to $\mathrm{C} 3 \mathrm{H} / \mathrm{HeN}$ mice bearing MTB-2 tumors [50]. Upon tumor colonization, the expression plasmid is transferred from $S$. choleraesuis to the tumor cells where the cytotoxic protein is expressed. This strategy resulted in tumor growth inhibition and prolonged survival of tumor-bearing mice. Importantly, transduction of the expression vector to normal tissue did also occur, thereby highlighting the need for additional levels of control. Similarly, S. choleraesuis transformed with a eukaryotic expression vector encoding thrombospondin-1 (TSP-1) was administered to C57BL/6 tumor-bearing mice. The recombinant $S$. choleraesuis inhibited the growth of melanomas and experimental lung metastasis by more than $40 \%$ compared with injection of $S$. choleraesuis carrying an empty vector. Survival rates of the tumor-bearing mice increased, but complete regression was never observed [55].

The principle focus with bacterial vectors has been the delivery of prodrug converting enzymes. The considerable advantage of using these enzymes lies within their amplifying effect as each individual enzyme can convert large quantities of innocuous prodrug into toxic therapeutic agents, a phenomenon known as the 'bystander' effect. Moreover, as the (pro)drug can diffuse in and out the bacterial cell, there is no need for secretion of the therapeutic protein, thereby avoiding potential problems with enzymatic breakdown in the extracellular environment. In the mid-nineties, $C$. beljerinckii and $C$. acetobutylicum were the first to be transformed with plasmids carrying either the $E$. coll enzyme cytosine deaminase (CD) (13) or nitroreductase (NTR) [56]. Upon in vitro confirmation of their biological activity, spores of the recombinant strains were injected into tumor-bearing animals. The NTR and CD protein were demonstrated to be produced solely in the tumors, thereby providing the proofof-principle that a foreign protein delivered by Clostridium can be expressed exclusively in the tumors of different animal models (Figure 2A). Due to the insufficient levels of viable clostridia in the tumor, these studies failed to produce anti-tumor activity.

In 2002, the development of an electroporation procedure by Liu et al [40] enabled for the first time the transformation of $C$. sporogenes. Intravenous spore injection of $C$. sporogenes transformed using this protocol with an expression plasmid for $C D$, combined with 5fluorocytosine (5-FC) prodrug administration, resulted in significant anti-tumor activity (Figure 2A). The reported development of this transformation system for $C$. sporogenes was certainly encouraging, however, the reported transformation turned out not to be reproducible. As exogenous endonucleases might represent a major impediment to DNA transfer, we therefore devised a procedure based on conjugative transfer from E.coli donors, initially developed for the introduction of plasmids into $C$. difficile [57]. Using this procedure, we have introduced a novel prodrug converting NTR enzyme with superior prodrug turnover characteristics into $C$. 
sporogenes and demonstrated the in vivo efficacy of the approach [58]. Both sets of data clearly show that use of the superior tumor colonizing $C$. sporogenes as a host instead of $C$. acetobutylicum or $C$. beijerinckii, results in increased in vivo anti-tumor efficacy.

In attenuated Salmonella, most experimental work using a prodrug converting enzyme has been done using TAPET-CD, i.e. VNP20009 with CD stably integrated into the chromosome [51]. Extensive preclinical toxicology was carried out in rodents and monkeys while preclinical data also demonstrated very similar biological characteristics for TAPET-CD as compared to VNP20009 [44]. High conversion capacity of 5-FC to 5-fluorouracil (5-FU) was observed following the use of a single TAPET-CD Injection combined with 5-FC administration. Although 5-FU was detectable in normal tissues, the levels were significantly lower. In vivo efficacy was further demonstrated in 3 different mouse tumor models, showing a $90 \%$ tumor growth inhibition at 6 weeks after the start of the treatment [28]. Based on these data, a protocol for the use of TAPET-CD in the clinic has been proposed (see below).

Although the obtained preclinical in vivo data are encouraging, the specificity of the Salmonella-mediated gene transfer system is negatively influenced by the additional colonization of normal tissues [47]. Obviously, this biodistribution pattern can cause undesired side-effects [59]. Therefore, to limit therapeutic gene expression specifically to the tumor, we recently developed a hypoxia-inducible promoter (HIP-1) system and showed that gene expression was driven off HIP-1 under both acute and chronic hypoxia, with induction factors up to -200 -fold following hypoxia treatment. Most interestingly, use of HIP-1 confined gene expression strictly to the tumor (Figure 2B). Thus, HIP-1 has the potential to increase the specificity of the Salmonella-mediated gene delivery system by establishing spatial control of gene expression [60]. Spatial and temporal control of therapeutic protein expression has previously also been demonstrated in Clostridium, that carried a plasmid in which the cDNA encoding TNF was ligated downstream of the radiation-inducible recA promoter (RIP) [61]. Genetic engineering of the wild-type recA promoter resulted in $412 \%$ increase in TNF activity following irradiation with a clinically relevant 2 Gray (Gy) dose. Moreover, reactivation of the promoter was possible by giving a second dose of 2 Gy [62]. The application of RIP thus holds promise for use in a clinical setting, as patients generally receive small 2 Gy daily fractions during fractionated radiotherapy.

\subsection{Group II intron-based genetic modifications}

As described earlier all such Clostridial genetic engineering relied upon plasmid transfer, using either conjugative or electroporation protocols. However, plasmid-mediated genetic modification has drawbacks, as plasmid-associated antibiotic resistant genes could impede future clinical use. Furthermore, plasmid is not stable, and can be lost during bacterial growth. In contrary to plasmid based strain modification, a very recent development of a strain alteration was made possible by deleting gene coding for toxin using simple heat treatment [34]. This was possible as the toxin gene was encoded on Phage. Chromosomally coded 
genes however, are not amenable for such modification. Apparently, novel and powerful genetic tool to manipulate Clostridial strains are exceedingly required.

Group II intron is a new genetic element that was initially found in the mitochondrial and chloroplast genome of lower eukaryotes and plants and recent research has shown promise as a tool for bacterial genetic modification [63,64]. In 1993, the first bacterial group II intron was discovered [65]. Since then, more and more group II introns have been found in both Gramnegative and Gram-positive bacteria, accounting for about a quarter of sequenced bacterial genomes [66-68].

Comprehensive analyses of the mobile group II intron from the ItrB gene of Lactococcus lactis (LI.ItrB) have revealed that such elements propagate into their specific target site via an RNAmediated 'retrohoming' mechanism [69]. The retrohoming reaction of the LI.LtrB intron is carried out by a ribonucleoprotein complex of an intron-encoded protein (IEP) and excised intron lariate RNA. During this process, target site recognition is achieved primarily by basepairing between the excised intron lariat RNA and the target site DNA $[70,71]$. The IEP first recognizes a small number of fixed positions in the flanking regions of the DNA target site and facilitates local DNA unwinding, enabling the intron RNA to base pair to a 14- to 16-nucleotide target region. The inserted RNA is then reverse transcribed by the associated intron-encoded enzyme protein, producing a DNA insertion that inactivates the disrupted gene. Since the DNA target site is recognized primarily by base pairing of intron RNA and IEP recognition spots, the intron targeting sequences can be modified to insert into a specific DNA target site unlike other retro transposable elements such as retroviral and lentiviral vectors, which integrate gene into many different DNA sequences randomly.

The preferred positions recognized by the IEP are few and flexible; multiple intron target sites can be easily identified in any gene by an intron prediction program using a computer algorithm. Intron target specificity can therefore be re-programmed by modifying the DNA sequence encoding the appropriate part of the intron. More importantly, since most activities required to effect the LI.ItrB Intron's site-specific integration are encoded within the intron, its mobility is essentially independent of host factors. The modified group II introns have a wide host range and have been shown to be efficiently mobile in genomic DNA of both grampositive and -negative bacteria such as E. coli, Shigella flexneri, S. typhimurium Lactococcus lactis, Staphylococcus aureus, and Clostridium perfringens [72-74].

In summary the relatively high frequency of stable gene inactivation observed in using intronmediated technology represents a potentially major technical advance for the following reasons: i) It has wide host range and can be further engineered to increase the frequency and efficiency of mobility; ii) The insertion mechanism is independent of host-cell recombinant function; iii) It can be reprogrammed to insert into any desired target sequence and develop new gene retargeting vectors; iv) it has the ability to readily insert additional genetic markers into target gene; v) It may have broad applications in a range of bacteria as well as higher organisms. 
A good example is ClosTron, a Clostridial specific targetron has recently reported [75], opening a new era for genetic manipulation of Clostridial strains. In this study they have been able to demonstrate generation of five mutants in four Clostridial species including $C$. acetobutylicum and C. sporogenes, commonly used strains in anti cancer research. The procedure is highly efficient and reproducible, and that would revolutionize future Clostridia related cancer researches. Furthermore, the technology may also be used for 'knock-in' as well as for 'knock-out', providing the opportunity to introduce therapeutic genes into the genomes of those Clostridial strains being explored as anti-tumor agents. Due to its high frequency and site-specific insertion, targetron approach is a promising tool to facilitate construction of recombinant Clostridia carrying multiple heterologous DNA insertions for expression from a single bacterial chromosome. This would open the possibility of using this technology to co-express therapeutic proteins with different therapeutic targets in the same bacterial cell, aflowing their co-delivery into tumor cells. More intriguingly, intron insertion is stable. This stability is particularly important for anti cancer vectors, where consistent therapeutic gene expression maintained over time is desired.

\subsection{Should we combine bacterial-mediated therapy with other treatment options?}

Although wild-type strains of C.novyi-NT and VNP20009 have been successfully used as a single treatment with some anti-tumor effects, concurrent treatments have been explored in an attempt to enhance their therapeutic efficacy. The two most extensively investigated strategies include the combination with radiation or vascular targeting agents (Figure 2B).

\subsubsection{Radiotherapy}

Radiation therapy (RT) is used in more than $75 \%$ of patients with malignant tumors [76]. While radiation is very efficient in killing well oxygenated cells, it is much less effective in killing hypoxic cells. Since the bacterial-mediated approach specifically targets these radiation-resistant hypoxic cells, it is anticipated that the combination of these two therapies can increase the therapeutic ratio.

The combination of radiotherapy with both C. novyi-NT and VNP20009 has been investigated in the past. Treatment of athymic nu/nu mice bearing HCT116 xenographs with $C$. novyi-NT spores and fractionated RT (2 Gy/day for 5 days) resulted in significant tumor shrinkage as compared to either treatments alone or to control tumors [77]. Importantly, this combination therapy was shown to be tumor-type specific and, in all cases, a small number of residual cells eventually caused tumor recurrence. In addition to external beam radiation, C. novyi-NT was also combined with high dose rate brachytherapy leading to a complete cure of two tumor types [77]. Recent experiments have suggested that damage to microvascular endothelial cells might be an important component of the radiation effects. Such microvascular damage is predicted to increase the niche for C.novyi-NT growth by creating more hypoxic areas within tumors, thereby increasing tumor colonization. Interestingly, the efficacy of the combination treatment was shown to be independent of the tumor volumes 
suggesting that a wide range of tumor volumes may be treated with this strategy [77]. Furthermore, the addition of radiosensitizing drugs such as 5-FU may increase the efficacy of this combined treatment. For example, it is conceivable to design a treatment regime combining C. novyi-NT with systemic 5-FU administration and RT. Perhaps the most interesting combination would be to combine $C D$-recombinant $C$. sporogenes with radiation and 5-FC as the 5-FU would be produced locally in the tumor via the CD activity of the recombinant bugs, thereby avoiding the toxicity of systemic 5-FU administration. We have calculated that $1-3 \%$ conversion of $5-\mathrm{FC}$ to 5 -FU would be sufficient to achieve clinically significant radiosensitization and importantly, reported conversion efficiencies of CD recombinant Clostridium strains exceed this value, making this combination particularly promising [76].

Analogous to C.novyi-NT, attenuated Salmonella have been shown to be effective when combined with radiotherapy. Platt and coworkers [78] applied doses ranging from 5 to $15 \mathrm{~Gy}$ in two melanoma tumor models. Although the combination treatment resulted in prolonged survival for both tumor models, the doses used were above clinically relevant levels. Therefore, further investigation using lower radiation doses is required to obtain more applicable information.

\subsubsection{Vascular Targeting Agents}

The use of vascular targeting agents is an attractive strategy that extended the use of clostridia to very small tumors which have yet to develop necrotic areas. These agents specifically larget the dividing endothelial cells and cause rapid vascular shutdown in tumors, thereby promoting necrosis and hypoxia [79]. Our group was the first to show the benefit of such vascular targeting agent such as Combretastatin A4-phosphate (CombreAp) to improve Clostridium tumor colonization. Our data demonstrated that systemic administration of CombreAp resulted in severe vascular shutdown specifically in the tumor within 3-4 hours with subsequent development of 


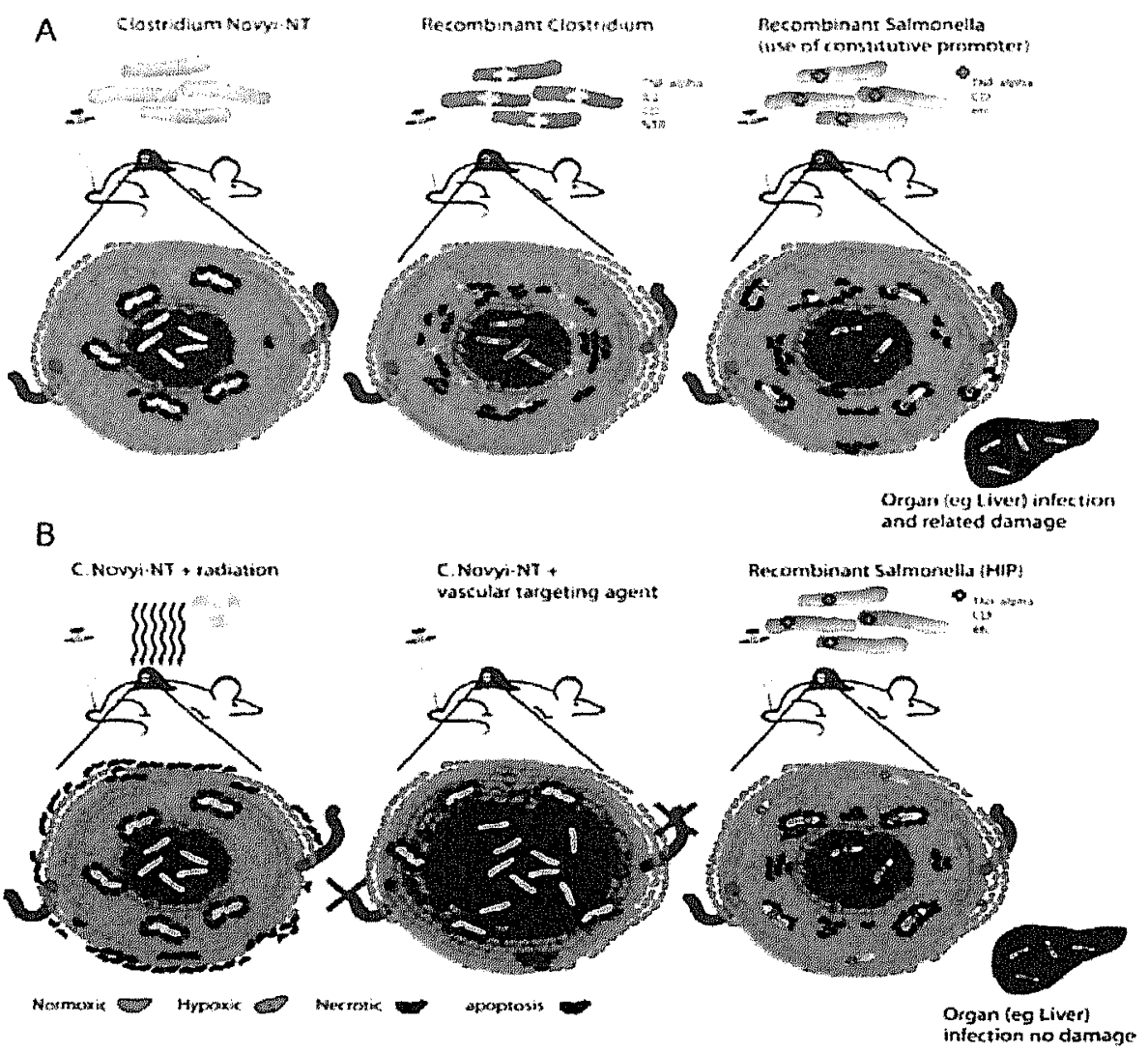

Figure 2.2. Scheme summarizing bacterial-mediated cancer therapy. (A) Intravenous administration of either $C$. novyi-NT of recombinant Clostridium spores into a tumor-bearing animal. The spores are dispersed throughout the body, but only those that encounter the hypoxic/necrotic regions of the tumor are able to germinate and multiply as vegetative cells. Administration of $\mathrm{C}$. novyi-NT results in the secretion of hydrolytic enzymes that lyse the surrounding tumor cells. The recombinant Clostridium is generated by transforming the bacteria with clastridial expression plasmids encoding either a prodrug-converting enzyme (CD, NTR) or a cytokine (TNF-alpha, IL-2). Depending on the type of therapeutic protein employed, use of these recombinant strains result in direct or indirect cytoloxic effects. Recombinant Salmonella spread throughout the body and colonize normal tissues (albeit transiently and to a lesser exteni) but preferentially replicate in the tumor. Its tumor localization is not restricted only to the hypoxic/necrotic region of solid tumors. When a therapeutic gene is driven off a constitutive promoter, undesired damage to colonized normal tissues may occur. (B) Combination therapy with radiotherapy or vascular targeting agents and use of spatial control of gene expression in recombinant Salmonella using HIP. Radiotherapy leads to cell killing of the well oxygenated cells, while the Clostridium specifically target the hypoxic/necrotic areas leading to an enhanced or supra-additive effect on tumor growh inhibition and/or cure. Vascular targeting agents lead to rapid lumor vascular shuldown thereby promoting hypoxia and necrosis that result in increased tumor colonization by Clostridium. Administration of recombinant Salmonella, with the therapeutic gene controlled by HIP restricts expression of cytotoxic proteins and cell killing to the hypoxic region of solid tumors. CD: cytosine deaminase, NTR: nitroreductase, TNF: tumor necrosis factor, IL: interleukin, HIP: hypoxia-inducible promoter. 
necrosis. This phenomenon led to consistent and high levels of clostridial colonization of (very) small tumors that were very inefficiently colonized in the absence of CombreAp (see Figure 2). Similarly, in animals treated with CD-recombinant $C$. acetobutylicum spores, the incidence of CD-positive tumors increased from $58 \%$ to $100 \%$ when treated concomitantly with CombreAp [17]. Dang et al [34] recently reported notable results using a comparable regime (anti-vascular agent dolastatin 10 in combination with other chemotherapeutics and $C$. novyi-NT). Although most treated mice showed tumor regression, and complete cures were observed in a considerable proportion of mice, this treatment strategy was also associated with significant toxicity due to the combination of vascular targeting and chemotherapeutic agents. Nevertheless, the available data certainly indicate the potential benefit of this combination strategy and therefore merits further investigation.

\subsection{Clinical experience so far}

Based on encouraging initial animal studies in the 60 's that demonstrated the ability of clostridia to target solid tumors, clinical trials were soon thereafter initiated as spores of $C$. butyricum M-55 were injected intravenously to cancer patients. As with the animal tumors, most of the human malignancies experienced partial tumor lysis with no evidence of clostridial germination or tissue destruction in the surrounding normal tissues. Although the patients suffered no adverse side effects from the injection of these organisms with the exception of mild to moderate fever, most patients showed no evidence of measurable tumor regression $[80,81]$. The clinical trials were discontinued due to the lack of clinical benefit, as well as tumor regrowth from an outer rim of viable tumor cells that usually remained despite the destruction of large parts of the tumor. Although these studies are difficult to repeat and would not live up to current standards for clinical trials, they clearly demonstrate that administration of spores from non-pathogenic Clostridium strains is nonetheless safe, and that the spores specifically germinate in the necrotic regions of tumor.

The use of attenuated Salmonella as tumor targeting agents in the clinic is much more recent. The first Phase I clinical trial included 26 patients with either metastatic melanomas or metastatic renal cell carcinoma [82]. This study showed that the maximum tolerated dose of VNP20009 was $3 \times 108 \mathrm{cfu} / \mathrm{m} 2$ as doses above this range resulted in dose-dependent elevated levels of circulating pro-inflammatory cytokines such as IL1-beta, TNF-alpha, and IL6. Unfortunately and rather unexpected based on preclinical data, no patients exhibited tumor regression and only three patients had tumors containing viable attenuated bacteria [82]. Despite the disappointing results with the parental VNP20009, another pilot clinical trial, this time using TAPET-CD, was conducted in 2003 [29]. In this study, the effects of a local intratumoral injection of TAPET-CD in combination with 5-FC was tested in three refractory cancer patients. Two patients had evldence of bacterial colonization of the tumor that persisted for at least 15 days following the initial injection. Conversion of 5-FC to 5-FU as a result of $C D$ expression was demonstrated in these two patients. Although no significant adverse events related to the treatment were reported, this clinical study also failed to 
demonstrate significant clinical efficacy, presumably because of insufficient bacterial colonization in the tumors. On the other hand, these human clinical trials do highlight the need for the generation of strains with reduced toxicities and improved tumor colonization properties.

\section{WHAT LESSONS ARE YET TO BE LEARNED?}

Despite significant progresses achieved so far, there are still several issues that need to be addressed before prokaryote-based therapy becomes a standard practice in the clinic. The significance of such issues varies among each therapeutic strain.

\subsection{Clostridium}

The vast majority of preclinical studies with clostridial vectors were conducted in only a limited number of murine experimental models. Consequently, detailed toxicologic, pharmacologic and pharmacokinetic information with clostridial vectors in a wider range of animal models is still absent. Therefore, extensive pharmaceutical studies need to be put in place before a clostridial vector can be routinely used in a clinical setting. One of the most important outstanding issues for recombinant Clostridium vectors is undoubtedly the development of bacterial strains that carry no antibiotic resistance genes along with the therapeutic gene. Furthermore, the development of a clinically relevant delivery vector requires the construction of a strain in which the introduced genes will be integrated into the Clostridium chromosome so that consistent gene expression is maintained over time and to prevent the occurrence of horizontal gene transfer. Recent advances in the field of clostridial engineering have suggested that these challenging issues can be resolved in the near future. The latter tasks are not relevant for wild-type C. novyi-NT, at least as long as this strain does not carry a therapeutic gene [34]. However, if this strain is to be used in the clinic, more detailed information on its genomic and transcriptomic profile will be required to overcome the observed toxicity during the preclinical studies. For example, if the specific toxins should be identified, they could subsequently be confronted. Furthermore, since use of $C$. novyi-NT has been shown to induce the so-called 'fumor lysis' syndrome, a mean to counteract this issue must be achieved [34].

Although for therapeutic efficacy of clostridial vectors, the nature of the best therapeutic gene can be argued (see above), independent of the gene that will be expressed; the levels of biologically active compound at the tumor site should be as high as possible. Optimizing the production of the therapeutic agent may require interference of the protein production process at different levels (transcription, translation). This may involve the use of strong promoters with optimized ribosomal binding sites and adaptation of the codon usage within the CDNA of the gene to the codon preferences in the Clostridium host. Indeed, since the $\mathrm{G}+\mathrm{C} \%$ content in Clostridium is extremely low $(<30 \%)$, insertion of heterologous DNA that does not follow the typical clostridial codon usage will probably lead to instability. Initial studies with the prodrugconverting NTR enzyme in which the codons were adapted for use in Clostridium appear to 
be useful [58]. In addition, benefit is anticipated from the use of more effective enzyme/prodrug combinations, more soluble prodrug derivatives and enzymes with improved catalytic properties. Several recent studies have highlighted the importance and the potential impact of these improvements, and experimental activity within these areas should be encouraged in order to fully exploit the clostridial-mediated approach.

Whether secretion of the therapeutic compound from the prokaryotic cell is advantageous, remains unclear. Although more extensive spreading of the compound within the tumor consequently increasing the therapeutic effect is expected, an increase in the likelihood of therapeutic protein leakage out of the tumor, and subsequent specific immune response against the protein may be seen. Moreover, since optimal tumor colonization requires the application of proteolytic strains such as $C$. sporogenes, it can be anticipated that proteolysis will decrease the levels of secreted therapeutic proteins.

\subsection{Salmonella}

During their clinical development, the attenuated Salmonella vectors have already been extensively tested using many different animal models ranging from mice to non-human primates. While preclinical studies have yielded sufficient information for approval of the conducted clinical trials, the disappointing results of the clinical trials clearly indicated that there are still some lessons to be learned. The key issue that remains before widely using the Salmonella-mediated approach is understanding the exact mechanisms that account for the preferential bacterial tumor colonization and that give rise to the observed innate anti-tumor effects. Hypoxic and necrotic areas within the tumors are speculated to give the attenuated strain a growth advantage by providing essential nutrients such as purines [42]. Furthermore, the tumor may be considered an immunological sanctuary where bacterial clearance mechanisms are inhibited [83]. Also, the major Salmonella virulence regulon, SPI-2 has been implicated in the observed intrinsic anti-tumor effects [41]. A recent study has suggested that bacterial chemotaxis towards certain chemoattractant compounds (e.g. aspartate, serine, citrate, ribose or galactose) produced by quiescent cancer cells, initiate accumulation of bacteria, and that preferential proliferation enhances region-specific accumulation at longer times. The effect of these mechanisms on accumulation was found to vary depending on the local tumor microenvironment that a nutrient-rich environment within the tumor could be a contributing factor to preferential bacterial replication [84]. However, the exact mechanisms leading to tumor accumulation of attenuated Salmonella remain poorly understood to date. $Y$ ret, this information is likely critical to understand why tumors in patients were so inefficiently colonized [82]. A possible explanation is that in patients a more robust immune reaction is induced towards the attenuated Salmonella thereby counteracting bacterial accumulation. Other factors such as the time during which the bacteria are present in the peripheral blood should also be considered as rapid clearance of VNP20009 from the blood was observed during the Phasel clinical trial. In contrast, during preclinical studies in a variety of experimental animal models, high level of administered bacteria could be maintained in the 
blood stream for longer duration. Extending the infusion times of the bacteria in humans might thus help to improve tumor colonization. Overall, a better understanding of the mechanism of preferential tumor accumulation and of host-vector interactions is essential when designing rational strategies to develop a better and more effective therapy for the future.

To date, a number of studies have reported therapeutic efficacy within the context of using Clostridium or attenuated Salmonella as gene therapy vectors $[11,13,51,85]$. Importantly, tumor cure was not tested in any of the aforementioned reports of therapeutic efficacy. To go beyond the point of 'proof-of-principle', a large scale assessment of tumor cure such as TCD50 experiments must be performed. This type of experiment which measures the required radiation dose to cure $50 \%$ of the tumors, has never been performed before in the context of prokaryote-mediated therapy and is the strongest proof of the potential of this system for improving tumor cure.

\section{CONCLUDING REMARKS}

Notwithstanding the lessons that yet have to be learned and despite some barriers that need to be torn down, the application of live prokaryote vectors hold considerable promise for treating solid tumors. Recent progress made in the field of genetic engineering of Clostridium will certainly allow the required progress to develop a relevant vector for clinical testing and without doubt, continuous investigations will eventually reveal the mechanisms that explain the preferential tumor colonization of attenuated Salmonella vectors. The arguments nonetheless remain as to which strain would be the best to use, which therapeutic gene should be integrated or which treatment combination would be most preferred.

In this review, we have discussed the various options with their advantages and shortcomings, and almost certainly the choice of bacteria and treatment regime will be different for each situation and tumor type. Currently, the most pressing need to establish the potential of prokaryote-mediated therapy in humans is for well designed clinical trials. These critical evaluations will facilitate the transfer of bacterial-based treatment to routine clinical practice by relieving the fears and concerns that some clinicians may have to deliberately infect patients with live bacteria.

\section{ACKNOWLEDGMENTS}

L.D. is a predoctoral fellow supported by the LSCH-CT-2003- 502932/EUROXY Grant. 


\section{REFERENCES}

1. Dachs, G.U., Dougherty, G.J., Stratford, I.J. and Chaplin, D.J. (1997) Targeting gene therapy to cancer: a review. Oncol Res, 9, 313-25.

2. Seth, P. (2005) Vector-mediated cancer gene therapy: an overview. Cancer Biol Ther, 4, 512-7.

3. Hajitou, A., Trepel, M., Lilley, C.E., Soghomonyan, S., Alauddin, M.M., Marini, F.C. 3rd, Restel, B.H., Ozawa, M.G., Moya, C.A., Rangel, R., Sun, Y., Zaoui, K., Schmidt, M., von Kalle, C., Weitzman, M.D., Gelovani, J.G., Pasqualini, R. and Arap, W. (2006) A hybrid vector for ligand-directed tumor targeting and molecular imaging. Cell, 125, 385-98.

4. Shen, Y. and Nemunaitis, J. (2006) Herpes simplex virus 1 (HSV-1) for cancer treatment. Cancer Gene Ther, 13, 975-92.

5. Wolff, J., Lewis, D.L., Herweijer, H., Hegge, J. and Hagstrom, J. (2005) Non-viral approaches for gene transfer. Acta Myol, 24, 202-8.

6. Wouters, B.G., Weppler, S.A., Koritzinsky, M., Landuyt, W., Nuyts, S., Theys, J., Chiu, R.K. and Lambin, P. (2002) Hypoxia as a target for combined modality treatments. Eur J Cancer, 38, 240-57.

7. Dreher, M.R., Liu, W., Michelich, C.R., Dewhirst, M.W., Yuan, F. and Chilkoti, A. (2006) Tumor vascular permeability, accumulation, and penetration of macromolecular drug carriers. J Natl Cancer Inst, 98, 335-44.

8. Greco, O., Marples, B., Joiner, M.C. and Scott, S.D. (2003) How to overcome (and exploit) tumor hypoxia for targeted gene therapy. J Cell Physiol, 197, 312-25.

9. Wouters, B.G., Koritzinsky, M., Chiu, R.K., Theys, J., Buijsen, J. and Lambin, P. (2003) Modulation of cell death in the tumor microenvironment. Semin Radiat Oncol, $13,31-41$.

10. Minton, N.P. (2003) Clostridia in cancer therapy. Nat Rev Microbiol, 1, 237-42.

11. Theys, J., Barbe, S., Landuyt, W., Nuyts, S., Van Mellaert, L., Wouters, B., Anne, J. and Lambin, P. (2003) Tumor-specific gene delivery using genetically engineered bacteria. Curr Gene Ther, 3, 207-21.

12. Pawelek, J.M., Low, K.B. and Bermudes, D. (2003) Bacteria as tumour-targeting vectors, Lancet Oncol, 4, 548-56.

13. Fox, M.E., Lemmon, M.J., Mauchline, M.L., Davis, T.O., Giaccia, A.J., Minton, N.P. and Brown, J.M. (1996) Anaerobic bacteria as a delivery system for cancer gene therapy: in vitro activation of 5 -fluorocytosine by genetically engineered clostridia. Gene Ther, 3, 173-8.

14. Minton, N.P., Mauchline, M.L., Lemmon, M.J., Brehm, J.K., Fox, M., Michael, N.P., Giaccia, A, and Brown, J.M. (1995) Chemotherapeutic tumour targeting using clostridial spores. FEMS Microbiol Rev, 17, 357-64.

15. Liu, S.C., Minton, N.P., Giaccia, A.J. and Brown, J.M. (2002) Anticancer efficacy of systemically delivered anaerobic bacteria as gene therapy vectors targeting tumor hypoxia/necrosis. Gene Ther, 9, 291-6.

16. Theys, J., Landuyt, A.W., Nuyts, S., Van Mellaert, L., Lambin, P. and Anne, J. (2001) Clostridium as a tumor-specific delivery system of therapeutic proteins. Cancer Detect Prev, 25, 548-57.

17. Theys, J., Landuyt, W., Nuyts, S., Van Mellaert, L., van Oosterom, A., Lambin, P. and Anne, J. (2001) Specific targeting of cytosine deaminase to solid tumors by engineered Clostridium acetobutyllcum. Cancer Gene Ther, 8, 294-7.

18. Tjuvajev, J., Blasberg, R., Luo, X., Zheng, L.M., King, I. and Bermudes, D. (2001) Salmonella-based tumor-targeted cancer therapy: tumor amplified protein expression therapy (TAPET) for diagnostic imaging. $J$ Control Release, 74, 313-5.

19. Yazawa, K., Fujimori, M., Amano, J., Kano, Y. and Taniguchi, S. (2000) Bifidobacterium longum as a delivery system for cancer gene therapy: selective localization and growth in hypoxic tumors. Cancer Gene Ther, 7, 269-74.

20. Vaupel, P., Kelleher, D.K. and Hockel, M. (2001) Oxygen status of malignant tumors: pathogenesis of hypoxia and significance for tumor therapy. Semin Oncol, 28, 29-35.

21. Theys, J., Landuyt, W., Nuyts, S., Van Mellaert, L., Bosmans, E., Rijnders, A., Van Den Bogaert, W., van Oosterom, A., Anne, J. and Lambin, P. (2001) Improvement of Clostridium tumour targeting vectors evaluated in rat rhabdomyosarcomas. FEMS Immunol Med Microbiol, 30, 37-41. 
22. Barbe, S., Van Mellaert, L. and Anne, J. (2004) Clostridium-mediated transfer system of therapeutic proteins to solid tumors: increased heterologous protein production. Commun Agric Appl Biol Sci, 69, 49-52.

23. Dang, L.H., Bettegowda, C., Agrawal, N., Cheong, I., Huso, D., Frost, P., Loganzo, F., Greenberger, L., Barkoczy, J., Pettit, G.R., Smith, A.B., 3rd, Gurulingappa, H., Khan, S., Parmigiani, G., Kinzler, K.W., Zhou, S. and Vogelstein, B. (2004) Targeting vascular and avascular compartments of tumors with $C$. novyi-NT and antimicrotubule agents. Cancer Biol Ther, 3, 326-37.

24. Landuyt, W., Ahmed, B., Nuyts, S., Theys, J., Op de Beeck, M., Rijnders, A., Anne, J., van Oosterom, A., van den Bogaert, W. and Lambin, P. (2001) In vivo antitumor effect of vascular targeting combined with either ionizing radiation or antiangiogenesis treatment. Int $J$ Radiat Oncol Biol Phys, 49, 443-50.

25. Luo, X., Li, Z., Lin, S., Le, T., Ittensohn, M., Bermudes, D., Runyab, J.D., Shen, S.Y., Chen, J., King, I.C. and Zheng, L.M. (2001) Antitumor effect of VNP20009, an attenuated Salmonella, in murine tumor models. Oncol Res, 12, 501-8.

26. Mei, S., Theys, J., Landuyt, W., Anne, J. and Lambin, P. (2002) Optimization of tumor-targeted gene delivery by engineered attenuated Salmonella typhimurium. Anticancer Res, 22, 3261-6.

27. Nuyts, S., Van Mellaert, L., Theys, J., Landuyt, W., Lambin, P. and Anne, J. (2001) The use of radiation-induced bacterial promoters in anaerobic conditions: a means to control gene expression in clostridium-mediated therapy for cancer. Radiat Res, 155, 716-23.

28. Cunningham, C. and Nemunaitis, J. (2001) A phase I trial of genetically modified Salmonella typhimurium expressing cytosine deaminase (TAPET-CD, VNP20029) administered by intratumoral injection in combination with 5 -fluorocytosine for patients with advanced or metastatic cancer. Protocol no: CL-017. Version: April 9, 2001. Hum Gene Ther, 12, 1594-6.

29. Nemunaitis, J., Cunningham, C., Senzer, N., Kuhn, J., Cramm, J., Litz, C., Cavagnolo, R., Cahill, A., Clairmont, C. and Sznol, M. (2003) Pilot trial of genetically modified, attenuated Salmonella expressing the $E$. coli cytosine deaminase gene in refractory cancer patients. Cancer Gene Ther, 10,737-44.

30. Connell, H. (1935) The study and treatment of cancer byproteolytic enzymes, a preliminary report. Can Med Ass J., 33, 364-370.

31. Parker, R.C., Plummber, H.C., Siebenmann, C.O. and Chapman, M.G. (1947) Effect of hispolyticus infection and toxin on transplantable mouse tumours. Proc. Soc. Exp. Biol. Med, 66, 461-465.

32. Malmgren, R.A. and Flanigan, C.C. (1955) Localization of the vegetative form of Clostridium tetani in mouse tumors following intravenous spore administration. Cancer Res, 15, 473-8.

33. Moese, J.R. and Moese, G. (1964) Oncolysis by Clostridia. I. Activity of Clostridium Butyricum (M-55) and Other Nonpathogenic Clostridia against the Ehrlich Carcinoma. Cancer Res, 24, 212-6.

34. Dang, L.H., Bettegowda, C., Huso, D.L., Kinzler, K.W. and Vogelstein, B. (2001) Combination bacteriolytic therapy for the treatment of experimental tumors. Proc Natl Acad SciU S A, 98, 15155-60.

35. Brown, J.M. and Wilson, W.R. (2004) Exploiting tumour hypoxia in cancer treatment. Nat Rev Cancer, 4, 437-47.

36. Schlechte, H. and Elbe, B. (1988) Recombinant plasmid DNA variation of Clostridium oncolyticum--model experiments of cancerostatic gene transfer. Zentralbl Bakteriol Mikrobiol Hyg [A], 268, 347-56.

37. Minton, N.P. and Oultram, J.D. (1988) Host: vector systems for gene cloning in Clostridium. Microbiol Sci, 5, 310-5.

38. Lambin, P., Theys, J., Landuyt, W., Rijken, P., van der Kogel, A., van der Schueren, E., Hodgkiss, R., Fowler, J., Nuyts, S., de Bruijn, E., Van Mellaert, L. and Anne, J. (1998) Colonisation of Clostridium in the body is restricted to hypoxic and necrotic areas of tumours. Anaerobe, 4, 183-8.

39. Van Mellaert, L., Barbe, S. and Anne, J. (2006) Clostridium spores as anti-tumour agents. Trends Microbiol, 14, 190-6.

40. Galagan, J.E., Nusbaum, C., Roy, A., Endrizzl, M.G., Macdonald, P., FitzHugh, W., Calvo, S., Engels, R., Smirnov, S., Atnoor, D., Brown, A., Allen, N. Naylor, J., 
Stange-Thomann, N., DeArellano, K., Johnson, R., Linton, L., McEwan, P., McKernan, K., Talamas, J., Tirrell, A., Ye, W., Zimmer, A., Barber, R.D., Cann, I., Graham, D.E., Grahame, D.A., Guss, A.M., Hedderich, R., Ingram-Smith, C., Kuettner, H.C., Krzycki, J.A., Leigh, J.A., Li, W., Liu, J., Mukhopadhyay, B., Reeve, J.N., Smith, K., Springer, T.A., Umayam, L.A., White, O., White, R.H., Conway de Macario, E., Ferry, J.G., Jarrell, K.F., Jing, H., Macario, A.J., Paulsen, I., Pritchett, M., Sowers, K.R., Swanson, R.V., Zinder, S.H., Lander, E., Metcalf, W.W. and Birren, B. (2002) The genome of $M$. acetivorans reveals extensive metabolic and physiological diversity. Genome Res, 12, 532-42.

41. Pawelek, J.M., Low, K.B. and Bermudes, D. (1997) Tumor-targeted Salmonella as a novel anticancer vector. Cancer Res, $57,4537-44$.

42. Bermudes, D., Low, B. and Pawelek, J. (2000) Tumor-targeted Salmonella. Highly selective delivery vectors. Adv Exp Med Biol, 465, 57-63.

43. Low, K.B., Ittensohn, M., Luo, X., Zheng, L.M., King, I., Pawelek, J.M. and Bermudes, D. (2004) Construction of VNP20009: a novel, genetically stable antibiotic-sensitive strain of tumor-targeting Salmonella for parenteral administration in humans. Methods Mol Med, 90, 47-60.

44. Lee, K.C., Zheng, L.M., Margitich, D., Almassian, B. and King, I. (2001) Evaluation of the acute and subchronlc toxic effects In mice, rats, and monkeys of the genetically engineered and Escherichia coli cytosine deaminase gene-incorporated Salmonella strain, TAPET-CD, being developed as an antitumor agent. Int J Toxicol, 20, 207-17.

45. Thamm, D.H., Kurzman, I.D., King, I., Li, Z., Sznol, M., Dubielzig, R.R., Vail, D.M. and MacEwen, E.G. (2005) Systemic administration of an attenuated, tumor-targeting Salmonella typhimurium to dogs with spontaneous neoplasia: phase I evaluation. Clin Cancer Res, 11, 4827-34.

46. Zheng, L.M., Luo, X., Feng, M., LI, Z., Le, T., Ittensohn, M., Trailsmith, M., Bermudes, D., Lin, S.L. and King, I.C. (2000) Tumor amplified protein expression therapy: Salmonella as a tumor-selective protein delivery vector. Oncol Res, 12, 127-35.

47. Clairmont, C., Lee, K.C., Pike, J., Ittensohn, M., Low, K.B., Pawelek, J., Bermudes, D., Brecher, S.M., Margitich, D., Turnier, J., Li, Z., Luo, X., King, I. and Zheng, L.M. (2000) Biodistribution and genetic stability of the novel antitumor agent VNP20009, a genetically modified strain of Salmonella typhimurium. J Infect Dis, 181, 1996-2002.

48. Pawelek, J.M., Sodi, S., Chakraborty, A.K., Platt, J.T., Miller, S., Holden, D.W., Hensel, M. and Low, K.B. (2002) Salmonella pathogenicity island-2 and anticancer activity in mice. Cancer Gene Ther, 9, 813-8.

49. Zhao, M., Yang, M., Li, X.M., Jiang, P., Baranov, E., Li, S., Xu, M., Penman, S. and Hoffman, R.M. (2005) Tumor-targeting bacterial therapy with amino acid auxotrophs of GFP-expressing Salmonella typhimurium. Proc Natl Acad Sci U S A, 102, 755-60.

50. Lee, C.H., Wu, C.L. and Shiau, A.L. (2004) Endostatin gene therapy delivered by Salmonella choleraesuis in murine tumor models, $J$ Gene Med, 6, 1382-93.

51. King, I., Bermudes, D., Lin, S., Belcourt, M., Pike, J., Troy, K., Le, T., Ittensohn, M., Mao, J., Lang, W., Runyan, J.D., Luo, X., Li, Z, and Zheng, L.M. (2002) Tumortargeted Salmonella expressing cytosine deaminase as an anticancer agent. Hum Gene Ther, 13, 1225-33.

52. Barbe, S., Van Mellaert, L., Theys, J., Geukens, N., Lammertyn, E., Lambin, P. and Anne, J. (2005) Secretory production of biologically active rat interleukin-2 by Clostridium acetobutylicum DSM792 as a tool for anti-tumor treatment. FEMS Microbiol Lett, 246, 67-73.

53. Theys, J., Nuyts, S., Landuyt, W., Van Mellaert, L., Dillen, C., Bohringer, M., Durre, P., Lambin, P. and Anne, J. (1999) Stable Escherichia coli-Clostridium acetobutylicum shuttle vector for secretion of murine tumor necrosis factor alpha. Appl Environ Microbiol, 65, 4295-300.

54. Lin, S., Spinka, T. and Le, T. (1999) Tumour-directed delivery and amplification of tumour-necrosis factor-alpha by attenuated Salmonella typhimurium. Clin Cancer Res, $5,3822 \mathrm{~s}$.

55. Lee, C.H., Wu, C.L. and Shiau, A.L. (2005) Systemic administration of attenuated Salmonella choleraesuis carrying thrombospondin-1 gene leads to tumor-specific transgene expression, delayed tumor growth and prolonged survival in the murine melanoma model. Cancer Gene Ther, 12, 175-84. 
56. Lemmon, M.J., van Zili, P., Fox, M.E., Mauchline, M.L., Giaccia, A.J., Minton, N.P. and Brown, J.M. (1997) Anaerobic bacteria as a gene delivery system that is controlled by the tumor microenvironment. Gene Ther, 4, 791-6.

57. Purdy, D., O'Keeffe, T.A., Elmore, M., Herbert, M., McLeod, A., Bokori-Brown, M., Ostrowski, A and Minton, N.P. (2002) Conjugative transfer of clostridial shuttle vectors from Escherichia coli to Clostridium difficile through circumvention of the restriction barrier. Mol Microbiol, 46, 439-52.

58. Theys, J., Pennington, O., Dubois, L., Anlezark, G., Vaughan, T., Mengesha, A. Landuyt, W., Anne, J., Burke, P.J., Durre, P., Wouters, B.G., Minton, N.P. and Lambin, $P$. (2006) Repeated cycles of Clostridium-directed enzyme prodrug therapy result in sustained antitumour effects in vivo. Br J Cancer, 95, 1212-9.

59. Jazowiecka-Rakus, J. and Szala, S. (2004) Antitumour activity of Salmonella typhimurium VNP20047 in B16(F10) murine melanoma model. Acta Biochim Pol, 51, $851-6$.

60. Mengesha, A., Dubois, L., Chiu, R.K., Paesmans, K., Wouters, B.G., Lambin, P. and Theys, J. (2007) Potential and limitations of bacterial-mediated cancer therapy. Front Biosci, 12, 3880-91.

61. Nuyts, S., Theys, J., Landuyt, W., van Mellaert, L., Lambin, P. and Anne, J. (2001) increasing specificity of anti-tumor therapy: cytotoxic protein delivery by nonpathogenic clostridia under regulation of radio-induced promoters. Anticancer Res, 21, 857-61.

62. Nuyts, S., Van Mellaert, L., Theys, J., Landuyt, W., Bosmans, E., Anne, J. and Lambin, P. (2001) Radio-responsive recA promoter significantly increases TNFalpha production in recombinant clostridia after 2 Gy irradiation. Gene Ther, 8, 1197-201.

63. Michel, F., Jacquier, A. and Dujon, B. (1982) Comparison of fungal mitochondrial introns reveals extensive homologies in RNA secondary structure. Biochimie, 64, 867-81.

64. Peebles, C.L., Perlman, P.S., Mecklenburg, K.L., Petrillo, M.L., Tabor, J.H., Jarrell, K.A. and Cheng, H.L. (1986) A self-splicing RNA excises an intron lariat. Cell, 44, 213-23.

65. Ferat, J.L. and Michel, F. (1993) Group II self-splicing introns in bacteria. Nature, 364, 358-61.

66. Martinez-Abarca, F. and Toro, N. (2000) Group II introns in the bacterial world. Mol Microbiol, 38, 917-26.

67. Dai, L. and Zimmerly, S. (2002) Compilation and analysis of group II intron insertions in bacterial genomes: evidence for retroelement behavior. Nucleic Acids Res, 30, $1091-102$.

68. Dai, L. and Zimmerly, S. (2003) ORF-less and reverse-transcriptase-encoding group II introns in archaebacteria, with a pattern of homing into related group II intron ORFs. Rna, 9, 14-9.

69. Toor, N., Hausner, G, and Zimmerly, S. (2001) Coevolution of group II intron RNA structures with their intron-encoded reverse transcriptases. Rna, 7, 1142-52.

70. Cui, X., Matsuura, M., Wang, Q., Ma, H. and Lambowitz, A.M. (2004) A group II intron-encoded maturase functions preferentially in cis and requires both the reverse transcriptase and $X$ domains to promote RNA splicing. $J$ Mol Biol, 340, 211-31.

71. Curcio, M.J. and Belfort, M. (1996) Retrohoming: CDNA-mediated mobility of group II introns requires a catalytic RNA. Cell, 84, 9-12.

72. Cousineau, B., Lawrence, S., Smith, D. and Belfort, M. (2000) Retrotransposition of a bacterial group II intron. Nature, 404, 1018-21.

73. Frazier, C.L., San Filippo, J., Lambowitz, A.M. and Mills, D.A. (2003) Genetic manipulation of Lactococcus lactis by using targeted group II introns: generation of stable insertions without selection. Appl Environ Microbiol, 69, 1121-8.

74. Chen, Y., McClane, B.A., Fisher, D.J., Rood, J.I. and Gupta, P. (2005) Construction of an alpha toxin gene knockout mutant of Clostridium perfringens type $A$ by use of a mobile group II intron. Appl Environ Microbiol, 71, 7542-7.

75. Heap, J.T., Pennington, O.J., Cartman, S.T., Carter, G.P. and Minton, N.P. (2007) The ClosTron: a universal gene knock-out system for the genus Clostridium. J Microbiol Methods, 70, 452-64. 
76. Lambin, P., Nuyts, S., Landuyt, W., Theys, J., De Bruijn, E., Anne, J., Van Mellaert, L. and Fowler, J. (2000) The potential therapeutic gain of radiation-associated gene therapy with the suicide gene cytosine deaminase. Int J Radiat Biol, 76, 285-93.

77. Bettegowda, C., Dang, L.H., Abrams, R., Huso, D.L., Dillehay, L., Cheong, I., Agrawal, N., Borzillary, S., McCaffery, J.M., Watson, E.L., Lin, K.S., Bunz, F., Baidoo, K., Pomper, M.G., Kinzler, K.W., Vogelsteln, B. and Zhou, S. (2003) Overcoming the hypoxic barrier to radiation therapy with anaerobic bacteria. Proc Natl Acad Sci U S A, 100, 15083-8.

78. Platt, J., Sodi, S., Kelley, M., Rockwell, S., Bermudes, D., Low, K.B. and Pawelek, J. (2000) Antitumour effects of genetically engineered Salmonella in combination with radiation. Eur J Cancer, 36, 2397-402.

79. Brekken, R.A., Li, C. and Kumar, S. (2002) Strategies for vascular targeting in tumors. Int J Cancer, 100, 123-30.

80. Carey, R. (1967) Clostridial oncolysis in man. . European J. Cancer 3(1967) 37-46, $37-46$.

81. Heppner, F. and Mose, J.R. (1978) The liquefaction (oncolysis) of malignant gliomas by a non pathogenic Clostridium. Acta Neurochir (Wien), 42, 123-5.

82. Toso, J.F., Gill, V.J., Hwu, P., Marincola, F.M., Restifo, N.P., Schwartzentruber, D.J., Sherry, R.M., Topalian, S.L., Yang, J.C., Stock, F., Freezer, L.J., Morton, K.E., Seipp, C., Haworth, L., Mavroukakis, S., White, D., MacDonald, S., Mao, J., Sznol, M. and Rosenberg, S.A. (2002) Phase I study of the intravenous administration of attenuated Salmonella typhimurium to patients with metastatic melanoma. J Clin Oncol, 20, 14252.

83. Bermudes, D., Low, K.B., Pawelek, J., Feng, M., Belcourt, M., Zheng, L.M. and King, I. (2001) Tumour-selective Salmonella-based cancer therapy. Biotechnol Genet Eng Rev, 18, 219-33.

84. Kasinskas, R.W. and Forbes, N.S. (2006) Salmonella typhimurium specifically chemotax and proliferate in heterogeneous tumor tissue in vitro. Biotechnol Bioeng, $94,710-21$.

85. Bermudes, D., Zheng, L.M. and King, I.C. (2002) Live bacteria as anticancer agents and tumor-selective protein delivery vectors. Curr Opin Drug Discov Devel, 5, 194-9. 


\section{CHAPTER 3}

\section{Efficacy of gene therapy-delivered cytosine deaminase is determined by enzymatic activity but not expression}

L Dubois, T Dresselaers, W Landuyt, K Paesmans, A Mengesha, BG Wouters, P Van Hecke, J Theys and P Lambin 


\section{Abstract}

The potential utility of tumor-selective 5-fluorouracil treatment using attenuated Salmonella serovar typhimurium recombinant for cytosine deaminase (TAPET-CD) has been documented in experimental settings. The present data demonstrate that in vivo 19Fmagnetic resonance spectroscopy measurements allow the outcome prediction of this prokaryotic-based therapy, demonstrating the necessity of non-invasive real-time imaging techniques for treatment monitoring.

\section{INTRODUCTION}

Positron emission tomography and (nuclear) magnetic resonance imaging (MRI) have been introduced to evaluate the biological characteristics of tumors and to monitor the efficacy of treatment on an individual basis. Fluor-containing chemotherapeutics, such as 5 -fluorouracil (5-FU) and its metabolites, can be detected noninvasively in tumor and liver tissues using 19F-magnetic resonance spectroscopy (19F-MRS). Preclinical animal investigations and patient studies suggest that trapping of 5-FU in the tumor correlates with response and may provide prognostic information on treatment outcome [1-3] Ample data exist on the use of the cytosine deaminase (CD) enzyme, which converts the nontoxic 5-fluorocytosine (5-FC) into the cytostatic 5-FU, in a number of experimental settings. Among these, we and others have demonstrated that recombinant bacteria such as Clostridium and attenuated Salmonella can be used to transfer $C D$ selectively to the rodent tumor microenvironment, resulting in antitumor effects [4-7]. In addition, we reported the feasibility of 19F-MRS to assess noninvasively the intratumor conversion of $5-\mathrm{FC}$ into 5 -FU mediated by $\mathrm{CD}$-recombinant Salmonella [8]. The aim of the present study was to investigate the value of in vivo 19F-MRS to predict the success of the TAPET-CD/5-FC cancer therapy system and to evaluate it as a tool to allow individualised treatment.

\section{MATERIALS AND METHODS}

HCT116 human colorectal carcinoma cells were xenografted $\left(1.5 \times 10^{6}\right.$ cells per $\left.100 \mathrm{ml}\right)$ subcutaneously at the lower flank of 8 - to 10 -week-old female NMRI nu/nu mice. Treatment and ${ }^{19}$ FMRS measurements started when tumor volumes reached $4300 \mathrm{~mm}^{3}$. Tumors were measured in three orthogonal dimensions with a calliper and volumes were calculated according to the formula $A B C \times \pi / 6$.

TAPET-CD (VION Pharmaceuticals Inc., New Haven, CT, USA), in detail described by Zheng et al [9], was cultured as described previously [7] and $2.0 \times 10^{6}$ bacteria were injected intravenously (tail vein). Six days after TAPET-CD administration, 5-FC was daily administered intraperitoneally in one group of animals $(n=12)$, whereas a control group $(n=$ 4) received saline according to the same schedule.

To determine the intratumor conversion activity of the TAPET-CD, in vivo 19F-MRS experiments were performed in a 4.7 T BIOSPEC horizontal magnet (Bruker), equipped with 
a double-tuned $\left({ }^{19} \mathrm{~F}-1 \mathrm{H}\right)$ surface coil of $1 \mathrm{~cm}$ diameter, as described previously [8]. 19F-MRS measurements were performed four times on each animal, starting 6 days after TAPETCD injection and then every sixth or seventh day. An additional 5-FC injection was given immediately before the ${ }^{19} \mathrm{~F}$-MRS measurements.

At the end of the follow-up period, animals were killed, tumors excised and homogenates were made to quantify bacterial colonization, presence (Western blotting) and activity (thinlayer chromatography (TLC) of CD, according to Theys et al [10]. Briefly, Western blotting was carried out by loading $25 \mathrm{mg}$ of tumor cell extracts on the gel. Anti-CD monoclonal antibody (MTM Laboratories inc., Westborough, MA, USA) in a 1: 5000 dilution was used as primary antibody. After overnight incubation of the sonicated lysates with 5-FC (10 mg ml$\left.l^{-1}\right)$. the conversion into 5-FU was analyzed by TLC on silica gel plates eluted with butanol. 5Fluorocytosine and 5-FU were loaded as reference. Histological evaluation of hypoxia and necrosis was performed on paraffin-embedded tumor pieces after administration of the exogenous hypoxia marker pimonidazole. Staining and evaluation of the sections were performed as described previously [11].

In vitro 19F-MRS analysis was performed on perchloric acid extracts using a AMX360 (8.4 T) spectrometer [8].

All animal experiments were in agreement with national guidelines, approved by the Animal Ethics Committee of the University 'KU Leuven', Belgium, and procedures were according to the guidelines defined by the UKCCCR.

\section{RESULTS}

${ }^{19} \mathrm{~F}$-MRS measurements were performed repeatedly on every animal starting at 6 days after TAPET-CD administration and immediately after the 5-FC injection. These spectroscopy analyses allowed us to evaluate the in vivo intratumor conversion of 5-FC into 5-FU, which resulted from TAPET-CD activity. Animals in which a 5-FU signal could be detected during the follow-up period were marked as 'responders' ( 9 out of 12), the others as 'nonresponders' (3 out of 12). Linear regression analysis showed a significant tumor growth delay for the 'responders' compared to the 'non-responders' (29.00 days; $b=5.72 ; P=0.001)$ and control saline-treated group (29.83 days; $b=3.32 ; P=0.001$ ), as witnessed from the interaction between time and group (Figure 1A). Representative spectra of 'responder' and 'nonresponder' animals are shown in Figure 1B. The final in vivo measurements were subsequently confirmed by quantification of the 5-FU amount 
A

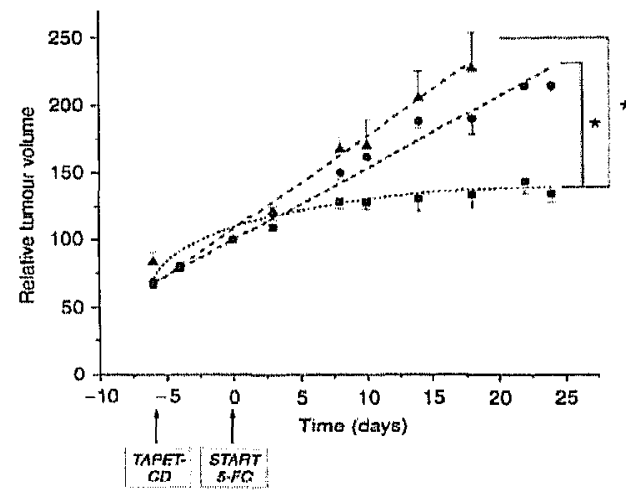

C

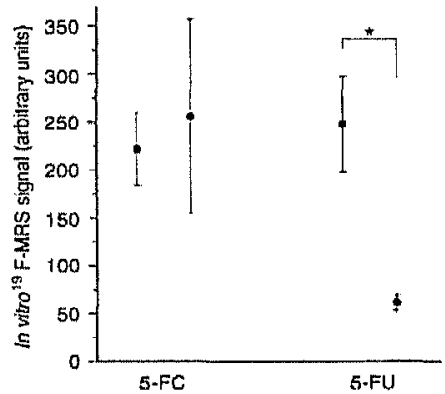

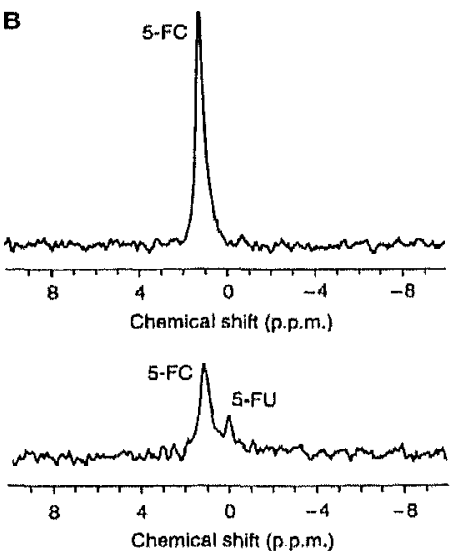

D

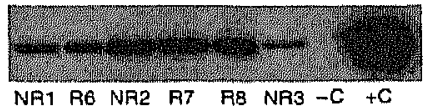

E
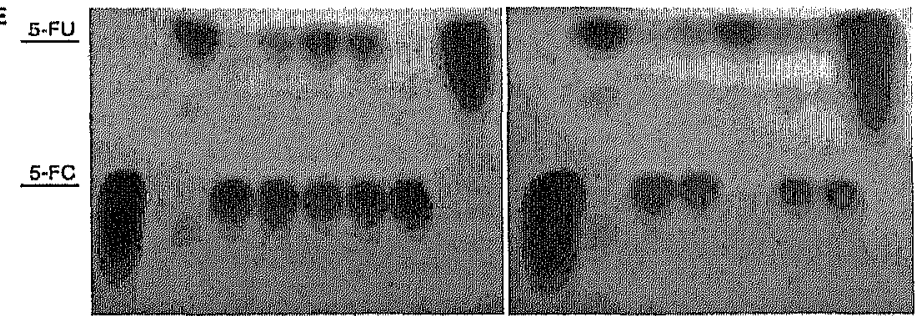

5-FC +C $\ldots$ C R1 A2 R3 NR1 5.FU 5.FC +C $\ldots$ C R1 R2 R3 NR1 5.FU

Figure 3.1 (A) Growth delay for 'responder' $(9 / 12 ; \mathbf{D})$ and 'nonresponder' $(3 / 12 ;-$ ) animals. Sham saline-treated animals are indicated with $\mathbf{A}$. Animals in which a 5-FU signal could be detected using in vivo ${ }^{19} \mathrm{~F}-\mathrm{MRS}$ during the follow-up period were marked as 'responders', the others as 'nonresponders'. The $100 \%$ value represents the tumor volume at day 0 (ie volume at the start of $5-\mathrm{FC}$ administration). Statistlcal slgniffcance at $P<0.001$ using linear regression analysis is indicated (). Data are shown as meants.e.m. (B) Representative spectra (13 min/spectrum: TR=0.75 s: $N A=1024 ; L B=6 \mathrm{~Hz}$; zerofilling to 4096 points) of a 'nonresponder' (top) and a 'responder' (bottom) animal. (C) Quantification of the amount of 5-FC and 5-FU using in vitro ${ }^{10} \mathrm{~F}$-MRS on perchloric acid tumor extracts of 'responders' (E) and 'nonresponders' ( ) Statistical significance at $P<0.05$ using a nonparametrlc Mann-Whitney $U$ test is indicated (). Data are shown as mean $\pm s, e, m$. (D-E) Western blotting and thin-layer chromatography (TLC) for CD expression and activity respectively in tumour homogenates from HCT116 xenograft In NMRI nu/nu mice injected with TAPET-CD. TLC was done before ( $E$ left) and after ( $E$ right) adding Lurla-bertani medium to the tumor extracts with overnight incubation. 'Responders' are indicated with $R$, 'nonresponders' with NR. The $+C$ Indicates a sample of bacterial lysate from in vitro growing TAPET-CD and represent the positive control. $-C$ represents the negative control, that is, bacterial lysate from the in vitro growing PC0698 strain, which does not encode CD. 
using in vitro ${ }^{19} \mathrm{~F}-\mathrm{MRS}$ analyses. Whereas equal amounts of 5-FC were found, significant differences in 5-FU amount existed between 'responders' and 'non-responders' ( $P=0.044)$ (Figure $1 \mathrm{C}$ ). This was not caused by a different level of colonization because the number of viable bacteria present in the tumors was not significantly different in both groups (equally high colonization, $4109 \mathrm{cfu}^{-1}$ tumor tissue). In addition, Western blotting on tumor extracts did not reveal differences in $C D$ protein expression (Figure $1 D$ ). To exclude presence of mutations within the $C D$ protein, lysates were made from bacteria isolated out of tumors from both 'responders' and 'non-responders'. TLC experiments with these bacterial lysates demonstrated conversion of 5-FC to 5-FU in all cases, indicating a fully functional $C D$ protein (data not shown). However, the ability for conversion of 5- FC into 5-FU, as determined by TLC experiments on tumor extracts, could only be shown in the 'responders' and not in the 'non-responders' group (Figure $1 \mathrm{E}$ left). This corresponds to the very small amount of 5-FU detected in the 'non-responder animals' using the more sensitive in vitro 19F-MRS (Figure 1C). Interestingly, the 'no-conversion phenomenon' in the 'non-responder' animals could be reversed by adding nutrients (Luria-Bertani medium) to the tumor extracts and allowing the mixture incubate overnight before making sonicated lysates (Figure 1E, right).

\section{DISCUSSION}

The present study shows that the dynamic 5-FC/5-FU conversion in the human colorectal HCT116 tumor xenograft following systemic injection of TAPET-CD and 5-FC can be monitored using in vivo ${ }^{19} \mathrm{~F}$-MRS. More importantly, we demonstrate the need for sequential non-invasive ${ }^{19} \mathrm{~F}$-MRS imaging as a tool for TAPET-CD/5-FC therapy prediction. Given the fact that a pilot clinical trial with TAPET-CD, in which two out of three refractory cancer patients maintained stable disease when functional $C D$ was produced within the tumor [12] have already started, our results point to the importance of not only monitoring tumor colonization but also CD functionality. Tumors in which a 5-FU signal could be detected using in vivo ${ }^{19} \mathrm{~F}$-MRS during the follow-up period were marked as 'responders', the others were marked 'non-responders'. Despite similar TAPETCD colonization levels in all tumors, growth delay assays showed a significant difference in success of the TAPET-CD/5-FC therapy for the 'responders' vs 'non-responders' and the control saline treated animals. In vitro ${ }^{19} \mathrm{~F}-\mathrm{MRS}$ analysis performed on the perchloric acid extracts of the resected tumors taken at the end of the follow-up period, confirmed the in vivo ${ }^{19} \mathrm{~F}-\mathrm{MRS} 5-\mathrm{FC} / 5-\mathrm{FU}$ measurements. Intriguingly, Western blotting did not reveal a difference in $C D$ protein expression between the samples of 'responders' and 'non-responders,' and TLC analysis on bacterial lysates confirmed the CD functionality in all cases. This indicates that in the TAPET-CD present in the tumor, the CD gene was not selectively lost. In other words, expression of $C D$ by recombinant bacteria in the tumor is not enough to establish an antitumor effect when combined with 5-FC administration. Kamm et al [13] have argued that differences in 5-FU levels could be explained by morphological heterogeneity in tumors. However, we did not find histological differences in the amount of hypoxia/necrosis between the tumors of 'responders' and 'non-responders' nor 
in the levels of 5-FC detected in the tumors via ${ }^{19} \mathrm{~F}$-MRS (both in vitro and in vivo). These results showed that prodrug diffusion to the bacterial colonization sites in both groups is not impaired. As no differences were seen in bacterial colonization and CD protein expression, but significance was obtained in growth delay between 'responders' and 'non-responders', we reasoned that the observed difference was probably owing to either the presence of an inhibitory factor in the tumors of the 'non-responders', or to the lack of factors needed for $C D$ enzyme activity. The catalytic activity of $C D$ is shown to be dependent on $\mathrm{Fe}^{2+}$ or other divalent metal ions that function as cofactor. Although it might be possible that these cofactors are present in varying amounts among tumors, this appeared not to be limiting in our study (data not shown). Alternatively, low intratumoral $\mathrm{pH}$ or high endogenous cytosine concentrations that compete with 5-FC for the active site might reduce $\mathrm{CD}$ activity. However, as TLC experiments revealed that adding fresh growth medium to the tumor extracts of nonresponders resulted in 5-FC/5-FU conversion, our data point towards the absence of yet other necessary factors. From our results, it is apparent that in a subgroup of tumors, the absence of these necessary nutrients for efficient $C D$ enzymatic activity can result in a lack of antitumor efficacy. Therefore, our results stress the importance of non-invasive real-time imaging tools as 19F-MRS for individualized treatment as it allows the prediction of antitumor efficacy when using TAPET-CD/5-FC therapy or related treatments.

\section{ACKNOWLEDGEMENTS}

This work was financially supported by the LSCH-CT-2003-502932/Euroxy 6th framework grant (LD) and the Vanderes Foundation (AM). We thank Ruud Houben for statistical assistance. 


\section{REFERENCES}

1. Wolf, W., Presant, C.A., Servis, K.L., el-Tahtawy, A., Albright, M.J., Barker, P.B., Ring, R., 3rd, Atkinson, D., Ong, R., King, M. and et al. (1990) Tumor trapping of 5fluorouracil: in vivo 19F NMR spectroscopic pharmacokinetics in tumor-bearing humans and rabbits. Proc Natl Acad Sci U S A, 87, 492-6.

2. Schlemmer, H.P., Becker, M., Bachert, P., Dietz, A., Rudat, V., Vanselow, B., Wollensack, P., Zuna, I., Knopp, M.V., Weidauer, H., Wannenmacher, M. and van Kaick, G. (1999) Alterations of intratumoral pharmacokinetics of 5-fluorouracil in head and neck carcinoma during simultaneous radiochemotherapy. Cancer Res, 59, 23639.

3. Martino, R., Gilard, V., Desmoulin, F. and Malet-Martino, M. (2005) Fluorine-19 or phosphorus-31 NMR spectroscopy: a suitable analytical technique for quantitative in vitro metabolic studies of fluorinated or phosphorylated drugs. J Pharm Biomed Anal, $38,871-91$

4. Minton, N.P., Mauchline, M.L., Lemmon, M.J., Brehm, J.K., Fox, M., Michael, N.P., Giaccia, A. and Brown, J.M. (1995) Chemotherapeutic tumour targeting using clostridial spores. FEMS Microbiol Rev, 17, 357-64.

5. Theys, J., Landuyt, A.W., Nuyts, S., Van Mellaert, L., Lambin, P. and Anne, J. (2001) Clostridium as a tumor-specific delivery system of therapeutic proteins. Cancer Detect Prev, 25, 548-57.

6. King, I., Bermudes, D., Lin, S., Belcourt, M., Pike, J., Troy, K., Le, T., Ittensohn, M., Mao, J., Lang, W., Runyan, J.D., Luo, X., Li, Z. and Zheng, L.M. (2002) Tumortargeted Salmonella expressing cytosine deaminase as an anticancer agent. Hum Gene Ther, 13, 1225-33.

7. Mej, S., Theys, J., Landuyt, W., Anne, J. and Lambin, P. (2002) Optimization of tumor-targeted gene delivery by engineered attenuated Salmonella typhimurium. Anticancer Res, 22, 3261-6.

8. Dresselaers, T., Theys, J., Nuyts, S., Wouters, B., de Bruijn, E., Anne, J., Lambin, P., Van Hecke, P. and Landuyt, W. (2003) Non-invasive 19F MR spectroscopy of 5 fluorocytosine to 5 -fluorouracil conversion by recombinant Salmonella in tumours. $\mathrm{Br}$ $J$ Cancer, 89, 1796-801.

9. Zheng, L.M., Luo, X., Feng, M., Li, Z., Le, T., Ittensohn, M., Trailsmith, M., Bermudes, D., Lin, S.L. and King, I.C. (2000) Tumor amplified protein expression therapy: Salmonella as a tumor-selective protein delivery vector. Oncol Res, 12, 127-35.

10. Theys, J., Landuyt, W., Nuyts, S., Van Mellaert, L., van Oosterom, A., Lambin, P. and Anne, J. (2001) Specific targeting of cytosine deaminase to solid tumors by engineered Clostridium acetobutylicum. Cancer Gene Ther, 8, 294-7.

11. Dubois, L., Landuyt, W., Haustermans, K., Dupont, P., Bormans, G., Vermaelen, P., Flamen, P., Verbeken, E. and Mortelmans, L. (2004) Evaluation of hypoxia in an experimental rat tumour model by $[(18) F]$ fluoromisonidazole $P E T$ and immunohistochemistry. Br J Cancer, 91, 1947-54.

12. Nemunaitis, J., Cunningham, C., Senzer, N., Kuhn, J., Cramm, J., Litz, C., Cavagnolo, R., Cahill, A., Clairmont, C. and Sznol, M. (2003) Pilot trial of genetically modified, attenuated Salmonella expressing the E. coli cytosine deaminase gene in refractory cancer patients. Cancer Gene Ther, 10, 737-44.

13. Kamm, Y.J., Heerschap, A., Rosenbusch, G., Rietjens, I.M., Vervoort, J. and Wagener, D.J. (1996) 5-Fluorouracil metabolite patterns in viable and necrotic tumor areas of murine colon carcinoma determined by 19F NMR spectroscopy. Magn Reson Med, 36, 445-50. 


\section{CHAPTER 4}

\section{Development of a Flexible and Potent Hypoxia- Inducible Promoter for Tumor-Targeted Gene Expression in Attenuated Salmonella}

Asferd Mengesha, Ludwig Dubois, Philippe Lambin, Willy Landuyt, Roland K. Chiu, Bradly G. Wouters, and Jan Theys 


\section{ABSTRACT}

To increase the potential of attenuated Salmonella as gene delivery vectors for cancer treatment, we developed a hypoxia-inducible promoter system to limit gene expression specifically to the tumor. This approach is envisaged to not only increase tumor specificity, but also to target those cells that are most resistant to conventional therapies. We demonstrate that the exponential growth of the attenuated bacteria is identical under normoxia and hypoxia. A hypoxia-inducible promoter (HIP-1) was created from a portion of the endogenous Salmonella pepT promoter and was shown to drive reporter gene expression under both acute and chronic hypoxia, but not under normoxia. Genetic engineering of the TATA- and FNR-box within HIP-1 allowed fine-tuning of gene induction, resulting in hypoxic induction factors of up to 200-fold. Finally, we demonstrate that HIP-1 can drive hypoxiamediated gene expression in bacteria which have colonized human tumor xenografts in mouse models. Expression of both GFP and RFP under control of HIP-1 demonstrated an 15-fold increase relative to a constitutive promoter when tumors were made hypoxic. Moreover, the use of a constitutive promoter resulted in reporter gene expression in both tumors and normal tissues, whereas reporter gene expressing using HIP-1 was confined to the tumor. 


\section{INTRODUCTION}

Genetically modified, nonpathogenic bacteria that preferentially localize and proliferate in solid tumors have been studied as alternative gene delivery vectors in cancer treatment. 1,2 In one approach, strictly anaerobic nonpathogenic Clostridium spores that are specifically targeted towards the hypoxic/necrotic regions of the tumor, are being explored.3 Another strategy involves the use of genetically engineered auxotrophic Salmonella typhimurium strains with strongly reduced virulence as potential gene delivery system.4,5 Salmonella are facultative anaerobes that are able to grow under both aerobic and anaerobic conditions.

To develop a safe gene delivery vector, wild type Salmonella typhimurium was attenuated by chromosomal deletion of the pur and $m s b B$ genes, thereby increasing safety and reducing toxicity. 6 Both bacterial and tumor-related factors have been implicated for its preferential accumulation in tumors. Salmonella are motile, and following their adherence to the tumor vasculature, they can invade in and spread throughout the tumor area.7 Within the tumor, areas of necrosis and apoptosis may provide additional nutrients such as purines required by the organism. In addition, the tumor may provide an immunosuppressive environment that inhibits the clearance of Salmonella.8,9 However, following the administration of attenuated Salmonella to tumor-bearing animals, it has been observed that not only the tumor but also normal tissues are colonized, albeit transiently and to a lesser extent. Obviously and since the recombinant strains used so far all employed a strong constitutive promoter to drive the therapeutic gene of interest, this biodistribution pattern can cause undesired side effects and negatively influence the specificity of the Salmonella mediated gene transfer system.10,11 One way to address this issue and to obtain controlled gene expression when using attenuated Salmonella is to exploit the unique hypoxic tumor microenvironment.

Hypoxia is a common characteristic of most malignant tumors and is considered to be an independent prognostic factor of poor outcome in a variety of tumor types. Although hypoxia leads to resistance to radiotherapy and most chemotherapeutic drugs, and to increased malignancy, it also represents a potential opportunity for obtaining tumorspecific gene expression.12,13 One promising way to achieve this goal, is to place a therapeutic gene under the transcriptional control of a hypoxia regulatory element.

Increased Tumor Specificity in Salmonella with HIP In E. coli and Salmonella, the Fumarate and Nitrate Reduction regulator (FNR) regulates the global response to the transition between aerobic and anaerobic growth. FNR is a bifunctional protein that acts both as a hypoxic sensor and a hypoxia-responsive transcription factor.14-16 The sensory domain contains four cysteine residues that act as ligands for an oxygen-labile [4Fe-4S] cluster. Acquisition of a [4Fe-4S] cluster initiates the formation of FNR homodimers that bind DNA site-specifically and regulate transcription from target promoters. Under aerobic conditions the $[4 \mathrm{Fe}-4 \mathrm{~S}]$ clusters are disassembled and the FNR dimers dissociated to form nonDNA-binding monomers.17,18 All FNR-regulated promoters are characterized by the presence of one or more FNR-binding sites. We thus reasoned that a FNR responsive promoter would be an attractive candidate to exploit for restricting therapeutic gene expression specifically to the tumor, thereby increasing 
the specificity of the Salmonella mediated gene delivery system. Moreover, targeting Salmonella to hypoxic areas represents another major advantage as these regions are most resistant to effective conventional cancer treatment. We therefore tested the potential hypoxic induction of a promoter

(HIP) derived from the FNR-dependent pepT promoter in attenuated Salmonella typhimurium.19 Here, we demonstrate that Salmonella grow as efficiently in both normoxic and hypoxic conditions and show that hypoxia induced bacterial promoters have the potential to increase the specificity of the Salmonella mediated gene delivery system by establishing spatial control of gene expression.

\section{MATERIALS AND METHODS}

\section{Bacterial strains, plasmids and growth conditions}

Attenuated Salmonella typhimurium VNP20009 [msbB-, purl-, xyl- and EGTAr] was obtained from Vion Pharmaceuticals (New Haven, CT, USA). Escherichia coli TG1 obtained from Gibco BRL (Invitrogen, Carlsbad, CA, USA) was used as host for all recombinant DNA manipulations. Detailed descriptions of the plasmids used in this work are listed in Table 2. The pZEP08 and pZEP15 carrying GFP+ were a kind gift from Dr. Jay Hinton (IFR, Norwich Research Institute, UK). The dsRed.T4 was obtained from Dr. Bumann (Max Planck Institute, Germany). For strain manipulations and maintenance, cells were grown at $37^{\circ} \mathrm{C}$ in liquid Luria-Bertani (LB) medium containing 0.5\% Bacto-yeast extract, 1\% Bacto-tryptone, and 1\% $\mathrm{NaCl}$ (Gibco BRL) and on LB agar plates using standard procedures. When required, ampicillin and chloramphenicol were added to the medium to a final concentration of 50 and $12 \mathrm{rg} / \mathrm{ml}$ respectively. Bacterial strains harboring the recombinant plasmids were grown overnight in liquid LB, with shaking at $37^{\circ} \mathrm{C}$. The following day cultures were diluted twice $(1: 100)$ when an optical density (OD600nm) of 0.3 was reached. Cultures were again diluted 100 fold and experiments were started. In order to determine the bacterial count, $100 \mathrm{Bl}$ of culture was serially diluted and plated on LB agar. Bacterial colonies were counted after overnight incubation at $37^{\circ} \mathrm{C}$. Aerobic conditions were obtained by shaking the culture vigorously $(250 \mathrm{rpm} / \mathrm{min})$. For anaerobic induction experiments, cultures were incubated in an hypoxic chamber (MACS Anaerobic Workstation; Don Whitiey Scientific, Shipley, UK $(5 \%$ $\mathrm{CO} 2-95 \% \mathrm{~N} 2$ ) at $37^{\circ} \mathrm{C}$ with shaking conditions as in the aerobic cultures. All the media and buffers used for anaerobic experiments were made hypoxic and kept in the anaerobic chamber for days before onset of the experiments. For acute stress hypoxia experiments, cultures were transferred to the hypoxic workstation following an aerobic dilution cycle as described. Samples were taken at different time points, OD600nm defined and the bacteria stored on ice prior to a luciferase assay. For chronic hypoxia experiments, cultures were maintained in the anaerobic chamber for days and the luciferase assay was performed following two cycles of mid log growth with in the anaerobic chamber. 
DNA manipulations and vector construction

All general DNA manipulations in E. coli were carried out as described by Sambrook et al.20 Restriction endonucleases and DNA-modifying enzymes were purchased from New England Biolabs (NEB Ltd, Ipswich, UK) and used as indicated by the suppliers. Chromosomal DNA was extracted from $E$. coli and Salmonella using the Gene Elute Bacterial Genomic DNA kit mini (Sigma, St. Louis, MO, USA). PCR was performed on the extracted chromosomal DNA as a template.

Primers used in this study are described in Table 1 and were designed using the published sequence of pepT gene [EMBL: STPEPT, AC: M62725] and FNR gene [EMBL: STPEPT, AC: AE008893]. PCR products were synthesized with Hot Star DNA polymerase (Qiagen $\mathrm{GmbH}$, Westburg, Hilden, Germany) to generate the $3^{\prime}$ deoxyadenosine necessary for direct cloning into pGEM-T Easy vector (Promega Corp, Madison, WI) and sequenced using standard $T 3 / 77$ forward and reverse primers (ABI prism 310 Genetic Analyzer, Applied Biosystems). Fragments for subcloning were isolated from low melting agarose using the QiaQuick gel extraction kit (Westburg, Hilden, Germany) and restriction sites incorporated into the primers were then used to subclone fragments into the PSP-Luc+NF expression vector (Promega Corp, Madison, WI) and pZEP-08.21Transformation into E. coli TG1 (supE hsd 55 thi .7lacproAB]) was performed using

chemocompetent cells (Gibco BRL) obtained with the $\mathrm{RbCl}$ method. Introduction of recombinant plasmids into attenuated Salmonella was done by electroporation $[25 \square F, 400$ and $2.5 \mathrm{kV}$,] using $0.2 \mathrm{~mm}$ cuvettes. Plasmid DNA isolations were performed using the Gene Elute plasmid miniprep kit (Sigma, St. Louis, MO, USA).

Site-directed mutagenesis was performed using the QuickChange Site-directed Mutagenesis Kit (Stratagene, La Jolla, CA, USA) according to the manufacturer's instructions using pGEMHIP-1

construct as template. Complimentary oligonucleotides were designed to contain the desired mutation (Table 1), flanked by the unmodified sequence to anneal to the same sequence on opposite 
Table 4.1 Oligonucleotide primers used in this study

\begin{tabular}{ll}
\hline Oligonucleotide & Sequence $^{\theta^{\prime}}$ \\
\hline FFmod_F1 & 5'-TGCAGGGATAAAATTGATCTGAATCAATATTTGTCTT-3' \\
FFmod_R1 & 5'-AGACAAATATTGATTCAGATCAATTTATCCCTGCAA-3' \\
PepTm_F1 & 5'-CAGGGATAAAAGGATCCGACGCAATATTTGTCTTT-3' \\
PepTm_R1 & 5'-AAAGACAAATATTGCGTCGGATCCTTTTATCCCTG-3' \\
pFNRg_F1 & 5'-CATCTAGAGAGTGGTTATTGCGCCATG-3' \\
pFNRg_R1 & 5'-CACTCGAGGCGGAAAAATCAGGCAACG-3' \\
pPepT_F1 & 5'-CAGGTACCCAGAAAGCGTGTCAAA-3' \\
pPepT_R1 & 5'-CAAGATCTCTTTTCGTGACAACATT-3' \\
pPepT_GFP_F1 & 5'-CACCCGGGCAGAAAGCGTGTCAAA-3' \\
pPepTGGP_R1 & 5'-CATCTAGACTTTTCGTGACAACATT-3' \\
\hline
\end{tabular}

"Sequences underlined indicate locations of restriction sites used for cloning.

Increased Tumor Specificity in Salmonella with HIP strands of the template plasmid. Sample reactions for PCR based site directed mutagenesis are prepared as follows: 5 ol of 10X reaction buffer, 5 वl (25 $\mathrm{ng}$ ) each oligonucleotide primers, 1 다 of dNTP (5 mM) and 25-50 $\mathrm{ng}$ of template DNA, mixed to a final volume of 50 ㄷll. PCR reactions were carried out using 1 다 Pfu DNA polymerase (2.5 U/Jl). The thermal cycling parameters were: 1 cycle $(30 \mathrm{~s}$, $\left.95^{\circ} \mathrm{C}\right), 18$ cycles $\left(30 \mathrm{~s}, 95^{\circ} \mathrm{C} ; 1 \mathrm{~min} 48-55^{\circ} \mathrm{C}\right)$ and $1 \mathrm{cycle}\left(10 \mathrm{~min}, 68^{\circ} \mathrm{C}\right)$. All mutations were verified by sequencing.

\section{Determination of in vitro promoter activities}

Promoter activities were determined by monitoring luciferase activity in vitro using a luciferase assay protocol (Promega, Corp, Madison, WI). Ninety microliters aliquots were taken from the 1:100 diluted overnight cultures at different time intervals, mixed with 10 ..ll of $1 \mathrm{M} \mathrm{K2HPO} 4$ (pH 7.8), $20 \mathrm{mM}$ EDTA and quick-frozen on dry ice. Following collection of all samples, they were equilibrated to room temperature and incubated for $10 \mathrm{~min}$ with 300 [.]l freshly prepared lysis mix ( $1 \mathrm{X}$ cell culture lysis reagent (CCLR), $1.25 \mathrm{mg} / \mathrm{ml}$ lysozyme and $2.5 \mathrm{mg} / \mathrm{ml} \mathrm{BSA}$ ). Twenty microliter aliquots of sample and $100 \mathrm{Dl}$ of luciferase assay reagent were then mixed into a luminometer tube and luciferase activity measured (10 s, delay $2 \mathrm{~s})$ in a LUMAC type luminometer (Perstorp Analytical Company) at room

temperature. Activities are given as relative light units (RLU) after subtraction of the instrumental background. Data are normalized by dividing the RLU by OD600nm at each time point. Induction factors are calculated by dividing the RLU/OD600nm of the induced sample displayed at the times indicated by that of the matched, nonlnduced samples. The induction factor of 1.0 represents no induction. 


\section{Western blot analysis}

Tumor and normal tissue samples were homogenized in $1 \mathrm{ml}$ of PBS. Five-hundred microliters of homogenate was subsequently mixed with 500 ol of $\operatorname{TrisHCl}(\mathrm{pH}=7.5,100$ $\mathrm{mM}$ ) and samples were lysed by $4 \times 30$ s sonications. Samples were kept on ice for at least 2 min between the sonications. Protein concentrations were determined by a Bradford assay with BSA as a standard. Lysed samples were separated by sodium dodecyl sulphate polyacrylamide gelelectrophoresis (SDS-PAGE). Transfer of proteins to nitrocellulose membranes was performed at $100 \mathrm{~V}$ during 1 hour at $4^{\circ} \mathrm{C}$ (BioRad PowerPac 300). Nitrocellulose membranes were blocked with $0.5 \%$ Blotting Grade Blocker non fat dry milk (BioRad) in PBS/Tween $0.2 \%$ overnight at $4^{\circ} \mathrm{C}$ and subsequently incubated with a 1:1000 dilution of anti-GFP monoclonal antibody (Living Colors A.v. mAb JL-8, Clontech) during 2 hours at room temperature. Membranes were washed in PBS/Tween $0.2 \%$ and incubated for 1 hour with horseradish peroxidase-conjugated goat antimouse $\lg G$ and autoradiographed using the ECL. Western Blotting detection system as described by the supplier (Amersham Biosciences).

\section{In vivo experiments}

Female adult NMRI nu/nu mice were used to assess the in vivo responsiveness of the recombinant attenuated Salmonella to hypoxia. $1.5 \times 106$ human colorectal carcinoma (HCT116) cells were injected subcutaneously in the left and right abdominal fiank under minor anesthetics. When tumors reached a predefined volume $(300 \mathrm{~mm} 3)$, recombinant bacteria (2 $\times 106$ colony forming units) carrying the pZEP-HIP-1-GFP+ or HIP-1-DsRed.T4 plasmid were systemically administered via a lateral tail vein. Recombinant Salmonella harboring the pZEPrpsM-GFP+ or rpsM-DsRed.T4 (resulting in constitutive activation of the reporter genes), or empty bacteria (VNP20009) injected in mice, were used as control. Tumor colonization was allowed for seven days, while selection antibiotics were added to the drinking water (chloramphenicol for the GFP+ constructs at $500 \mathrm{mg} / \mathrm{l}$ and ampicilline for the DsRed.T4 constructs

at $20 \mathrm{mg} / \mathrm{l})$. In the first set of experiments animals were analyzed on the BonsAl imager for noninvasive evaluation of reporter gene expression. Tumors and normal tissues were then excised and processed for Western blot analysis. In another set of experiments, one tumor was removed immediately for colonization testing, further histological processing as described previously.5,22 In the contra lateral tumor, production of fluorescent protein was monitored for several hours using the bonSAl optical imager (Siemens AG, München, Germany). All animal experiments were conducted in accordance with local institutional guidelines, approved by the Animal Ethics Committee of the University. 
Table 4.2. Strains and plasmids used in this study.

\begin{tabular}{|c|c|c|}
\hline Strains or plasmids & Genotype & Reference \\
\hline E. coli TG1 cells & $\begin{array}{l}\text { (supE hsd } \Delta 5 \text { thi } \triangle(l a c-p r o A B) F^{\prime} \text { [traD36 pro } \\
\left.\left.A B^{+} l a c\right|^{q} l a c Z \Delta M 15\right]\end{array}$ & Gibco BRL \\
\hline $\begin{array}{l}\text { Salmonella Typhimurium } \\
\text { [VNP2009] }\end{array}$ & $\left(m s b B ;\right.$, pur $\Gamma, x y \Gamma$ and EGTA ${ }^{r}$ ) & $\begin{array}{l}\text { Vion } \\
\text { Pharmaceutical }\end{array}$ \\
\hline \multicolumn{3}{|l|}{ Plasmids } \\
\hline pGEM-T Easy vector & MCS, $A p^{r}$, LacZ $\alpha$ & Promega \\
\hline $\mathrm{pSp}-\mathrm{Luc}+\mathrm{NF}$ fusion vector & MCS, $A p^{r}, L U C+N F$ & Promega \\
\hline pSp-HIP-1-Luc+NF & pSp-Luc+NF, HIP-1promoter & This study \\
\hline pSp-HIP-1 MUT-Luc+NF & HIP-1promoter, $\triangle F N R$ box & This study \\
\hline pSp-HIP-1 TATA-Luc+NF & HIP-1promoter, TATA box modified & This study \\
\hline$p S p-H I P-1_{F N R}-L U C+N F$ & HIP-1promoter, FNR box optimized & This study \\
\hline pSp-HIP-1-Luc+NF/FNR & HIP-1promoter, over expressing FNR gene & This study \\
\hline pSp-HIP-1 ${ }_{M U T}-L U c+N F / F N R$ & HIP-1 promoter, $\triangle \mathrm{FNR}$ box over expressing & This study \\
\hline pZEP-pepT-GFP' & FNR gene] & This study \\
\hline HIP-1-DsRed.T4 & OHIP-1-gfp ${ }^{+}$, pZEP08 derivative $\left(\mathrm{Cm}^{r} \mathrm{Km}^{\mathrm{s}}\right)$ & This study \\
\hline prpsM-DsRed.T4 & DsRed.T4, HIP-1 promoter & This study \\
\hline pZEP-08 & DsRed.T4, rpsM promoter & [21] \\
\hline pZEP-16 & & [21] \\
\hline \multirow[t]{3}{*}{ pDsRed.T4 } & pBR322 derivative $\left(m o b^{+} / b l a^{+} \phi g f p^{+} \mathrm{Cm}^{\top} \mathrm{Km}^{r}\right)$ & [37] \\
\hline & Orps $M^{\prime}-g f p^{+}$, pZEP08 derivative $\left(\mathrm{Cm}^{r} \mathrm{Km}^{\mathrm{s}}\right)$ & \\
\hline & MCS, Ap ${ }^{R}$, DsRed & \\
\hline
\end{tabular}

$\overline{A p^{\prime}}$, ampicillin resistant; $\mathrm{Km}^{r}$, kanamycin resistantant; $\mathrm{Km}^{\mathrm{s}}$, kanamycin sensitive; $\mathrm{Cm}^{r}$, chloramphenicol resistant; MCS, multiple cloning site. đIndicates a transcriptional gene fusion.

\section{RESULTS}

\section{Effect of oxygen on the growth of Salmonella}

Salmonella are gramnegative facultative anaerobes and grow readily in simple culture media, under both aerobic and anaerobic conditions. Since the effects of hypoxia on the growth pattern of Salmonella are only poorly described, we compared the growth characteristics of Salmonella under both hypoxic and normoxic conditions by measuring the optical density (OD600nm) as a function of time. We observed that the growth rate of the bacteria during the exponential phase was identical under both conditions, but that the cells plateau at a lower density in an anaerobic environment (Fig. 1A). To test whether this effect was directly due to hypoxia itself or whether this was the consequence of hypoxia-mediated depletion of nutrients, their growth was evaluated following long term hypoxic exposure. Cultures were maintained under hypoxic conditions for several generations by repeated serial 100-fold dilutions with fresh anaerobic media each time when bacterial growth reached mid-exponential phase. Interestingly, as observed for bacteria growing in normoxic 
conditions, the bacteria continued to grow under prolonged hypoxia without any evidence for growth inhibition, provided the nutrient supply in the growth media was replenished (Fig. 18 and C). We subsequently investigated whether hypoxic exposure influences long term bacterial viability by plating the bacteria at different time points after hypoxic growth and assaying for colony survival (Fig. 1D). Similar to our observations with cell density measurements, no difference in survival was observed in normoxic versus hypoxic conditions. Importantly, these growth kinetic studies allowed us to evaluate gene expression in

aerobic and hypoxic cells over long periods of time without the confounding effects of early induction of stationary plateau phase, thereby enabling precise and quantitative comparisons of reporter gene expression profiles at the cellular level in the subsequent experiments.
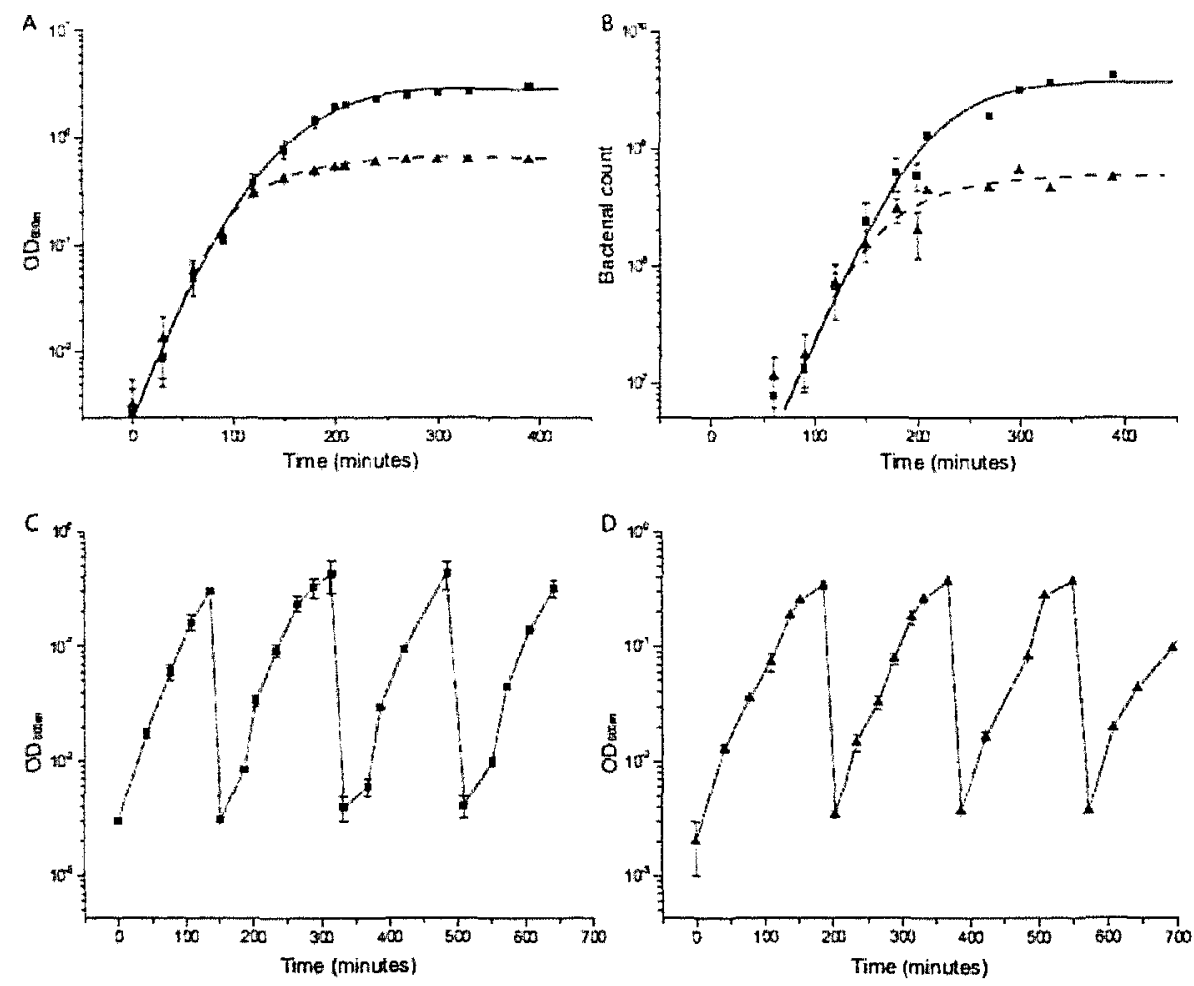

Figure 4.1. Growth characteristics of attenuated Salmonella typhimurium under both hypoxic and normoxic conditions. (A) Bacterial growth defined by optical density $(0 D 600 \mathrm{~nm})$ as a function of time under aerobic ( $(\mathbf{)})$ and anaerobic (S) conditions. Cultures are maintained under aerobic (B) or anaerobic (C) growth conditions for 4 cycles of mid exponential growth by serial 10-fold dilutions with fresh media each time when the bacteria reach an OD600nm of $\sim 0.3$. (D) Bacterial growth defined by cell count as a function of time under aerobic ( $\mathbf{m}$ ) and anaerobic (s) conditions. Each data point represents the mean of 3-4 independent experiments. 


\section{Use of HIP-1 promoter to drive hypoxia specific gene expression}

Having demonstrated that the hypoxic and normoxic growth rate of attenuated Salmonella are identical, we investigated whether we could deveiop the wild-type strain into a prokaryotic hypoxia-regulated vector with spatially controlled gene expression. Analogous to the eukaryotic context in which the HRE is the recognition site for the hypoxia-inducible factor-1 (HIF-1), an oxygen-responsive global transcription factor (FNR) induces the expression of a number of bacterial genes during anaerobic growth following binding to a consensus FNR recognition sequence. Based on available literature data, the FNR-regulated pepT gene promoter was chosen as a starting point for our investigations. 16 pep $T$ is transcribed from two promoters.

The $\mathrm{P} 1$ promoter is activated by anaerobiosis and requires the activator FNR, while the other promoter, located upstream of $\mathrm{P1}$, is constitutive and unaffected by anaerobiosis. $23 \mathrm{We}$ isolated the $\mathrm{P} 1$ fragment, designated it the Hypoxia Inducible Promoter-1 (HIP-1), cloned it upstream of the firefly luciferase coding sequence in the expression vector and used it to transform the attenuated Salmonella strain. To test the FNR dependent activation of the HIP. 1 promoter in the recombinant bacteria, an in vitro transcription assay was performed under hypoxic conditions.

In a first set of experiments, we evaluated the inducibility upon acute transition from aeroblc to anaerobic growth. Following two cycles of mid exponential growth under aerobic growth conditions, cultures were transferred to the hypoxic chamber and kept under hypoxic conditions in exponential growth phase for up to three hours to monitor at the cellular level whether hypoxia-induction of luciferase takes place. Samples were taken at different time points and luciferase activity assessed. The wild type HIP-1 promoter was induced immediately following hypoxic exposure and reporter protein activity further increased during the follow-up period, whereas the basal activity under aerobic conditions remained low (Fig. 2A). In these experiments, we ensured cells were continuously kept in exponential phase during the induction period and performed normalization towards measured OD600nm values, which we have shown to be equivalent to bacterial number. This allowed us to precisely calculate induction factors following hypoxic exposure, without influence of other growth parameters (Fig. 2B). A 37-fold increase in reporter gene activity was observed within three hours of hypoxic treatment, establishing the hypoxia-inducibility of the HIP.1 promoter during an acute change from aerobic to hypoxic conditions. To evaluate the induction following long term chronic hypoxia exposure and to ensure that the induction observed following acute hypoxia is not transient, we tested the expression profile of the reporter gene during several generations of prolonged chronic hypoxia. Cells were grown for several days under continuous hypoxic exposure. HIP-1 driven gene expression was then subsequently evaluated over a period of ten hours, during which cells were kept in exponential phase. The observed reporter gene expression was not only maintained during the entire follow-up period, but was also found to be 2-3 fold higher compared to the induction observed in the acute hypoxic exposure. This indicates a constant hypoxiainduced 
gene expression in all individual Salmonella bacteria (Fig. 2C). Gene expression levels rose from 37 -fold at three hours following acute transition to hypoxia to $\sim 85$-fold under chronic hypoxia.

A
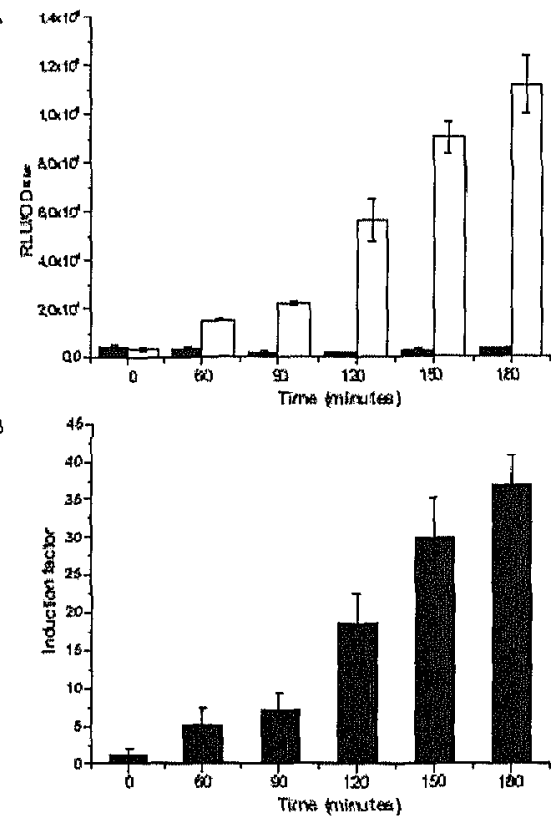

$c$

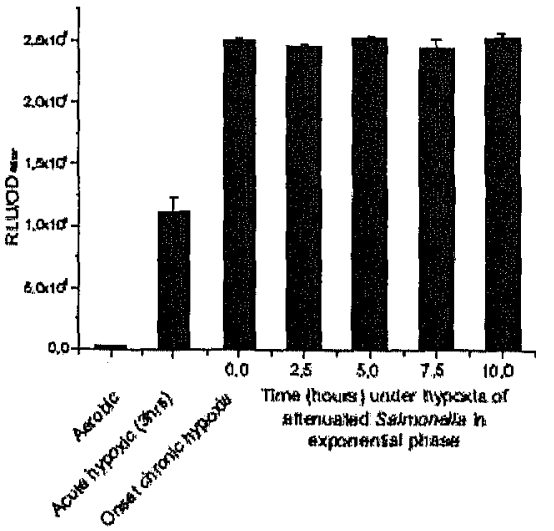

Figure 4.2. HIP-1 promoter drives $h$ oxia s ecific ene ex ression. A Normalized luciferase activity of attenuated Salmonella carrying the HIP-1-luciferase construct under aerobic (black bars) and hypoxic (white bars) conditions. (B) Induction factor of wild type (wt) HIP-1 promoter activity as a function of time. (C) HIP-1 romoter activity under chronic state hypoxia.

Attenuated Salmonella typhimurium were allowed to grow in the hypoxic chamber for two to three days prior to the start of the luciferase assay. After two cycles of mid-exponential growth in strictly hypoxic conditions, enzyme activity was determined every two to three hours while maintaining the exponential growth. Samples were taken when the bacteria reached OD600nm $\sim 0.3$ at each growth cycle. Data from the acute hypoxic experiment are included for comparison. Time 0 hours indicates the first time oint for the chronic hypoxia experiment, The data represent from three to four independent experiments. Error bars represent the standard errors of the mean (SEM). 


\section{HIP-1 driven expression is mediated by FNR}

The putative FNR binding site (GTGA-N4-CGCAA) in the HIP-1 promoter is centered at position -41.5 , upstream of the transcription start site. To confirm the pivotal role of the FNR box in regulating the induction following hypoxia, mutations were introduced by site directed mutagenesis resulting in the destruction of the binding site (Table 3). The promoter containing the desired mutation was then cloned into the luciferase expression vector and tested for its activity under hypoxia. The mutation affecting the FNR binding region of the HIP-1 promoter completely abolished the hypoxia inducibility of the HIP-1 promoter (Fig. 3A). This is in line with a previous report where an $A$ to $G$ change at position -45 in the FNR binding site of Figure 2. HIP-1 promoter drives hypoxia specific gene expression. (A) Normalized luciferase activity of attenuated Salmonella carrying the HIP-1- luciferase construct under aerobic (black bars) and hypoxic (white bars) conditions. (B) Induction factor of wild type (wt) HIP-1 promoter activity as a function of time. (C) HIP-1 promoter activity under chronic state hypoxia. Attenuated Salmonella typhimurium were allowed to grow in the hypoxic chamber for two to three days prior to the start of the luciferase assay. After two cycles of mid-exponential growth in strictly hypoxic conditions, enzyme activity was determined every two to three hours while maintaining the exponential growth. Samples were taken when the bacteria reached OD600nm $\sim 0.3$ at each growth cycle. Data from the acute hypoxic experiment are included for comparison. Time 0 hours indicates the first time point for the chronic hypoxia experiment. The data represent from three to four independent experiments. Error bars represent the standard errors of the mean (SEM).

the narG promoter totally abolished the anaerobic expression profile.24 Since we use a high copy plasmid-based expression system, endogenous FNR protein may not be sufficient to activate all available FNR boxes. Therefore, we overexpressed FNR by cloning the FNR coding sequence on the same expression plasmid under the control of its own promoter to result in a maximum desired induction under hypoxic conditions. The comblnation of the wild type HIP-1 and the overexpressed FNR gene indeed resulted in a significant increase in expression compared to the wild type promoter alone, with an average 2.5-fold higher induction in response to hypoxia ( $p<0.05$, Student's t-test) (Fig. 3B). Overexpression of the FNR gene did not affect the activity of the HIP-1 with a deleted FNR-box (data not shown). Both sets of data clearly established that the FNR gene and the FNR box are responsible for the observed hypoxia response. 
Table 4.3 Nucleotide sequence of the wild type and modified HIP-1 promoter region

\begin{tabular}{|c|c|}
\hline Type of Promoter & Sequence $^{8}$ \\
\hline HIP-1 & GGATAAAAGTGACCTGACGCAATATTTGTCTTTCT TGCTIAATAAT GTTGTCA \\
\hline HIP-1 & GGATAAAAGTGACCTGAEGCAATATTTGTCTTTTCT TGCTTIATAAI GTTGTCA \\
\hline$H I P-1_{F N B}$ & GGATAAAATTGATCTGAATCAATATTTGTCTITTCT TGCTTAATAAT GTTGTCA \\
\hline$H I P-1_{\text {mul }}$ & GGATAAAAGGATCCGACGCAATATT GTCTITCT TGCTTAATAAT GTTGTCA \\
\hline
\end{tabular}

a The highly conserved 5-base inverted repeat of the FNR consensus sequence is boxed. The putative 10 hexamer are underlined. The arrow indicates the transcription start site.

\section{Optimization of HIP-1 promoter}

Having shown that the HIP-1 promoter can drive hypoxia specific gene expression and that the FNR binding site is responsible for its inducibility, we further aimed at improving the specificity and expanding the applicability of the system by optimizing the -10 region and the FNR box. The 5'-AATAAT-3' hexamer $(-12$ to -7$)$ matching the TATA box of the wild-type (wt) HIP-1 promoter has five of the six bases matched to those of the consensus sequence. We performed a single nucleotide substitution changing the -10 region of the putative FNRdependent promoter to match the -10 consensus sequence for $\square 70$ promoters (TATAAT) (Table 3 ) and predicted that the -10 consensus sequence would enhance the activity of this promoter, resulting in elevated gene expression under anaerobic conditions. (Fig. 4A) shows the

expression profile of the modified promoter compared to the wild type. Correction of the TATA-box increased expression by a factor of 4 . This increase was observed in both basal and induced conditions (Fig. 4A), resulting in overall similar induction factors as obtained when applying the wt promoter construct (Fig. 4C). We then investigated whether we could decrease the basal activity by mutating the FNR binding site to the consensus sequence. Interestingly, basal expression levels were now barely detectable under aerobic conditions (Fig. 4B). The absolute expression levels with the FNR-optimized promoter sequence following acute hypoxia were similar to these observed with the wt promoter. The acute inducibility of the system could thus be increased from 37-fold in the wt promoter to 83-fold in the promoter with an optimized FNR box (Fig. 4C). Taken into account that the maximal expression levels under chronic hypoxia are even $2-3$ fold higher, this inherently means that use of this promoter can induce gene expression levels up to $\sim 200$-fold. Recombinant Salmonella harboring a construct in which the promoter had both the TATA- and FNR-box mutated to their respective consensus sequences, behaved similar like the promoter with the modified TATA-box alone (data not shown). This is likely due to saturation effects, as the 
higher basal levels resulting from optimizing the TATA-box might mask the effect of the optimized FNR sequence in our high copy plasmid-based system.

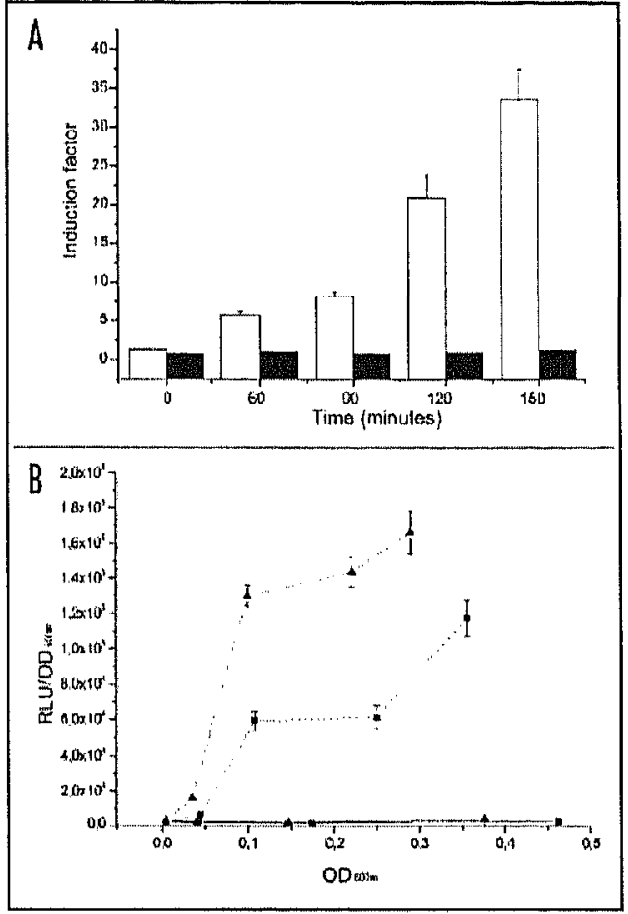

Figure 4.3. HIP-1 driven expression is FNR dependent. (A) Induction factors of the HIP-1 promoter wt construct (white bars) and the HIP-1 promoter with the deleted FNR-box (black bars) at the indicated time points following onset of hypoxic conditions. (B) Normalized luciferase activity in attenuated Salmonella carrying the wt

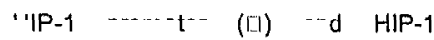
promoter with overexpressed FNR gene (s) under hypoxic (dashed line) and normoxic (straight line) conditions as a function of optical density. Enzyme activity was determined as a function of optical density as the rate of bacterial growth differed between recombinant Salmonella harboring either constructs. The data represent three independent experiments. Vertical bars represent SEM.

\section{In vivo validation of the HIP-1 promoter a ctivity}

As the in vitro data provide strong evidence of luciferase expression by attenuated Salmonella under hypoxic conditions and since the bacteria preferentially accumulate in tumors, we subsequently aimed to demonstrate that the HIP-1 promoter was capable of tumor-specific gene expression and importantly of exhibiting hypoxla-inducibility in an in vivo context. Animals harboring HCT116 human colorectal xenografts were therefore systemically injected with Salmonella that harbor HIP-1 driven GFP+ or DsRedT4 reporter genes. Both genes are derivatives of the well known fluorescent reporters GFP and RFP, respectively, and are adapted for use in a prokaryotic background. 25 
A

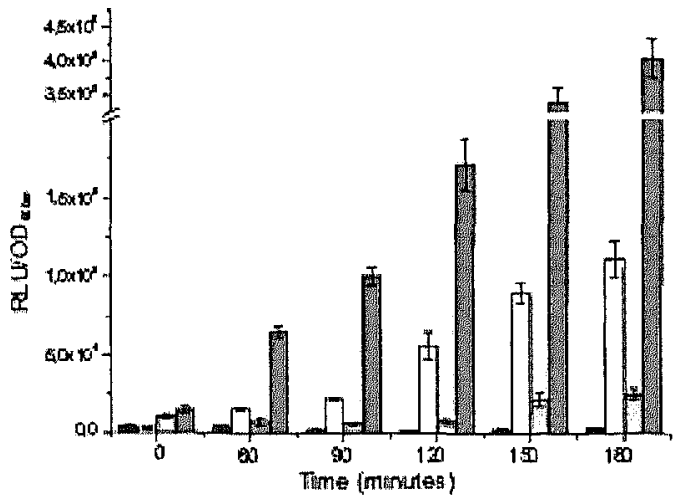

B

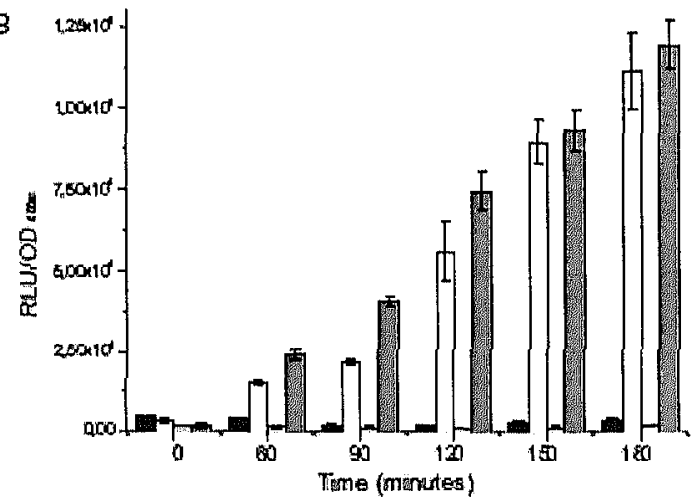

C

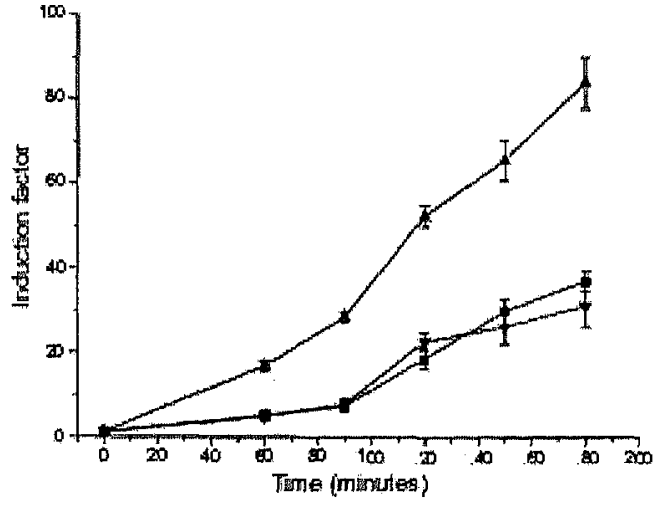

Fi_ur 4.4. Eff $c$ of regulatory sequence modification on the HIP-1 promoter activity. (A) wt HIP-1 promoter activity under normoxic (black bars) and hypoxic (white bars) conditions compared to activity of HIP-1 promoter with optimized TATAbox under normoxic (light grey bars) and hypoxic (dark grey bars) conditions. (B) wt HIP-1 promoter activity under normoxic (black bars) and hypoxic (white bars) conditions compared to activity of HIP-1 promoter with optimized FNRbox under normoxic (light grey bars) and hypoxic (dark grey bars) conditions. optimized HIP-1 promoter under normoxic hypoxic conditions. (C) Induction factors of the wt HIP$1(\nabla)$, the HIP-1 with optimized TATA-box (w) and the HIP-1 with optimized FNR-box (A). Data represent results from 3 independent experiments. Vertical bars represent the SEM.

Control animals received empty bacteria or recombinant bacteria carrying the same plasmid but with reporter gene expression under control of the constitutive rpsM promoter.21 In a first set of experiments, we aimed to evaluate the presence of reporter protein in different tissues. At 7 days following injection, tumor and normal tissues were excised and homogenates prepared to quantify colonization and expression of the GFP reporter. All tumors (up to 1010 cfu/g tumor tissue) and normal tissues (up to $107 \mathrm{cfu} / \mathrm{g}$ tissue in liver and spleen) were well colonized. GFP was strongly expressed in tumors colonized with recombinant Salmonella 
harboring constructs with GFP driven off the constitutive rpsM promoter and was also detected in tumors colonized with Salmonella in which GFP expression was controlled by HIP-1 (Fig. 5A). We also attempted to detect reporter signals in normal tissues. Although we could readily detect GFP in normal tissues (liver, spleen) when expression was driven by the rpsM promoter, no signal could be demonstrated in normal tissues of animals carrying the HIP-1 GFP+ construct (data not shown).

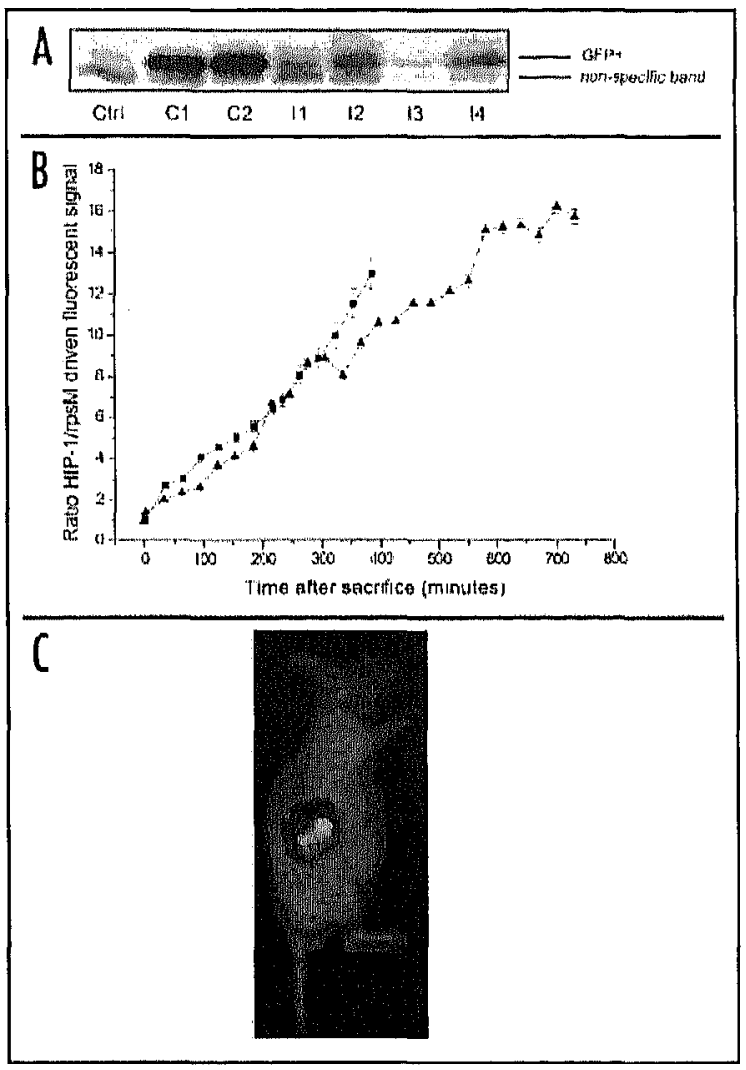

Figure 4.5. In vivo validation of HIP-1 promoe activity. (A) Western blot for GFP in cell extracts from HCT116 tumors from NMRI nu/nu mice injected l.V. 7 days before sacrifice with empty VNP20009 (Ctrl) or recombinant Salmonella expressing GFP driven by the constitutive rpsM promoter (indicated as $C$ ) or by he inductor HIP-1 (indicated as I). 250!.jg of tumor cell extract was loaded on the gel. A tumor extract colonized with nonrecombinant VNP20009 was used as negative control. Different numbers represent extracts from independent tumors. (B) GFP+ ( $\square$ ) and DsRed.T4 (s) reporter gene activity in Salmonolla, carrying the HIP.1 inducible or the rpsM constitutive promoter, Injected in colorectal tumor bearing NMRI-nu (nu/nu) tumor bearing NMRl-nu (nu/nu) mice. Normalized ratio of the HIP-1 to rpsM driven fluorescent reporter gene activity is shown as a function of time, Data represent results from two independent experiments for each reporter gene. Vertical bars represent the SEM (C) Illustration of HIP-1 SEM. (C) Illustralion driven DsRed.T4 reporter gene expression 12 hours

after sacrlficing the animal. The fluorescent excitation light was provlded by a $150 \mathrm{~W}$ halogen lamp, flltered for a wavelength of $500-555 \mathrm{~nm}$. The fluorescent light colligh emilted from the animal was detected by a charge-coupled device camera after filtering for wavelengths of $610 \pm 23.5 \mathrm{~nm}$. $\mathrm{D}^{-} \mathrm{p}^{--} \mathrm{di}^{-}$- th flu $^{-\cdots-} \mathrm{c}^{-\cdots} \mathrm{c}^{-}$ intensity. Integration tlmes ranged from 1.4 to $2.0 \mathrm{~s}$.

Xenografts growing in mice are known to be heterogeneous and to contain substantial areas of hypoxia. We thus expected a priori that the colonized tumors would demonstrate HIP-1 promoter activity and this is likely responsible for the fact that we can detect in our Western blots GFP at different levels in tumor extracts containing HIP-1 GFP+ recombinant bacteria. However, this does not show directly that the hypoxia per se is responsible for the observed reporter gene expression. Therefore, to definitively demonstrate the in vivo inducibillty of HIP. 1 , we chose to evaluate changes in reporter activity in individual tumors in which the oxygenation state was dramatically altered. This was accomplished by sacrificing the animals 
containing the colonized tumors. The production of the fluorescent reporter protein (GFP+ or DsRed.T4) was monitored prior to sacrifice and for several hours afterwards using noninvasive animal imaging technology (BonSAI, Siemens). Tumors were confirmed to contain high levels of Salmonella bacteria (up to $1010 \mathrm{cfu} / \mathrm{g}$ tumor tissue) (data not shown). Despite the fact that these tumors are known to contain already substantial hypoxia at the onset of the measurements, the level of GFP+ under the control of HIP-1 promoter was induced and progressively increased during the entire follow up period in comparison to the level of GFP+ driven by the constitutive rpsM promoter (Fig. 5B). We also evaluated the HIP-1 promoter driving the red Dsred.T4 gene, which exhibits substantially less background than the GFP+ constructs.10 Quantitative evaluation of fluorescence induction following induction of tumor hypoxia yielded highly similar results to GFP+. A representative illustration of the tumor colonized with attenuated Salmonella carrying the pepT-DsRed.T4 recombinant plasmid is shown in Figure $5 \mathrm{C}$.

\section{DISCUSSION}

Success of gene therapy as a treatment for cancer will ultimately depend on the targeting of therapeutic gene expression specifically to the tumor site.26-28 One of the most promising ways to accomplish this is by exploiting the lower oxygen levels found in tumors compared to normal tissues. This strategy of using tumor hypoxia has a second potential advantage, because hypoxic areas of the tumor are the most refractory to traditional types of cancer treatment. Most experimental tumors and a wide variety of clinical tumors are characterized by the presence of very low pO2 values. 29 Even in small clinical metastases, relatively large a-vascular regions, in general constituting $25-75 \%$ of the tumor mass, are often present. 30 In this study, we demonstrate that the prokaryotic attenuated Salmonella gene delivery vector can be genetically engineered to spatlally control gene expression using a hypoxia-inducible promoter. Results were obtained with a fragment of the FNR-responsive pepT promoter. Analogous eukaryotic hypoxia-inducible gene expression vectors have been developed for cancer gene therapy, based on the presence of hypoxia response elements (HREs), with varying success.31-33 In order to be able to use a prokaryotic hypoxia-driven spatial level of gene expression, we evaluated the growth pattern of attenuated Salmonella and demonstrated that the hypoxic exponential growth and survival of attenuated Salmonella is identical to that under normoxia. Moreover, in the presence of sufficient nutrients continued proliferation under hypoxic conditions was possible. The plateau observed at lower cell density under hypoxic compared to normoxic conditions can thus most likely be attributed to increased loss of nutrients and not directly to the presence of hypoxia per se. This finding is highly relevant since the irregular tumor vasculature in vivo often fails to supply growing tumors with sufficient oxygen, resulting in areas of diffusion-limited chronic hypoxia. Thus, stable transgene expression over an extended period, as shown here, may be necessary for therapeutic application of the hypoxia-regulated promoter in vivo. Consistent with the necessity of hypoxia for activation of HIP-1, our in vivo data confined the HIP-1 driven signal 
to the tumor. Indeed, no signals in normal tissues could be detected when the reporter was driven off the hypoxia-inducible promoter. It may therefore be well anticipated that the use of a hypoxia-inducible promoter will eventualiy result In increased therapeutic ratio. We subsequently sought to further fine-tune the specificity and potency of the HIP-1 hypoxiaresponsive promoter. The specificity (relative hypoxia/normoxia expression) could be increased by engineering the FNR box to its consensus sequence. Our first attempt to increase the potency (absolute expression levels), was to increase the amount of FNR activator protein in order to activate all available FNR boxes present in our high copy plasmid reporter. Interestingly, we demonstrated that this resulted in an additional 2.5-fold induction upon hypoxia. In other words, it can be anticipated that integration of the therapeutic gene as a single copy in the bacterial host's chromosome, where the FNR-box can consequently be more readily activated, may lead to even higher induction factors. Although it has yet to be shown in this system, the efficacy of single copy gene expression in attenuated Salmonella has already been demonstrated in in vivo anti-tumor experiments. 10 In that context, we also showed that absolute expression levels can be enhanced by a factor of 4 by mutating the -10 TATA-box to its consensus sequence. Overall, these data show that engineering of the HIP-1 promoter can be used to maximize the inducibility and/or vary the absolute gene expression levels. This may be necessary to achieve optimal expression levels of the therapeutic gene. We also conducted in vivo experiments to assess the hypoxia inducibility of HIP-1 in combination with non-invasive imaging. Our results indicated that reporter protein levels originating from tumors colonized with constitutive rpsM-driven GFP-expressing attenuated Salmonella were similar, whereas they were variable across tumors when GFP expression was driven off the HIP-1 promoter. This finding was not surprising, since hypoxic levels can vary significantly from one tumor to another. In addition, mouse and human tumors are characterized not only by reduced overall oxygenation, but also by a very heterogeneous spatial distribution of oxygen. Tumor hypoxia is often characterized as "chordal' indicating the presence of hypoxia at the diffusion limit (typically $100 \mathrm{um}$ ) around every blood vessel.34 Consequently, hypoxia exists throughout the entire tumor, but only in localized regions. Moreover, tumor hypoxia does not correlate well with tumor size. Thus, rather than attempting to correlate reporter signal with tumor size, or overall tumor oxygenation, we chose to evaluate the ability of the reporter to respond to a change in tumor oxygenation. This can be accomplished by administration of oxygen modifying drugs or by applying techniques such as tumor clamping to reduce blood flow.35,36 However, the most straightforward and easiest approach Involves sacrifice of the animal.

The loss of blood flow results in the rapid development of anoxia throughout the tumor and ensures that all previous aerobic areas also are depleted of oxygen. Subsequent comparison of the induction pattern of reporter signals from the HIP-1 versus the constitutive rpsM promoter in time, validated the in vivo hypoxia-inducibility of the system. The lower in vivo induction levels as compared to the in vitro findings are most likely due to the fact that these tumors contain substantial areas of hypoxia prior to sacrifice. It is thus not possible to 
measure the basal (aerobic) gene expression levels. Despite this complication, however, the trend in the gene expression profile following hypoxic treatment was very similar to that observed in vitro. In summary, our data show the potential for tumor-specific expression with supporting molecular biology with regards to FNR and engineered improvements of the promoter region in terms of specificity and potency. We provide a proof-of-principle that an inducible bacterial promoter system can be employed to target the hypoxic region of solid tumors. Since hypoxia has been shown to be present in most solid human tumors and to be a primary cause of treatment failure for conventional therapeutic agents, we believe that this approach will act in a complementary way to current radiotherapy and chemotherapy treatments, which preferentially kill well oxygenated cells. Therefore, the application of this hypoxia-driven targeting approach might be applicable to an extensive patient population. 


\section{References}

1. Lemmon MJ, van Zijl P, Fox ME, Mauchline ML, Glaccia AJ, Minton NP, Brown JM. Anaerobic bacteria as a gene delivery system that is controlled by the tumor microenvironment. Gene Ther 1997; 4:791-6.

2. Yazawa K, Fujimori M, Amano J, Kano $Y$, Taniguchi S. Bifidobacterium longum as a delivery system for cancer gene therapy: Selective localization and growth in hypoxic tumors. Cancer Gene Ther 2000; 7:269-74.

3. Nuyts S, Theys J, Landuyt W, van Mellaert L, Lambin P, Anne J, Increasing specificity of antitumor therapy: Cytotoxic protein delivery by nonpathogenic clostridia under regulation of radio-induced promoters. Anticancer Res 2001b; 21:857-61.

4. Lee SJ, Jang JW, Kim YM, Lee HI, Jeon JY, Kwon YG, Lee ST. Endostatin binds to the catalytic domain of matrix metalloproteinase-2. FEBS Lett 2002; 519:147-52.

5. Mei S, Theys J, Landuyt W, Anne J, Lambin P. Optimization of tumor-targeted gene delivery by engineered attenuated Salmonella typhimurium. Anticancer Res 2002; 22:3261-6.

6. Pawelek JM, Low KB, Bermudes D. Tumor-targeted Salmonella as a novel anticancer vector. Cancer Res 1997; 57:4537-44.

7. Clairmont C, Lee KC, Pike J, Ittensohn M, Low KB, Pawelek J, Bermudes D, Brecher SM, Margitich D, Turnier J, Li Z, Luo X, King I, Zheng LM. Biodistribution and genetic stability of the novel antitumor agent VNP20009, a genetically modified strain of Salmonella typhimurium. J Infect Dis 2000; 181:1996-2002.

8. Jazowiecka-Rakus J, Szala S. Antitumour activity of Salmonella typhimurium VNP20047 in B16(F10) murine melanoma model. Acta Biochim Pol 2004; 51:851-6.

9. Low KB, Ittensohn M, Le T, Platt J, Sodi S, Amoss M, Ash O, Carmichael E, Chakraborty A, Fischer J, Lin SL, Luo X, Miller SI, Zheng L, King I, Pawelek JM, Bermudes D. Lipid A mutant Salmonella with suppressed virulence and TNFalpha induction retain tumor-targeting in vivo. Nat Biotechnol 1999; 17:37-41.

10. King I, Bermudes D, Lin S, Belcourt M, Pike J, Troy K, Le T, Ittensohn M, Mao J, Lang W, Runyan JD, Luo $\mathrm{X}, \mathrm{Li} Z$, Zheng LM. Tumor-targeted salmonella expressing Cytosine deaminase as an anticancer agent. Hum Gene Ther 2002; 13:1225-33.

11. Lee KC, Zheng LM, Margitich D, Almassian $B$, King I. Evaluation of the acute and subchronic toxic effects in mice, rats, and monkeys of the genetically engineered and Escherichia coll cytosine deaminase gene-incorporated Salmonella strain, TAPET-CD, being developed as an antitumor agent. Int $J$ Toxicol 2001; 20:207-17.

12. Shibata T, Giaccia AJ, Brown JM. Development of a hypoxia-responsive vector for tumorspecific gene therapy. Gene Ther 2000; 7:493-8.

13. Wouters BG, Weppler SA, Koritzinsky M, Landuyt W, Nuyts S, Theys J, Chiu RK, Lambin P. Hypoxia as a target for combined modality treatments. Eur $J$ Cancer 2002; 38:240-57.

14. Crack J, Green J, Thomson AJ. Mechanism of oxygen sensing by the bacterial transcription factor fumarate-nitrate reduction (FNR). J Biol Chem 2004; 279:9278-86.

15. Jamieson DJ, Higgins CF. Two genetically distinct pathways for transcriptional regulation of anaerobic gene expression in Salmonella typhimurium. J Bacteriol 1986; 168:389-97.

16. Strauch KL, Lenk JB, Gamble BL, Miller CG. Oxygen regulation in Salmonella typhimurium. J Bacteriol 1985; 161:673-80.

17. Kiley PJ, Beinert $H$. Oxygen sensing by the global regulator, FNR: The role of the iron-sulfur cluster. FEMS Microbiol Rev 1998; 22:341-52.

18. Sutton VR, Mettert EL, Beinert H, Kiley PJ. Kinetic analysis of the oxidative conversion of the [4Fe-4S]2+ cluster of FNR to a [2Fe-2S]2+ Cluster. J Bacteriol 2004; 186:8018-25.

19. Chang EH, Miller PS, Cushman C, Devadas K, Pirollo KF, Ts'o PO, Yu ZP. Antisense inhibition of ras p21 expression that is sensitive to a point mutation. Biochemistry 1991; 30:8283-6.

20. Sambrook J FE, Maniatis T. Molecular cloning. A laboratory manual. 2nd ed. New York, NY: Cold Spring Harbor Laboratory Press, 1989.

21. Hautefort I, Proenca MJ, Hinton JC. Single-copy green fluorescent protein gene fusions allow accurate measurement of Salmonella gene expression in vitro and during infection of mammalian cells. Appl Environ Microbiol 2003; 69:7480-91.

22. Dubois L, Landuyt W, Haustermans K, Dupont P, Bormans G, Vermaelen P, Flamen $P$, Verbeken $E$, Mortelmans $L$. Evaluation of hypoxia in an experimental rat tumour model by [(18)F]fluoromisonidazole PET and immunohistochemistry. Br J Cancer 2004; 91:1947-54 
23. Lombardo MJ, Lee AA, Knox TM, Miller CG. Regulation of the Salmonella typhimurium pepT gene by cyclic AMP receptor protein (CRP) and FNR acting at a hybrid CRP-FNR site. $J$ Bacteriol 1997; 179:1909-17.

24. Walker MS, DeMoss JA. Role of alternative promoter elements in transcription from the nar promoter of Escherichia coli. J Bacteriol 1992; 174:1119-23.

25. Sorensen M, Lippuner C, Kaiser T, Misslitz A, Aebischer T, Bumann D. Rapidly maturing red fluorescent protein variants with strongly enhanced brightness in bacteria. FEBS Lett 2003; 552:110-4.

26. Bainbridge JW, Mistry A, Binley K, De Alwis M, Thrasher AJ, Naylor S, Ali RR. Hypoxiaregulated transgene expression in experimental retinal and choroidal neovascularization. Gene Ther 2003; 10:1049-54.

27. Dachs GU, Coralli C, Hart SL, Tozer GM. Gene delivery to hypoxic cells in vitro. Br J Cancer 2000; 83:662-7.

28. Marignol L, Lawler M, Coffey M, Hollywood D. Achieving hypoxia-inducible gene expression in tumors. Cancer Biol Ther 2005; 4:359-64.

29. Vaupel $P$, Kelleher DK, Hockel M. Oxygen status of malignant tumors: Pathogenesis of hypoxia and significance for tumor therapy. Semin Oncol 2001; 28:29-35.

30. Dang $L H$, Bettegowda $C$, Huso DL, Kinzler KW, Vogelstein B. Combination bacteriolytic therapy for the treatment of experimental tumors. Proc Natl Acad Sci USA 2001; 98:1515560.

31. Dachs GU, Tozer GM. Hypoxia modulated gene expression: Angiogenesis, metastasis and therapeutic exploitation. Eur J Cancer 2000; 36:1649-60.

32. Greco O, Marples B, Dachs GU, Williams KJ, Patterson AV, Scott SD. Novel chimeric gene promoters responsive to hypoxia and ionizing radiation. Gene Ther 2002; 9:1403-11.

33. Semenza GL. Regulation of hypoxia-induced angiogenesis: A chaperone escorts VEGF to the dance. J Clin Invest 2001; 108:39-40.

34. Brown JM, Wilson WR. Exploiting tumour hypoxia in cancer treatment. Nat Rev Cancer 2004; 4:437-47.

35. Patterson LH, McKeown SR, Ruparelia K, Double JA, Bibby MC, Cole S, Stratford IJ. Enhancement of chemotherapy and radiotherapy of murine tumours by $A Q 4 N$, a bioreductively activated anti-tumour agent. $\mathrm{Br} \mathrm{J}$ Cancer 2000; 82:1984-90.

36. Sersa G, Krzic M, Sentjurc M, Ivanusa T, Beravs K, Cemazar M, Auersperg, MSwartz HM. Reduced tumor oxygenation by treatment with vinblastine. Cancer Res 2001; 61:4266-71. 


\section{CHAPTER 5}

\section{Identification of highly induced Salmonella genes to increase the specificity of Salmonella mediated cancer therapy}

Asferd Mengesha, Roy Bongaerts, Ludwig Dubois, Brad Wouters, Jay Hinton, Philippe Lambin and Jan Theys 


\begin{abstract}
:
Prokaryotic anti-cancer therapies employ bacterial strains that selectively proliferate within tumors. Attenuated Salmonella represent one of the most promising of these agents, as they preferentially accumulate in tumors as opposed to normal tissues and have been shown to generate potent anti-tumor effects in experimental animals. However, since normal tissues can also be colonized, application of this delivery system may lead to side-effects. The identification of Salmonella promoters that are specifically upregulated upon external or internal stimuli would therefore increase the specificity of protein delivery and may allow spatial and/or temporal control of protein expression. Toward this goal, we applied microarray technology to screen for highly inducible molecular targets following hypoxia or radiation treatment in attenuated Salmonella. Hundred to thousand fold induced expression of certain gene operons following both acute and chronic exposure to hypoxia were identified. Interestingly, we also identified a number of genes that were $>10$-fold upregulated following treatment with a clinically relevant dose of 2 Gray. In addition, we describe a method that allows the screening for endogenous Salmonella promoters which are specifically upregulated in tumors and not in normal tissues in vivo.

Our results clearly indicate the potential of microarrays to identify gene promoters that are induced following exposure to hypoxia, or radiation or that are activated specifically in tumors in vivo. Application of such promoters to drive therapeutic gene expression in attenuated Salmonella has the potential to increase the specificity and thus the therapeutic ratio of Salmonelia-mediated drug delivery.
\end{abstract}




\section{INTRODUCTION:}

A number of studies have now demonstrated the potential of genetically engineered live bacteria as tumor-targeting vectors in human cancer therapy [1-6]. In animal tumor models, these bacteria target and multiply selectively within tumors, thus amplifying intra-tumoral gene delivery and therapeutic effects $[4,7,8]$. In some cases the applied microorganisms also exhibit inherent tumor-suppressing activities [4,9]. Salmonella typhimurium, a motile, invasive Gram-negative bacterium, is able to colonize solid tumors. Chemo-attractive compounds produced by quiescent tumor cells have been shown to contribute to this effect in vitro $[10,11]$. However, the exact mechanisms explaining why attenuated Salmonella prefers to colonize tumors instead of normal tissues (at ratios ranging from 250:1 to 9000:1) remain to be elucidated. In vivo, S. typhimurium preferentially colonizes hypoxic, nutrient-rich, necrotic areas within tumors and also in clinical trials, systemically administered Salmonella strains have been demonstrated to colonize tumors $[12,13]$. Attenuated Salmonella typhimurium has been successfully used to deliver therapeutic molecules such as prodrug-converting enzymes and antigens to tumors [14,15]. Expression of these molecules has invariably been driven by constitutive promoters. However, since these prokaryotic vectors also colonize normal tissues, therapeutic gene expression may cause side-effects, thereby pointing out the need for more selective tumor targeting. An inducible system, in which the therapeutic gene would be placed under the transcriptional control of a promoter that is responsive to either internal micro-environment related stimuli such as hypoxia or to external stimuli such as radiation, would therefore be more appropriate. In the context of prokaryotic delivery vectors, a range of promoters that respond to various stimuli such as hypoxia, radiation or other environmental conditions have been characterized for strains such as Clostridium $[16,17]$.

The majority of solid tumors have been shown to contain hypoxic and/or necrotic regions. This microenvironmental condition causes resistance to conventional cancer therapy. However, it also represents a unique environment not found elsewhere in the body that could be exploited for a patient's advantage via inducible promoter systems. In Gram-negative bacteria, the Fumarate and Nitrate Reduction regulator (FNR) regulates the global response to the transition between aerobic and anaerobic growth. FNR is a bifunctional protein that acts both as a hypoxic sensor and a hypoxia-responsive transcription factor. All FNR-regulated promoters are characterized by the presence of FNR-binding sites. FNR responsive DNA promoters are thus considered to be attractive candidates that can be exploited for such purpose. In addition, bacteria possess an adaptive mechanism called the "SOS-response" to cope with various types of DNA damage induced for instance by radiation. Thus radiationinduced promoters could obviously be of major importance in a bacterial transfer system using attenuated Salmonella for control of gene expression. For studies on tumor-specific gene induction in Salmonella, we previously explored two inducible systems: an FNRregulated hypoxia induced gene promoter and SOS-responsive radiation inducible promoters [[18] and unpublished data].These studies clearly demonstrated the proof-of-principle that 
regulation of anti-cancer genes through internal and/or externally-applied stimuli using genetically engineered Salmonella is a feasible therapeutic approach.

To extend our initial findings and to investigate whether we could isolate inducible promoter systems with superior characteristics, microarray technology was used to screen for endogenous Salmonella promoters that are activated upon exposure to hypoxia or radiation. The bacteria were exposed to acute and chronic hypoxia or were irradiated at doses of 2 and $10 \mathrm{~Gy}$. Analysis of the microarray data revealed the presence of a large group of highly induced genes following both kinds of stress. Reporter gene analysis was used to confirm the inducibility of selected promoters, In addition, we developed a method that allows the isolation of promoters that are preferentially activated in bacteria present in tumors and not in normal tissues in vivo.

This broad microarray-based methodology revealed that a variety of inducible promoters are available that could be utilized to drive expression of therapeutic proteins, thereby improving the specificity of drug delivery targeting.

\section{MATERIALS AND METHODS:}

\section{Bacterial strains, plasmids and growth conditions}

Attenuated Salmonella Typhimurium [VNP20009] [msbB', purr, xyr, and EGTA ${ }^{r}$ ] were obtained from Vion Pharmaceuticals (New Haven, CT). VNP20009 is a msbB- and pur ${ }^{-}$ mutant that was specifically developed as a nonpathogenic, tumoricidal agent. Escherichia coli TG1 obtained from Gibco BRL (Invitrogen, Carlsbad, CA, USA) was used as host for all recombinant DNA manipulations. Detailed descriptions of the plasmids used in this work are listed in Table 1. For strain manipulations and maintenance, cells were grown at $37^{\circ} \mathrm{C}$ in Luria-Bertani (LB) medium (Gibco BRL, Gaithersburg, MD) comprised of $0.5 \%$ Bacto-yeast extract, $1 \%$ Bacto-tryptone, and $1 \% \mathrm{NaCl}$ and on agar plates using standard procedures. Bacterial strains harboring the recombinant plasmids were grown overnight in liquid LB, with shaking at $37^{\circ} \mathrm{C}$. The following day cultures were diluted twice $(1: 100)$ when an optical density $\left(O D_{600 n m}\right)$ of 0.3 was reached. Cultures were again diluted 100 fold and experiments were started. For microarray experiment samples were taken for RNA isolation when $O D_{600 \mathrm{~nm}}$ reach 0.8 and 0.15 . Aerobic conditions were obtained by shaking the culture vigorously (250 $\mathrm{rpm} / \mathrm{min}$ ). For anaerobic induction experiments, cultures were incubated in a hypoxic chamber (MACS Anaerobic Workstation; Don Whitley Scientific, Shipley, UK $\left(5 \% \mathrm{CO}_{2}-95 \% \mathrm{~N}_{2}\right)$ ) at $37^{\circ} \mathrm{C}$ with shaking conditions as in the aerobic cultures. All the media and buffers used for anaerobic experiments were made hypoxic and kept in the anaerobic chamber for days before onset of the experiments. When required, Ampicillin and chloramphenicol were added to the medium at concentrations of 50 and $100 \mathrm{mg} / \mathrm{ml}$ respectively. For acute stress hypoxia experiments, cultures were transferred to the hypoxic workstation following an aerobic dilution cycle as described. Samples were taken at different time points, $O_{600 n m}$ defined and the bacteria stored on ice prior to a luciferase assay. For chronic hypoxia experiments, cultures 
were maintained in the anaerobic chamber for days and samples for microarray were taken following two cycles of mid log growth within the anaerobic chamber.

Table 5.1. Strains and plasmids used in this study.

\begin{tabular}{|c|c|c|}
\hline Strains or plasmid & Genotype & Zeference \\
\hline E. coll TG1 cells & $\begin{array}{l}\text { (supE hsd } \triangle 5 \text { thi } \Delta(\text { lac-proAB) F'/traD36 pro } \\
\left.A B^{+} \text {lac/ } l a c Z \Delta M 15\right]\end{array}$ & Gibco BRL \\
\hline $\begin{array}{l}\text { Salmonella Typhimutium } \\
\text { [VNP2009] }\end{array}$ & (msbB- purr, $x y r$, and EGTA ${ }^{r}$ ) & Vion Pharmaceutical \\
\hline \multicolumn{3}{|l|}{ Plasmids } \\
\hline pGEM-T Easy vector & MCS, Ap', LacZa & Promega \\
\hline$p S p-L u c+N F$ fusion vector & MCS, Ap $p^{r}, L U C+N F$ & Promega \\
\hline pSp-HIF-1-Luc+NF & pSp-Luc+NF, HIP-1promoter & [18] \\
\hline pSp- citC-Luc+NF & citC-promoter & This study \\
\hline pSp- fdhG-Luc+NF & fdhG-promoter & This study \\
\hline pSp-narK-Luc+NF & nark-promoter & This study \\
\hline pSp- glpA-Luc+NF & glpA-promoter & This study \\
\hline$p S p-o m p-L u c+N F /$ & omp-promoter & This study \\
\hline pSp-narG-Luc+NF & narG-promoter & This study \\
\hline$p S p-r e c A-L u c+N F$ & recA-promoter & This study \\
\hline$p S p-f d g H-L u c+N F$ & fdgH-promoter & This study \\
\hline pSp-STM-Luc+NF & STM-promoter & This study \\
\hline$p S p-$ nifS-Luc+NF & nifS-promoter & This study \\
\hline$p S p-$ ducB-Luc+NFI & ducB-promater & This study \\
\hline pSp- recN-Luc+NF & recN-promoter & This study \\
\hline pSp-napF-Luc+NF/ & napF-promoter & This study \\
\hline
\end{tabular}

\section{DNA manipulations and vector construction}

All general DNA manipulations in $E$. coli were carried out as described by Sambrook et al [19]. Restriction endonucleases and DNA-modifying enzymes were purchased from New England Blolabs (NEB Ltd, Ipswich, UK) and used as indicated by the suppliers. Chromosomal DNA was extracted from E.coli and Salmonella using the Gene Elute Bacterial Genomic DNA kit mini (Sigma, St. Louis, MO, USA). PCR was performed on the extracted chromosomal DNA as a template. PCR products were synthesized with Hot Star DNA polymerase (Qiagen $\mathrm{GmbH}$, Westburg, Hilden, Germany) to generate the $3^{\prime}$ deoxyadenosine necessary for direct cloning into pGEM-T Easy vector (Promega Corp, Madison, WI) and 
sequenced using standard T7 forward and reverse primers ( $A B \mid$ prism 310 Genetic Analyzer, Applied Biosystems). Fragments for subcloning were isolated from low melting agarose using the QiaQuick gel extraction kit (Westburg, Hilden, Germany) and restriction sites incorporated into the primers were then used to subclone fragments into the pSP-Luc+NF expression vector (Promega Corp, Madison, WI). Transformation into E. coli TG1 (supE hsd 55 thi $\triangle$ [lacproAB]) was performed using chemocompetent cells (Gibco BRL) obtained with the RbCl method. Introduction of recombinant plasmids into attenuated Salmonella was done by electroporation [25 $\mu \mathrm{F}, 400 \Omega$, and $2.5 \mathrm{kV}$,] using $0.2 \mathrm{~mm}$ cuvettes. Plasmid DNA Isolations were performed using the Gene Elute plasmid miniprep kit (Sigma, St. Louis, MO, USA).

\section{Determination of in vitro promoter activities}

Promoter activities were determined by monitoring luciferase activity in vitro. Luciferase assays are performed with some modification of the luciferase assay protocol (Promega). Briefly, overnight cultures of Salmonella [VNP20009] cells harboring plasmids of the pSPLuc+NF fusion which carried the respective promoters were grown at $37^{\circ} \mathrm{C}$ in $\mathrm{LB}$ medium, containing $5 \mu$ of Ampicillin $(50 \mu \mathrm{g} / \mathrm{ml})$ and diluted $1: 100$ in the same medium $(50 \mu \mathrm{g} / \mathrm{ml}$ Ampicillin). Aliquots of $90 \mu \mathrm{l}$ were removed from the cultures at different time intervals, mixed with $10 \mu$ l of $1 \mathrm{M} \mathrm{K}_{2} \mathrm{HPO}_{4}(\mathrm{pH} 7.8) 20 \mathrm{mM}$ EDTA and quick-frozen on dry ice. After all samples were collected, they are equilibrated to room temperature by placing the tubes in a water bath at room temperature followed by mixing and incubating the samples with $300 \mu$ freshly prepared lysis mix ( $1 X$ cell culture lysis reagent (CCLR), $1.25 \mathrm{mg} / \mathrm{ml}$ lysozyme and $2.5 \mathrm{mg} / \mathrm{ml}$ BSA) for $10 \mathrm{~min}$ at room temperature. Twenty $\mu$ aliquots of sample and $100 \mu$ l of luciferase assay reagent are mixed into the luminometer tube and luciferase activity was measured (10 s, delay 2s) in a LUMAC type luminometer (A perstorp Analytical Company) at room temperature. Activities are given as relative light units (RLU) after subtraction of the instrumental background.

\section{RNA isolation from Salmonella RNA}

A $2 O D_{600}$ units of bacterial culture were harvested and added to a $50 \mathrm{ml}$ Falcon tube

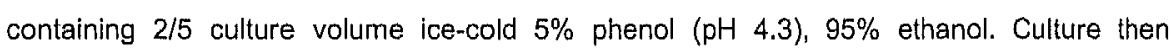
incubated on ice for at least $30 \mathrm{~min}$. Following $30 \mathrm{~min}$ incubation on ice samples were centrifuge at $3220 \times \mathrm{g} 4^{\circ} \mathrm{C}$ for $10 \mathrm{~min}$. Bacterial pellets were then resuspend in $100 \mu \mathrm{TE}$ buffer containing $50 \mathrm{mg} / \mathrm{ml}$ lysozyme and incubated for $5 \mathrm{~min}$ at room temperature. $75 \mu \mathrm{l}$ lysis reagent (Promega) was added and mixed by inversion followed with $350 \mu$ l RNA dilution buffer (Promega SV). Samples were then incubated at $70^{\circ} \mathrm{C}$ for $3 \mathrm{~min}$ and centrifuge for 10 $\min$ at full speed $(13000 \mathrm{rpm})$. The supernatant was mixed with $200 \mu$ ethanol and centrifuge for 1 more min. Columns then washed with $600 \mu$ wash buffer and centrifuge for $1 \mathrm{~min}$ at full speed. $50 \mu$ ) of DNase mix $\left(5 \mu l 90 \mathrm{mM} \mathrm{MnCl}{ }_{2,} 40 \mu \mathrm{l}\right.$ DNase core buffer, $5 \mu l$ DNase) was added to the column and incubated at room temperature for $15 \mathrm{~min}$. Following incubation 200 $\mu \mathrm{l}$ DNase stop mix were added and centrifuge for $1 \mathrm{~min}$ at full speed. Columns were washed 
with $600 \mu l$ wash buffer. Finally, columns were eluted with $100 \mu$ RNAse-free distilled $\mathrm{H}_{2} \mathrm{O}$ at $4500 \mathrm{Xg}$ for $2 \mathrm{~min}$. RNA was quantified using a nanodrop ND-1000 device (NanoDrop Technologies, Wilmington, $D E$ ) and quality confirmed by bioanalyser to ensure the RNA is not degraded.

\section{Direct labeling of RNA and DNA}

Random priming reactions (10 $\mu \mathrm{g}$ of total RNA, $5 \mu \mathrm{g}$ of random hexamers (Invitrogen) in a total volume of $9.4 \mu \mathrm{t}$ of Sigma ultra-pure water were set up and incubated at $70^{\circ} \mathrm{C}$ for $5 \mathrm{~min}$. and then chilled on ice for $10 \mathrm{~min}$. Using the Stratagene AffinityScript, multi-temperature Reverse TranscriptaseRT reaction mix ( $2 \mu$ l of $10 \times$ RT buffer, $2 \mu$ of 0.1 M DTT, $0.6 \mu$ l of 50 $X$ dNTP's) were prepared. $4.6 \mu$ per reaction of RT reaction mix was added to RNA. Finally, $2 \mu \mathrm{l}$ of Cy5-dCTP ( $1 \mathrm{mM}$ stock, GE Healthcare Life sciences) and $4 \mu$ l of reverse transcriptase were mixed in a total reaction volume of $20 \mu \mathrm{l}$ and incubated at $25^{\circ} \mathrm{C}$ for $10 \mathrm{~min}$. Following an overnight incubation at $42^{\circ} \mathrm{C}$, a $15 \mu$ l of freshly prepared $0.1 \mathrm{M} \mathrm{NaOH}$ was added to stop the reaction and RNA is hydrolyzed at $70^{\circ} \mathrm{C}$ for 10 minutes.

Genomic Salmonella DNA was labeled by Klenow random priming, incorporating Cy3-dCTP (GE Healthcare), and spun through a Qiaquick column (Qiagen, Valencia, CA), following the manufacturers protocol. In short, $2 \mu \mathrm{g}$ of chromosomal DNA in $21 \mu \mathrm{l} \mathrm{Sigma} \mathrm{ultra-pure} \mathrm{water}$ was mixed to $20 \mu \mathrm{l}$ of $2.5 \mathrm{X}$ Random primer/reaction buffer mix (Invitrogen BioPrime® DNA Labeling System) and boiled for $5 \mathrm{~min}$ and then incubated on ice for $5 \mathrm{~min}$. Five $\mu$ of $10 \mathrm{X}$ dNTP mix and $3 \mu$ l of Cy 3 dCTP ( $1 \mathrm{mM}$ stock, GE Healthcare Lifesciences) were mixed with 1 $\mu l$ of Klenow enzyme in the total reaction volume of $50 \mu \mathrm{l}$ and the reaction mixture were incubated at $37^{\circ} \mathrm{C}$ overnight.

Finally, labeled cDNA with labeled genomic DNA were mixed and cleaned up using Qiaquick PCR purification kit (Qiagen) to remove unincorporated CY dyes. Pellets were finally resolved in $10 \mu$ S Sigma ultra pure water.

\section{Microarray Hybridizations}

$1.5 \mu$ of $50 \times$ Denhardts solution, $2.25 \mu$ of $20 \times$ SSC , $1.125 \mu \mathrm{l}$ of E. coli tRNA $(10 \mu \mathrm{g} / \mu \mathrm{l})$ (Sigma), $0.375 \mu$ l of $1 \mathrm{M}$ HEPES ( $\mathrm{pH} 7.0$ ) were added to $10 \mu \mathrm{l}$ of labeling reactions, $0.375 \mu \mathrm{l}$ of $10 \%$ SDS was then added to the mixture and incubated at $100{ }^{\circ} \mathrm{C}$ for $2 \mathrm{~min}$. Following incubation samples were centrifuge for $5 \mathrm{~min}$ and supernatant was transferred to clean tube. The hybridization solution was then pipetted on to a microarray slide in a metal Agilent hybridization chamber (Agilent Technologies). To maintain the correct humidity in the hybridization chamber $20 \mu \mathrm{l}$ of $3 \times$ SSC were applied around the 4 corners of the slides. Hybridizations were performed in water bath at $63^{\circ} \mathrm{C}$ overnight. Microarray slides were prehybridised in $3.5 \times \mathrm{SSC}, 0.1 \%$ SDS and $10 \mathrm{mg} \mathrm{mL}^{-1} \mathrm{BSA}$ for $65^{\circ} \mathrm{C}$ for 20 mlnutes, washed with water and isopropanol and eventually dried with an airbrush. Following the first hybridization, the slides were washed in $2 \times$ SSC, $0.2 \%$ SDS for $10 \mathrm{~min}$. at $60^{\circ} \mathrm{C}$, followed by washes at $2 \times$ SSC and $0.2 \times$ SSC for ten mlnutes, each at room temperature. 
Microarray data acquisition and analysis

The microarray slides were scanned using a GenePix 4000A scanner (Axon Instruments, Union City, California, United States). Spot intensities were quantified using BlueFuse software (BlueGnome, Cambridge, United Kingdom) with the local background-correction option selected. The $\mathrm{Cy} 5 / \mathrm{Cy} 3$ intensity ratio was calculated for each spot. Median density values and background values of each spot were extracted for both the experimental samples (Cy5) and the reference samples (Cy3). Spot data were extracted from images and manually flagged to remove artifacts before fusion. Data analysis and visualization were then performed using GeneSpring GX 7.3 (Agilent, Palo Alto, California, United States).

\section{In vivo Experiments}

Female adult NMRI nu/nu mice were used to assess the in vivo gene expression profile of the attenuated Salmonella typhimurium infecting tumor tissue. $5 \times 10^{6}$ human colorectal carcinoma HCT116 cells were injected subcutaneously in the left and right abdominal flank under minor anesthetics. When tumors reached a predefined volume $\left(300 \mathrm{~mm}^{3}\right)$, bacteria $\left(2 \times 10^{6}\right.$ colony forming units) were systemically administered via a lateral tail vein. Tumor colonization was allowed for 7 days. Tumors and normal tissues were then excised for salmonella gene expression analysis. All animal experiments were conducted in accordance with local institutional guidelines, approved by the Animal Ethics Committee of the University.

\section{Isolation Bacterial RNA from infected tumor tissues}

Tumor tissues were homogenized in liquid $\mathrm{N}_{2}$ using a mortar and pestle cooled with liquid $\mathrm{N}_{2}$ (Fisher Emergo, Landsmeer, The Netherlands). Homogenates are collected in cold Eppendorff containing phenol/ethanol and pellets were collected by fractionated centrifugation (10 min, 600 g $-4000 \mathrm{~g}, 4^{\circ} \mathrm{C}$ ). The supernatant is removed at each centrifugation steps for further centrifuge and finally pellets re-suspended with phenol:ethanol. This is repeated with increased centrifugation speed until all the bacteria from a particular step are present in one micro centrifuge tube. Pellets are used for RNA preparation and labeling. As only a small amount of bacterial RNA is obtained by this protocol the labeling protocol for reduced amounts of RNA was used. Total RNA was isolated from these homogenates using TRIzol reagent (Invitrogen, San Diego, CA) according to the manufacturer's instructions. The purity and concentration were measured with the bioanalizer and Nanodrop (Isogen Life Science, Maarssen, The Netherlands).

\section{RESULTS:}

Identification of hypoxia-inducible promoters using microarray technology

To determine the level of gene induction following hypoxic treatment in attenuated S.typhymirium, bacteria were grown at $37{ }^{\circ} \mathrm{C}$ in both aerobic cultures and anaerobic conditions. Hypoxia is a dynamic and highly heterogeneous condition within a tumor. 
Similarly, the cellular response to hypoxia includes both transient and stable changes in gene expression. Therefore, we monitored changes in gene expression during both a transient shift to hypoxia as well as during chronic hypoxic exposure.

To study the effect of a long time exposure to hypoxia (chronic hypoxia), cultures were kept in anaerobic conditions for several days before the start of the experiments. Following multiple dilution cycles to ensure that the bacteria are in exponential growth phase, samples were taken at two different time points (at $\mathrm{OD}_{600 \mathrm{~nm}} 0.15$ and 0.8 ). For each experiment, RNA was extracted in parallel from hypoxia-treated and control aerobic cultures and its purity checked. The $O D A_{260} / A_{2 B O}$ ratios were between 2.08 and 2.10 for all samples, indicating reliable and constant RNA quality. RNA samples were then labeled in a reverse transcriptase reaction, and the cDNAs from the test and control cultures were combined and hybridized to Salmonella microarrays. The level of gene expression was monitored by competitive hybridization to the microarray. Each hybridization experiment was repeated twice (technical replicate) using total RNA isolated from three independent experiments (biological replicate). Microarray data were extracted using gene fuse software (Axon). The microarrays featured 3,169 of the $4,451(71 \%)$ protein coding genes (CDS) or open reading frames derived from the complete genome sequence identified in $S$. typhimurium LT2 genome.

The data shown in figure 1 are representative for the three biological replicates, and represent the fold-change of gene expression following exposure to either acute or chronic hypoxia, using the aerobic gene expression profile as a control. All three biological replicates showed a consistent gene induction profile in both treatment conditions. 


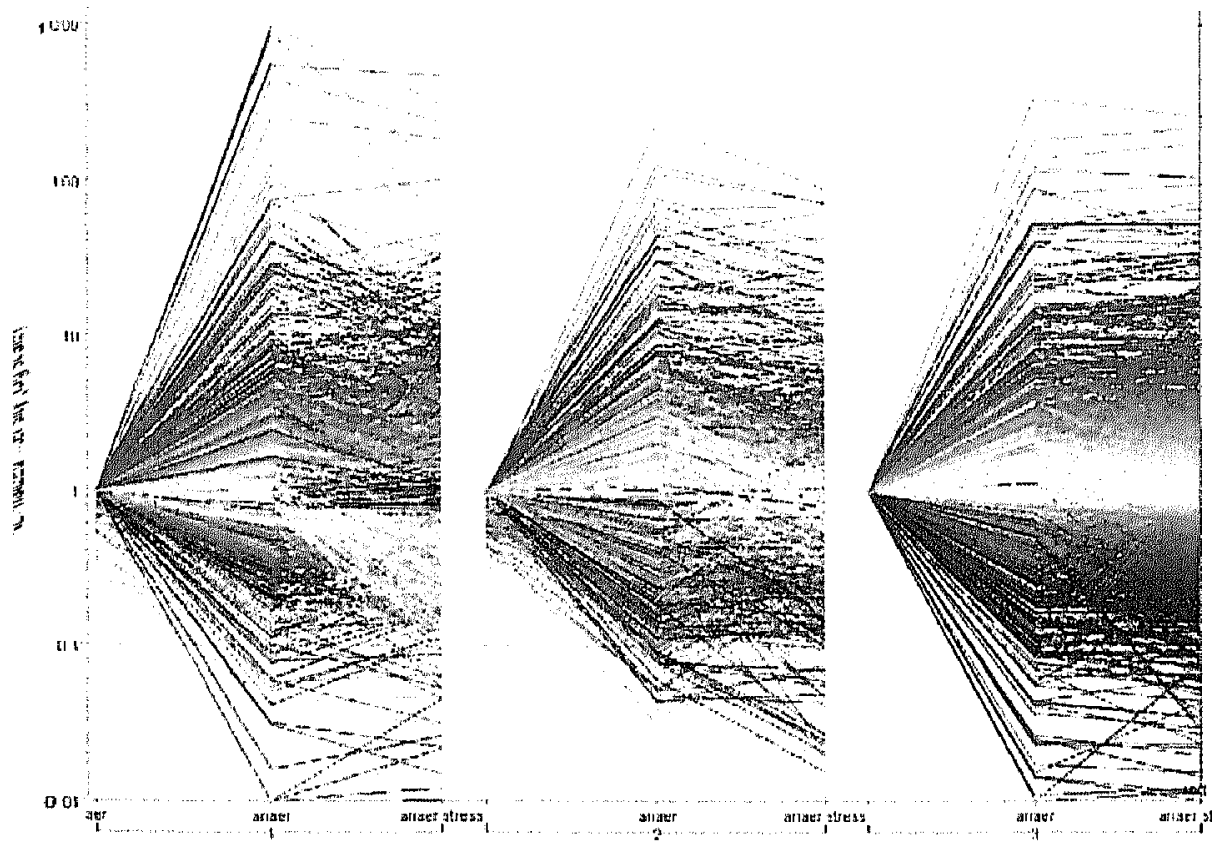

gure 5.1. Three biological replicates of hypoxic experiments Illustrating similar pattern of gene induction following -ute (stress) and steady state (chronic) hypoxlc conditions. Normalized gene expression profiles showing altered igulation of genes induced by hypoxia in altenuated salmonella. Samples were collected at various time point past «posure to hypoxia. RNA was isolated, hybridized to salmonella cDNA arrays, scanned and data analyzed using ene Spring. Normalized for aerobic (aer) condilion. Anaer (steady state hypoxia), anaer stress (acute hypoxic undition). Color code: yellow, no variallon; red, upregulation; green, downregulatlon.

\section{.nalysls of hypoxia-inducible promoter elements}

ifty-five transcripts were $>10$ fold upregulated in the hypoxia treated sample (table 2) under hronic hypoxic stress conditions. Furthermore, 38 genes abundantly upregulated during the cute transition from aerobic to hypoxic conditions (acute hypoxia) were also highly ( $>10$ fold) Iduced upon chronic exposure to hypoxia (steady state condition). Intriguingly, desplte the 3W level induction observed in some genes (these are genes upregulated in a range of 6-8 دld), all genes upregulated under acute stress condition are also upregulated during chronic xposure to hypoxia. More importantly, except one gene (ccmC) the basal expression level of rese genes appeared to be very low (data not shown). As expected all abundantly pregulated genes 
Chapter 5

Table 5.2. Two technical replicates of hypoxic experiments illustrating more than 10 fold induced gene following acute (stress) and steady state (chronic) hypoxic conditions. Normalized for aerobic (aer) condition.

\begin{tabular}{|c|c|c|c|c|c|c|c|}
\hline File Name & aerobic & steady state & acute(stress) & aerobic & $\begin{array}{l}\text { steady } \\
\text { state }\end{array}$ & acute(stress) & \\
\hline Technical replicate & 1 & 1 & 1 & 2 & 2 & 2 & \\
\hline Systematic & Normalized & Normalized & Normalized & Normalized & Normalized & Normalized & Synonyms \\
\hline narl & 1.0555556 & 484.2346 & 663.57574 & 0.9444444 & 471.81577 & 485.13132 & STM1761 \\
\hline narJ & 0.8280851 & 311.744 & 1079.1364 & 1.1719149 & 319.97757 & 942.8543 & STM1762 \\
\hline nark & 1.2097489 & 243.23361 & 875.1531 & 0.7902511 & 149.25586 & 75.48821 & STM1765 \\
\hline STM1765_RED & 0.576779 & 220.60237 & 436.25153 & 1.4232209 & 266.32803 & 478.69717 & \\
\hline narH & 1.091419 & 122.93925 & 942.4722 & 0.9085811 & 117.44148 & 824.5227 & STM1763 \\
\hline dcuB & 1.054755 & 106.75714 & 76.36508 & 0.9452449 & 100.904915 & 76.90507 & STM4301 \\
\hline narG & 1.0659072 & 54.266182 & 983.0025 & 0.93409276 & 56.14052 & 917.6245 & STM1764 \\
\hline citC & 0.9733697 & 45.080486 & 27.601751 & 1.0266304 & 47.697098 & 29.290586 & STM0624 \\
\hline STM1763_RED & 0.9863548 & 38.228905 & 584.29144 & 1.0136453 & 39.37812 & 598.58264 & \\
\hline fdnl & 0.90960073 & 36.630707 & 79.004585 & 1.0903991 & 31.186314 & 65.34917 & STM1568 \\
\hline fdhF & 0.962503 & 34.298992 & 19.861485 & 1.0374972 & 36.493317 & 19.829906 & STM4285 \\
\hline STM0701_RED & 0.97189474 & 32.81802 & 15.627914 & 1.0281053 & 31.212631 & 15.572789 & \\
\hline hycc & 1.0644348 & 32.654694 & 8.349384 & 0.93556535 & 34.888313 & 8.513964 & STM2851 \\
\hline glpA & 0.9390519 & 32.124172 & 4.0138144 & 1.060948 & 35.326897 & 3.8654807 & STM2284 \\
\hline napH & 1.0307692 & 26.108917 & 25.329401 & 0.9692308 & 26.163822 & 24.15754 & STM2257 \\
\hline speF & 0.995324 & 23.457912 & 13.164286 & 1.0046761 & 27.925293 & 11.752668 & STM0701 \\
\hline napG & 0.9974393 & 22.499352 & 36.037693 & 1.0025607 & 21.258326 & 33.880264 & STM2258 \\
\hline potE & 1.0446428 & 20.48752 & 6.618851 & 0.9553571 & 23.430334 & 6.5775075 & STM0700 \\
\hline STM4302 & 0.95672697 & 20.459253 & 16.319307 & 1.043273 & 22.537857 & 12.992944 & \\
\hline hycD & 0.98727393 & 19.876028 & 13.913937 & 1.0127261 & 19.525307 & 13.400571 & STM2850 \\
\hline
\end{tabular}


Chapter 5

\begin{tabular}{|c|c|c|c|c|c|c|c|}
\hline STM1562 & $0.87 \uparrow 47343$ & 19.453056 & 30.145615 & 1.1285267 & 19.083033 & 22.088182 & \\
\hline citX & 0.95934296 & 18.974024 & 11.012163 & $1.04065 ?$ & 20.901241 & 11.785594 & STM0620 \\
\hline STM2250 & 0.88687116 & 17.982555 & 6.797104 & 1.1131289 & 19.36423 & 6.1972604 & \\
\hline yhbV & 0.96695656 & 15.487694 & 42.59375 & 1.0330435 & 15.28535 & 37.75875 & STM3275 \\
\hline nrfa & 0.97991973 & 15.157347 & 30.149446 & 1.0200803 & 14.179568 & 30.135096 & STM4277 \\
\hline hybB & 1.0461321 & 14.7063675 & 39.420403 & 0.953868 & 9.892189 & 36.66465 & STM3148 \\
\hline napF & 1.0904338 & 14.4601 & 43.539074 & 0.9095661 & 16.23165 & 37.80068 & STM2261 \\
\hline STM2259_RED & 1.0111978 & 14.430036 & 63.694794 & 0.9868022 & 16.870022 & 52.208694 & \\
\hline nirD & 0.9830508 & 14.15183 & 90.68764 & 1.0169492 & 14.6903 & 99.491516 & STM3475 \\
\hline ynfK & 0.99442405 & 13.812878 & 23.657322 & 1.0055761 & 13.606963 & 20.30314 & STM1489 \\
\hline frdD & 1.0119663 & 13.416936 & 24.344584 & 0.9880336 & 14.955104 & 21.242985 & STM4340 \\
\hline napB & 0.90697676 & 12.7100525 & 27.329506 & 1.0930233 & 14.424235 & 26.231121 & \begin{tabular}{|l} 
STM2256 \\
\end{tabular} \\
\hline hybE & 1.0392313 & 12.699908 & 14.04694 & 0.9607686 & 12.682249 & 13.839641 & STM3145 \\
\hline hycA & 1.0417760 & 12.124984 & 7.133676 & 0.958223 & 12.210322 & 8.064306 & STM2853 \\
\hline nrfD & 0.92358304 & 11.955212 & 8.078144 & 1.076412 & 12.057392 & 7.2912903 & STM4280 \\
\hline nrfe & 0.9910648 & 11.571307 & 4.751045 & 1.0089352 & 12.739146 & 4.7855506 & STM4281 \\
\hline citF & 0.844792 & 11.551577 & 30.25661 & 1.1552081 & 12.144232 & 27.299967 & STM0621 \\
\hline moaE & 1.0136812 & 11.45146 & 8.251647 & 0.98631877 & 11.385207 & 9.101154 & STM0806 \\
\hline hydN & 1.0308642 & 11.459353 & 6.869854 & 0.9691358 & 12.274267 & 6.3873067 & STM 2843 \\
\hline ccmG & 0.9696395 & 11.456791 & 8.20374 & 1.0303605 & 13.000352 & 9.075875 & STM3813 \\
\hline$y d f z$ & 1.036586 & 10.969463 & 97.880646 & 0.9634138 & 11.396228 & +32.44022 & STM1509 \\
\hline nary & 1.0839365 & 10.814435 & 5.713121 & 0.9160635 & 12.094711 & 6.1915336 & STM 1578 \\
\hline hybD & 1.0742759 & 10.658722 & 21.139658 & 0.9257239 & 8.885916 & 20.01118 & STM3146 \\
\hline STM0621_RED & 0.9799195 & 10.548096 & 30.766756 & 1.0200803 & 9.361269 & 28.56047 & \\
\hline hybF & 0.9671288 & 10.206213 & 15.62375 & 1.0328712 & 13.487807 & 13.0223465 & STM3144 \\
\hline hybA & 1.0912344 & 10.186721 & 52.681828 & 0.90876573 & 9.180716 & 53.15431 & STM3149 \\
\hline
\end{tabular}


following hypoxia are operons regulated by a well known oxygen-responsive transcription regulator FNR.

To confirm the expression data, 10 genes highly induced following (acute and chronic) hypoxia were selected for use in subsequent experiments. Their promoter region was isolated and cloned upstream of a reporter CDNA. Reporter gene analysis following exposure to hypoxic conditions, revealed induction in all cases. As anticipated, the levels of gene expression changes were lower in the reporter gene analysis as compared to the micro-array data (figure 2). This is due to the fact that the reporter constructs are multi-copy plasmid based whereas micro-array monitors the behavior of single copy gene activity in the bacterial genome. Overall, our data clearly indicate the potential of using hypoxia-induction to drive expression of heterologous genes in Salmonella.

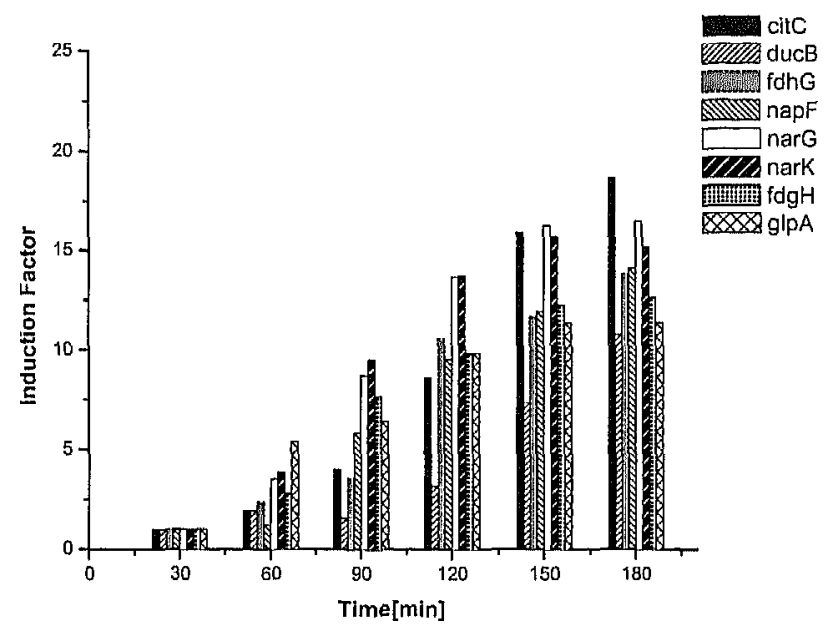

Figure 5.2. Induction factor of hypoxia induced gene promoter activity as a function of time following acute hypoxia. Eight reporter constructs are shown. Attenuated Salmonella typhimurium were allowed to grow in the anaerobic condition prior to the start of the luciferase assay. After two cycles of mid-exponential growth in strictly hypoxic conditions, enzyme activity was determined every 30 minutes.

Identification of radiation-inducible promoters using micro-array technology

To identify radiation-inducible genes in Salmonella and to measure the level of their induction following different doses of radiation, we ran microarrays following treatment of the bacteria with doses of 1,2 or 10 Gray (Gy) of ionizing radiation (IR). Salmonella were grown under aerobic conditions at $37^{\circ} \mathrm{C}$ and were irradiated at an $O D_{600 \mathrm{~nm}}$ of 0.2 , when they were growing at an exponential growth rate. Samples were then collected for RNA isolation immediately and after 45 minutes following each different radiation dose.

Figure 3 shows the normalized gene expression profile of Salmonella genome following a 1, 2 and $10 \mathrm{~Gy}$ dose of ionizing radiation. A number of genes were induced following a 1 gray radiation dose. Furthermore, all genes that are induced at low radiation doses are appear to be highly induced at 10 gray radiation dose. Interestingly, 42 genes were upregulated more 
than 2 fold immediately following a clinically relevant dose of 2 Gy. The expression of the majority of these genes (30) remained high after about 45 min post exposure, despite 'dilution' of the signal due to the continued growth of the bacteria. As shown in figure 3 , the number of genes upregulated upon radiation with $10 \mathrm{~Gy}$ increases further. Similar to the situation at $2 \mathrm{~Gy}$, most of these genes remained upregulated at $45 \mathrm{~min}$ post radiation (data not shown). The SOS response genes (lexA, recA, uvrA, uvrB, uvrD RecN, Dinl, UmuDC) showed a similar pattern of induction, where recA and recN were induced more than 2 fold at 2 gray and 8 and 10 fold respectively following a 10 gray dose (figure 4 ).

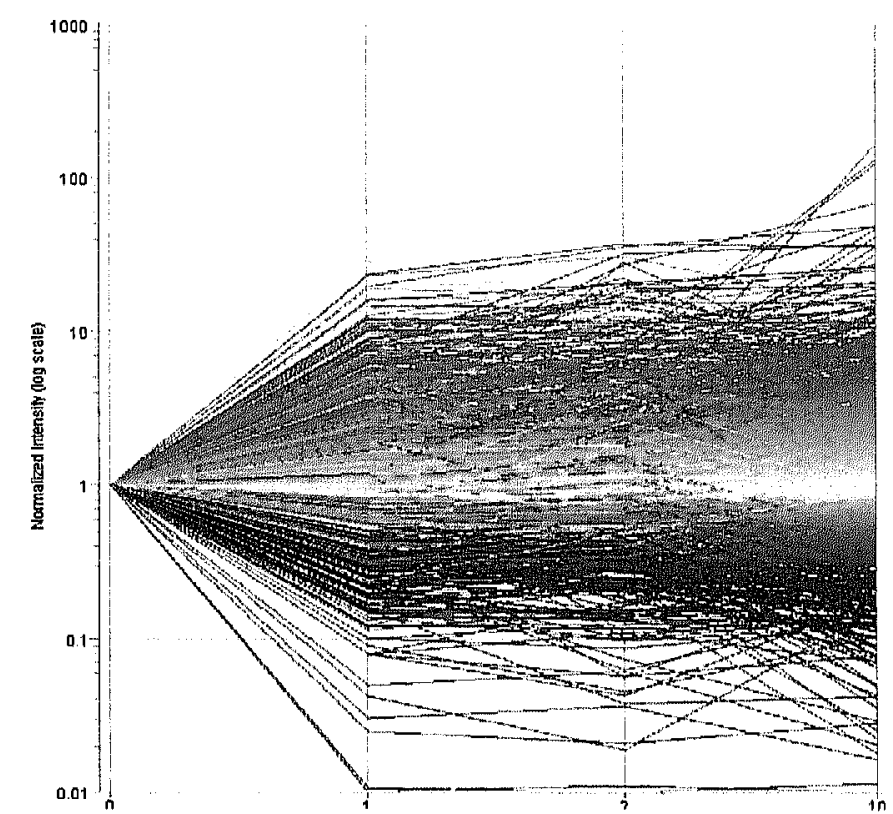

Figure 5.3. Changes in gene expression in attenuated salmonella following different doses of lonizing radiation (normalized for 0 gray IR dose). The normalized intensity shown on the $y$ axis and the different radialion doses are shown on the $x$ axis. Samples were collected immediately following each radiatlon doses. RNA was isolated, hybridized to salmonella cDNA arrays, scanned and data analyzed using Gene Spring. Color code: yellow, no variation; red, upregulation; green, downregulation. No.= IR dose in gray.

Based on the microarray Induction profile, five highly induced genes were selected for use in subsequent experiments. RecA and recN genes were included as control. As described 


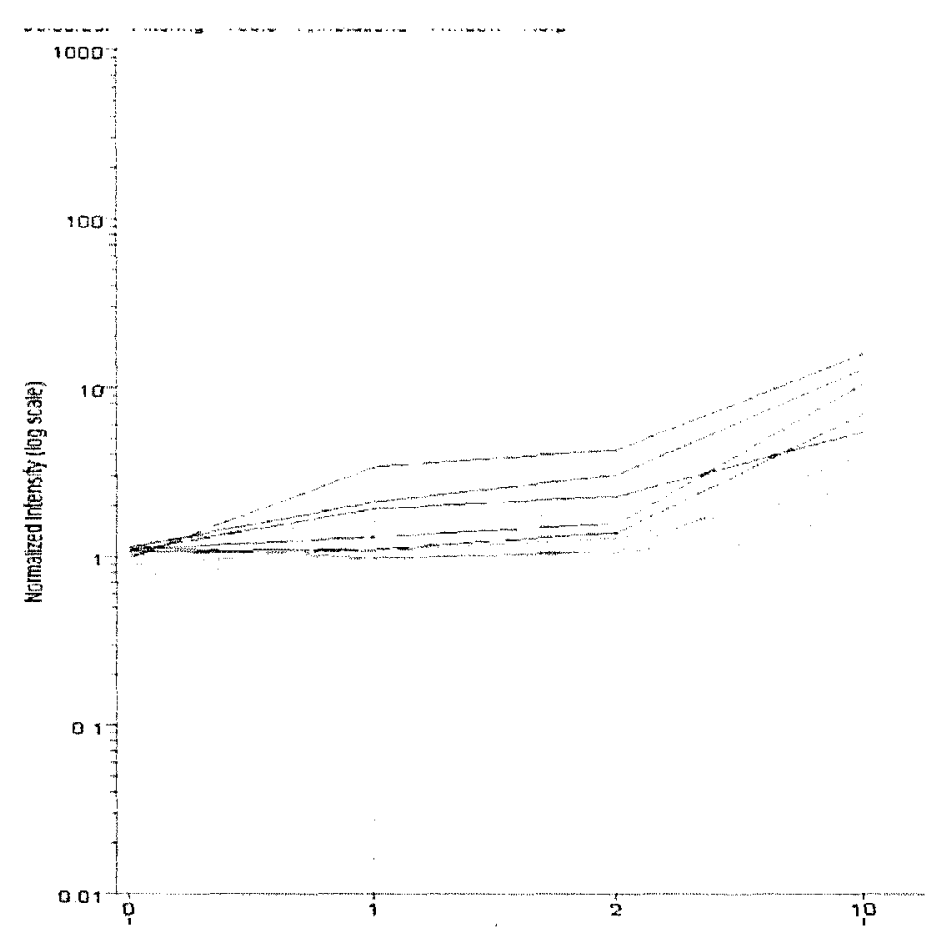

Figure 5.4. Changes in SOS gene expression in attenuated salmonella following different doses of lonizing radiation. Samples were collected immediately following each radiation doses. RNA was isolated, hybridized to salmonella CDNA arrays, scanned and data analyzed using Gene Spring. selecled genes include lexA, recA, uvrA, uvrD RecN, Dinl, UmuDC. No. $=\mathbb{R}$ dose in gray.

previously their promoter region were isolated and a cloned upstream of reporter gene. Reporter assays were performed following a 1,2 and 10 gray ionizing radiation. recA and recN promoter construct (figure $5 \mathrm{~A}$ and $5 \mathrm{~B}$ ) showed more than 2 fold induction at clinically relevant dose of 2 gray. However, as shown in figure $5 \mathrm{C}$ no change in gene induction was observed on selected genes promoter following each radiation dose treatment. Though, the induction factor following radiation treatment in general is low compared to the hypoxia experiments, the multicopy plasmid system of the assay may probably be not sensitive enough to detect changes and may account for the observed absence of inducibility of these genes promoter. 
A)

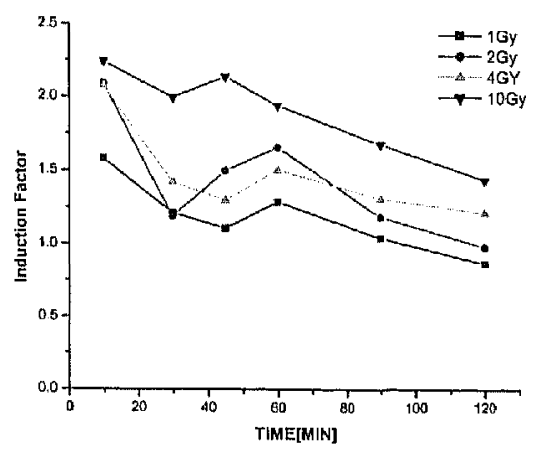

B)

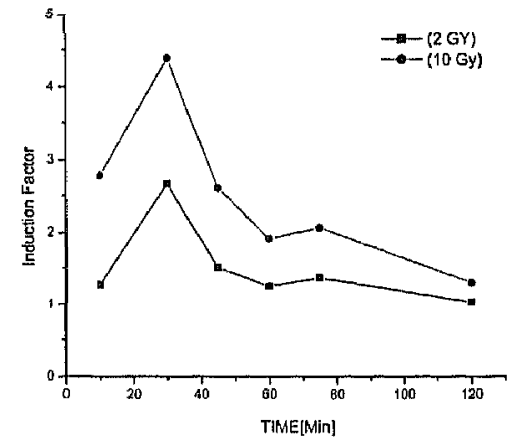

C)

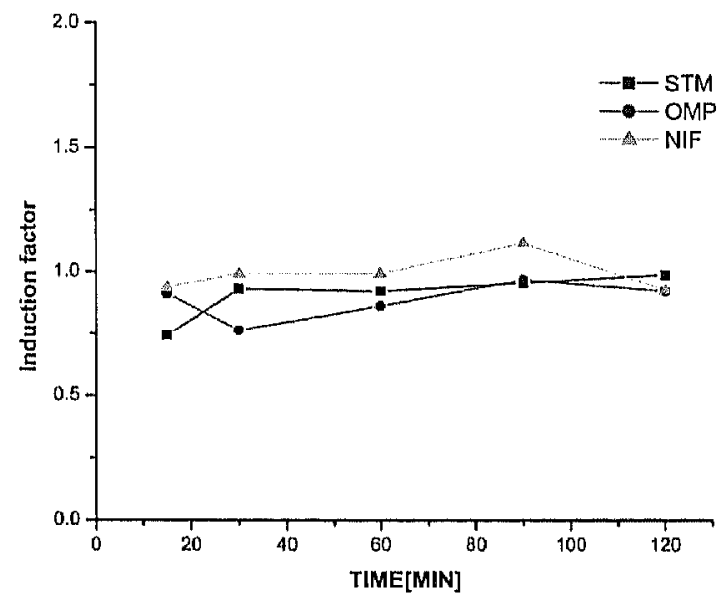

Figure 5.5. Fold increase of luciferase production by recombinant attenuated salmonella containing recA (A) recN (B) and OMP, STM, nltS (C) reporter construct following different doses of IR. Only a 2 gray IR dose is shown in case of OMP, STM, NifS reporter constructs. Attenuated Salmonalla typhimurium were allowed to grow in the aerobic condition until $\mathrm{OD} 600 \sim 0.2$ and irradiated with different doses of IR and sample were taken at different time polnt.

\section{Microarray for screening tumor specific genes}

Finally, we aimed to establish a method that would allow us to directly determine the gene expression profile of Salmonella proliferating in vivo. Although beyond the scope of the current investigations, such a method could eventually lead to the isolation of Salmonella promoters from genes that are preferentially activated in tumors. This would not only have the potential to improve the targeting of gene delivery, but could also enhance our understanding of the preferential tumor colonization phenomenon by these Salmonella bacteria.

To Identify tumor-specific promoters, Salmonella was injected intravenously in nu/nu mice bearing subcutaneous HCT116 colorectal xenografts. Seven days following injection, when colonization became evident, RNA was purified from infected tumors. Analysis of the isolated 
RNA with the bioanalyser revealed the presence of $23 S$ and $16 S$ bacterial rRNA as well as the 285 mammalian rRNA (figure 6). The CDNA generated from infected-tumor RNA was subsequently labeled and hybridized to the Salmonella microarrays as described above. RNA prepared from an uninfected HCT116 tumor was used to assess cross hybridization between the bacteria and mammalian genes ('cross-species hybridization'). Based on the scanned slides, we didn't detect cross-species hybridized spots in RNA samples extracted from noninfected tumor tissues, indicating the absence of sequence homology. The hybridizations revealed that the bacterial mRNAs in the infected tumors were derived from Salmonella. These results showed that bacterial RNA could be isolated from infected tumors and subsequently be used in micro-arrays. Using this technique, it will thus be possible to identify tumor-specific activated genes in Salmonella.
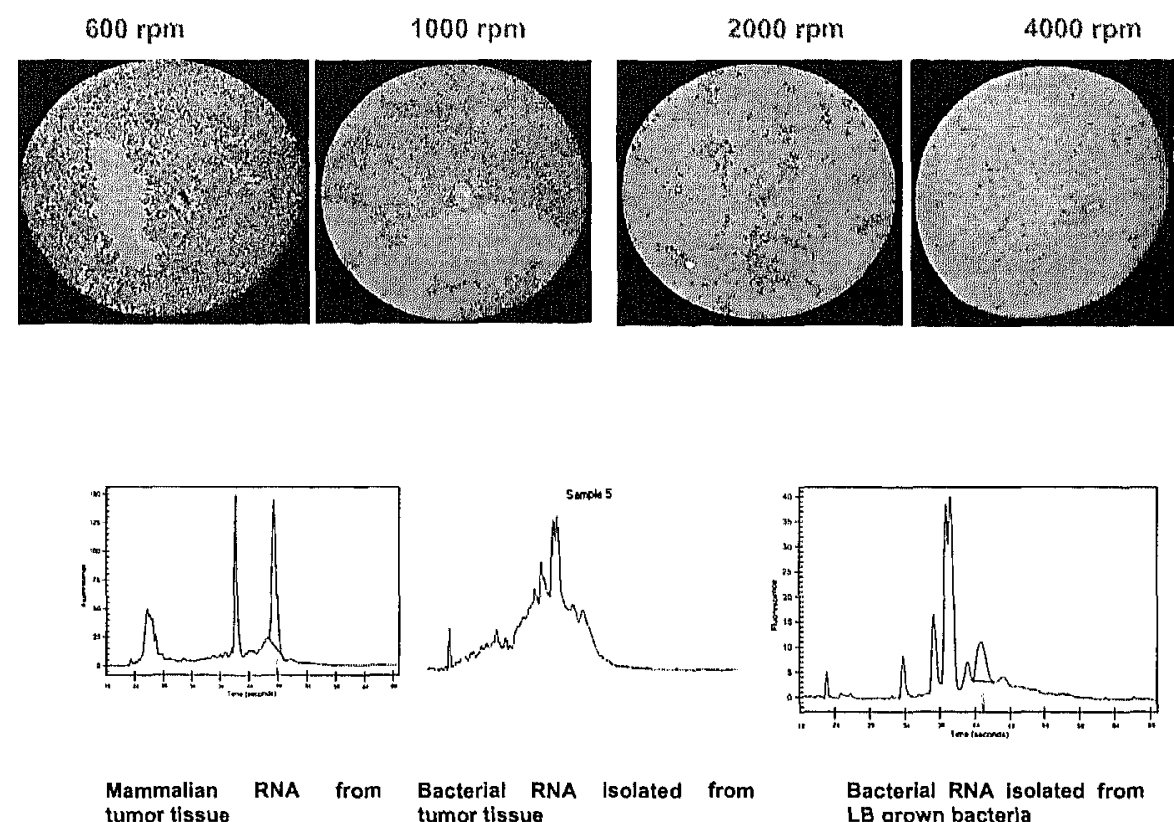

Bacterial RNA isolated from LB grown bacterla

Figure 5.6. Bacterial RNA isolation from infected tumor tissues: Tumor tlssues were homogenized in liquid $\mathrm{N}_{2}$ using a mortar and pestle cooled with liquid $\mathrm{N}_{2}$. Homogenates are collected in cold Eppendorff containing phenol/ethanol and pellets were collected by fractionated centrifugation $\left(10 \mathrm{~min}, 600 \mathrm{~g}-4000 \mathrm{~g}, 4^{\circ} \mathrm{C}\right)$. The supernatant is removed at each centrifugation steps for further centrifuge and finally pellets re-suspended with phenol:ethanl. Total RNA was isolated from these homogenates using TRIzol reagent according to the manufacturer's instructions. The purity and concentration were measured with the bioanalizer.

When we compared the in vivo tumor-specific Salmonella expression profile with the profile of Salmonella growing in vitro, most transcripts were found to be present at equal levels (data not shown). Intriguingly, several bacterial transcripts were expressed at much higher levels in Salmonella that colonized the HCT116 tumor (figure 7). This is consistent with literature describing bacterial invasion to be associated with differential gene expression of certain genes [20]. 


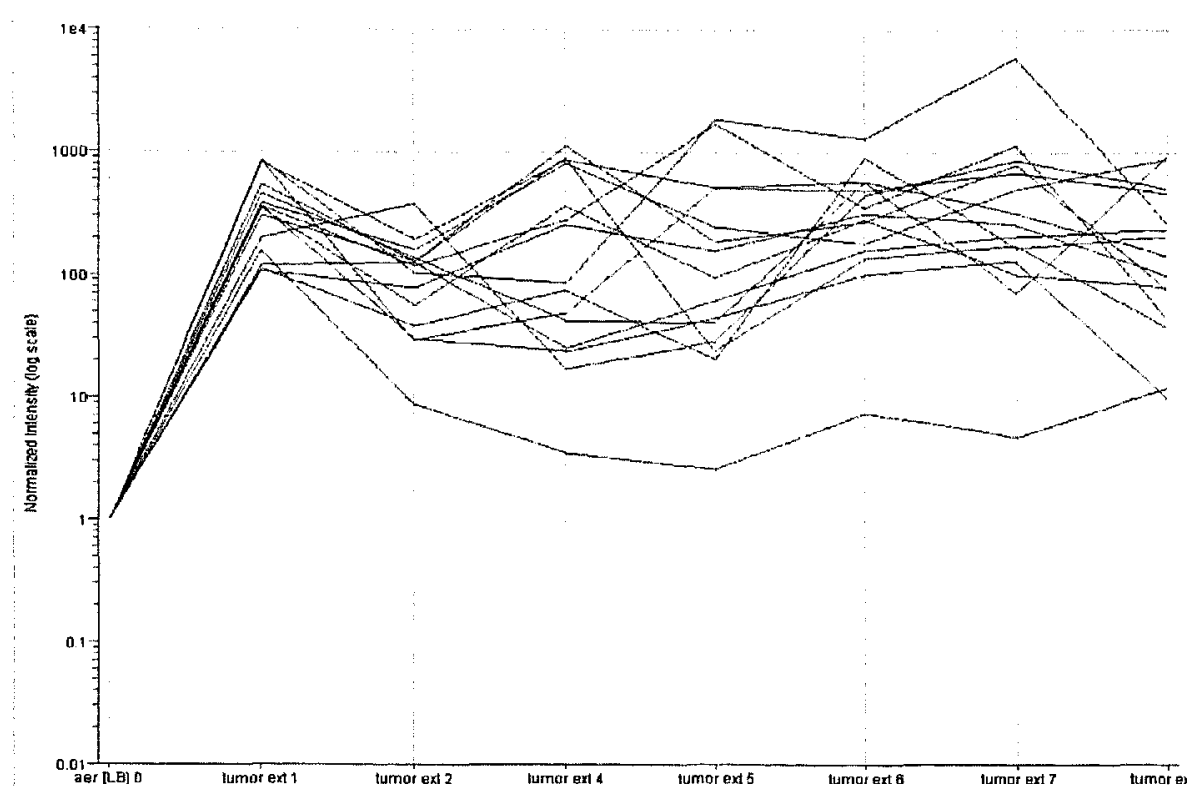

Figure 5.7. Gene expression profile of attenuated saimonella infecting tumor in vivo compared with LB grown bacteria. Each column represents a different microarray performed with RNA extracted from bacteria growing in different tumor tissues (tumor No.1 to 7) compared to RNA extracted from LB grown bacteria. Each line represents a gene that was differentially expressed in each tumor tissues compared to LB taking tumor 1 as a reference for a 100 fold induction (a total of 15 genes are shown).

\section{DISCUSSION:}

One of the most essential aspects of gene therapy for cancer continues to be targeting of therapeutic gene expression to solid tumors. In order to exclusively target malignant cells while at the same time sparing normal tissue, cancer gene therapy needs to combine highly selective gene delivery with highly specific gene expression. The attenuated Salmonella typhimurium [VNP20009] carrying deletion of the $m s b B$ and pur / genes, was developed as a vector suitable for tumor selective delivery of therapeutic proteins $[14,21]$. Available data suggested that tumor-targeting Salmonella could be used to deliver proteins to tumors producing therapeutic effects $[3,22,23]$. Despite its preferential tumor accumulation, however, normal tissues are also colonized albeit to a lesser extent. This feature negatively affects the specificity of the Salmonella mediated gene transfer system. One of the strategies to overcome this problem involves the use of inducible promoters that are only activated under certain controlled conditions. To this end, the therapeutic gene could be positioned under regulatory control of an inducible promoter that is typically turned on only in tumors and not when bacteria are growing in normal tissues, or promoters which are activated upon tumorspecific internal (e.g. hypoxia) or external stimuli (radiation).

We have previously established the proof-of-principle that the use of a hypoxia-inducible promoter in attenuated Salmonella is feasible. This study led us firstly to rigorously evaluate 
the presence and potential application of hypoxia-responsive promoters in Salmonella under both acute "stress" and steady state hypoxic conditions using microarray analysis. Our analysis revealed that $1-2 \%(55 / 3169)$ of all genes represented on the micro-array were $>10$ fold upregulated upon acute change from aerobic to hypoxic growth conditions. All of these genes are operons driven by promoters that are regulated by the well-known FNR transcription factor. Though the level of induction differs to some extent, all genes upregulated during stress conditions are also significantly induced under steady state of hypoxia. Therefore, these promoters can be considered as good candidates for consistent gene activation under chronic state of hypoxia in solid tumor.

Reporter gene analysis of selected promoters confirmed the inducibility of the promoters, although induction levels were generally lower. This is not surprising. Perhaps the most likely explanation is the fact that all the reporter assays were carried out based on a multicopy plasmid system. Such a system may not represent the bacterial gene behavior at a single copy level in the genome. Furthermore, as many copies of the transcription binding sites are available on the multicopy plasmid, cellular concentration of the transcription factor could be a limiting factor to activate the entire FNR box. In addition, the promoter region isolated and used in the reporter constructs may not incorporate all the promoter elements that could affect the overall gene expression profile of individual genes. Some of the promoter elements, such as transcription binding sites or distant enhancer elements might have been lost during reporter construction. In proposing the use of highly regulated promoters in Salmonella vectors so that therapeutic gene expression is minimal in normal tissues, the ultimate success depends on the specific promoter/therapeutic cDNA combination. For instance genes that are very toxic needs to be driven by promoters that show very low basal expression levels (but that are highly induced) whereas for genes of which the expression needs to be very high, a promoter with higher level of absolute gene expression could be used.

Next to internal stimuli, several external stimuli can be applied that allow spatial and temporal control of gene expression. Application of radiotherapy also is such a promising way to focus the activation of anti-tumor gene therapy systems [24]. Application of radiotherapy for therapeutic purposes in prokaryotes is limited. This is probably not surprising, as bacteria are known to be extremely radioresistant, presumably due to the small size of their genome. Despite this observed resistance, we were the first to show that radiation-induced promoters can be applied in the context of prokaryotic gene delivery vectors using non-pathogenic Clostridium [17,25-27]. Consistent with the observations made in Clostridium, genes that are significantly upregulated upon treatment with doses as low as 1 or $2 \mathrm{~Gy}$, could be identified in Salmonella. Use of reporter constructs clearly revealed that there is a two fold increase in luciferase production following a clinically relevant dose of 2 Gy when SOS responsive recA and recN promoter constructs were used. In addition, we could observe upregulation of most known DNA damage inducible genes following a single dose of radiation (2 and $10 \mathrm{~Gy}$ ). Moreover, a 2-fold induction observed while using recA and recN promoters, is exceedingly high when compared to the published data in bacterial systems [27]. It should be noted that 
Salmonella replicate every $\sim 20$ minutes. This would generate a dilution effect on the level of induction following radiation exposure. For the radiation experiments, samples were taken 10 $15 \mathrm{~min}$ ("immediately") and $45 \mathrm{~min}$ post-radiation exposure. This means that even at the early time-point, the entire population aiready doubled, and thus that half of the bacteria from which RNA was isolated have actually never been irradiated. This effect undoubtedly masks the real quantitative effect of the radiation.

Finally, we have developed a method to isolate RNA from Salmonella directly from in vivo colonized tissue. This method will eventually allow the identification of genes that are specifically upregulated only within the colonized tumor. Identification and characterization of these genes will probably help to explain the phenomenon of the preferential tumor colonization by certain strains of Salmonella. In addition, expression of therapeutic genes under control of these tumor-specific promoters may well improve the specificity of this tumortargeted drug delivery approach.

Taken together, our data suggest that several different stimuli may be applicable to improve the potential of the Salmonella-mediated delivery system. The best 'inducible promotertherapeutic cDNA' combination will probably depend on the nature of the therapeutic gene. Overall, such an inducible strategy could provide a simple, safe and flexible alternative to the constitutively activated Salmonella strains currently used in cancer gene therapy.

\section{ACKNOWLEDGEMENTS:}

This work was financially supported by GROW-School for Oncology \& Developmental Biology

(AM) 


\section{REFERENCES:}

1. Theys, J., Barbe, S., Landuyt, W., Nuyts, S., Van Mellaert, L., Wouters, B., Anne, J. and Lambin, P. (2003) Tumor-specific gene delivery using genetically engineered bacteria. Curr Gene Ther, 3, 207-21.

2. Liu, S.C., Minton, N.P., Giaccia, A.J. and Brown, J.M. (2002) Anticancer efficacy of systemically delivered anaerobic bacteria as gene therapy vectors targeting tumor hypoxia/necrosis. Gene Ther, 9, 291-6.

3. Lee, C.H., Wu, C.L. and Shiau, A.L. (2005) Systemic administration of attenuated Salmonella choleraesuis carrying thrombospondin-1 gene leads to tumor-specific transgene expression, delayed tumor growth and prolonged survival in the murine melanoma model. Cancer Gene Ther, 12, 175-84.

4. Pawelek, J.M., Low, K.B. and Bermudes, D. (1997) Tumor-targeted Salmonella as a novel anticancer vector. Cancer Res, 57, 4537-44.

5. Dang, L.H., Bettegowda, C., Huso, D.L., Kinzler, K.W. and Vogelstein, B. (2001) Combination bacteriolytic therapy for the treatment of experimental tumors. Proc Natl Acad Sci U S A, 98, 15155-60.

6. Fujimori, M., Amano, J. and Taniguchi, S. (2002) The genus Bifidobacterium for cancer gene therapy. Curr Opin Drug Discov Devel, 5, 200-3.

7. Barbe, S., Van Mellaert, L., Theys, J., Geukens, N., Lammertyn, E., Lambin, P. and Anne, J. (2005) Secretory production of biologically active rat interleukin-2 by Clostridium acetobutylicum DSM792 as a tool for anti-tumor treatment. FEMS Microbiol Lett, 246, 67-73.

8. Fox, M.E., Lemmon, M.J., Mauchline, M.L., Davis, T.O., Giaccia, A.J., Minton, N.P. and Brown, J.M. (1996) Anaerobic bacteria as a delivery system for cancer gene therapy: in vitro activation of 5-fluorocytosine by genetically engineered clostridia. Gene Ther, 3, 173-8.

9. Agrawal, N., Bettegowda, C., Cheong, I., Geschwind, J.F., Drake, C.G., Hipkiss, E.L., Tatsumi, M., Dang, L.H., Diaz, L.A., Jr., Pomper, M., Abusedera, M., Wahl, R.L., Kinzler, K.W., Zhou, S., Huso, D.L. and Vogelstein, B. (2004) Bacteriolytic therapy can generate a potent immune response against experimental tumors. Proc Natl Acad Sci U S A, 101, 15172-7.

10. Forbes, N.S., Munn, L.L., Fukumura, D. and Jain, R.K. (2003) Sparse initial entrapment of systemically injected Salmonella typhimurium leads to heterogeneous accumulation within tumors. Cancer Res, 63, 5188-93.

11. Kasinskas, R.W. and Forbes, N.S. (2006) Salmonella typhimurium specifically chemotax and proliferate in heterogeneous tumor tissue in vitro. Biotechnol Bioeng, $94,710-21$.

12. Nemunaitis, J., Cunningham, C., Senzer, N., Kuhn, J., Cramm, J., Litz, C., Cavagnolo, R., Cahill, A., Clairmont, C. and Sznol, M. (2003) Pilot trial of genetically modified, attenuated Salmonella expressing the E. coli cytosine deaminase gene in refractory cancer patients. Cancer Gene Ther, 10, 737-44.

13. Toso, J.F., Gill, V.J., Hwu, P., Marincola, F.M., Restifo, N.P., Schwartzentruber, D.J. Sherry, R.M., Topalian, S.L., Yang, J.C., Stock, F., Freezer, L.J., Morton, K.E., Seipp, C., Haworth, L., Mavroukakis, S., White, D., MacDonald, S., Mao, J., Sznol, M. and Rosenberg, S.A. (2002) Phase I study of the intravenous administration of attenuated Salmonella typhimurium to patients with metastatic melanoma. J Clin Oncol, 20, 14252.

14. King, I., Bermudes, D., Lin, S., Belcourt, M., Pike, J., Troy, K., Le, T., Ittensohn, M., Mao, J., Lang, W. Runyan, J.D., Luo, X., Li, Z. and Zheng, L.M. (2002) Tumortargeted Salmonella expressing cytosine deaminase as an anticancer agent. Hum Gene Ther, 13, 1225-33.

15. Nishikawa, H., Sato, E., Briones, G., Chen, L.M., Matsuo, M., Nagata, Y., Ritter, G., Jager, E., Nomura, H., Kondo, S., Tawara, I., Kato, T., Shiku, H., Old, L.J., Galan, J.E. and Gnjatic, S. (2006) In vivo antigen delivery by a Salmonella typhimurium type III secretion system for therapeutic cancer vaccines. J Clin Invest, 116, 1946-54.

16. Shibata, T., Giaccia, A.J. and Brown, J.M. (2000) Development of a hypoxiaresponsive vector for tumor-specific gene therapy. Gene Ther, 7, 493-8.

17. Nuyts, S., Theys, J., Landuyt, W., van Mellaert, L., Lambin, P. and Anne, J. (2001) Increasing specificity of anti-tumor therapy: cytotoxic protein delivery by non- 
pathogenic clostridia under regulation of radio-induced promoters. Anticancer Res, $21,857-61$.

18. Mengesha, A., Dubois, L., Lambin, P., Landuyt, W., Chiu, R.K., Wouters, B.G. and Theys, J. (2006) Development of a flexible and potent hypoxia-inducible promoter for tumor-targeted gene expression in attenuated Salmonella. Cancer Biol Ther, 5, 11208.

19. Sambrook J, F.E. and D.W. Russell (2001) Molecular cloning:A laboratory manual. Cold Spring Harbor Laboratory Press, New York, NY.

20. Hautefort, I., Thompson, A., Eriksson-Ygberg, S., Parker, M.L., Lucchini, S., Danino, V., Bongaerts, R.J., Ahmad, N., Rhen, M. and Hinton, J.C. (2008) During infection of epithelial cells Salmonella enterica serovar Typhimurium undergoes a timedependent transcriptional adaptation that results in simultaneous expression of three type 3 secretion systems. Cell Microbiol, 10, 958-84.

21. Jazowiecka-Rakus, J. and Szala, S. (2004) Antitumour activity of Salmonella typhimurium VNP20047 in B16(F10) murine melanoma model. Acta Biochim Pol, 51, 851-6.

22. Clairmont, C., Troy, K., Lu, X., Li, Z. and Pike, J. (2000) Expression of colicin E3 by tumour targeted Salmonella, enhances anti-tumour efficacy. Amer Assoc Cancer Res 41:466. $41,466$.

23. Lee, C.H., Wu, C.L. and Shiau, A.L. (2004) Endostatin gene therapy delivered by Salmonella choleraesuis in murine tumor models. $J$ Gene Med, 6, 1382-93.

24. Greco, O., Marples, B., Wilson, G.D., Joiner, M.C. and Scott, S.D. (2005) Radiationinduced gene therapy. Radiat Res, 163, 707-8.

25. Nuyts, S., Van Mellaert, L., Barbe, S., Lammertyn, E., Theys, J., Landuyt, W. Bosmans, E., Lambin, P. and Anne, J. (2001) Insertion or deletion of the Cheo box modifies radiation inducibility of Clostridium promoters. Appl Environ Microbiol, 67, 4464-70.

26. Nuyts, S., Van Mellaert, L., Theys, J., Landuyt, W., Bosmans, E., Anne, J. and Lambin, P. (2001) Radio-responsive recA promoter significantly increases TNFalpha production in recombinant clostridia after 2 Gy irradiation. Gene Ther, 8, 1197-201.

27. Nuyts, S., Van Mellaert, L., Theys, J., Landuyt, W., Lambin, P. and Anne, J. (2001) The use of radiation-induced bacterial promoters in anaerobic conditions: a means to control gene expression in clostridium-mediated therapy for cancer. Radiat Res, 155, 716-23. 


\section{CHAPTER 6}

\section{Repeated cycles of Clostridium-directed enzyme prodrug therapy result in sustained antitumor effects in vivo}

J Theys, O Pennington, L Dubois, G Anlezark, T Vaughan, A Mengesha, WLanduyt, J Anne', PJ Burke, P Durre, BG Wouters, NP Minton and P Lambin 


\section{ABSTRACT}

The unique properties of the tumor microenvironment can be exploited by using recombinant anaerobic clostridial spores as highly selective gene delivery vectors. Although several recombinant Clostridium species have been generated during the past decade, their efficacy has been limited. Our goal was to substantially improve the prospects of clostridia as a gene delivery vector. Therefore, we have assessed a series of nitroreductase (NTR) enzymes for their capacity to convert the innocuous CB1954 prodrug to its toxic derivative. Among the enzymes tested, one showed superior prodrug turnover characteristics. In addition, we established an efficient gene transfer procedure, based on conjugation, which allows for the first time genetic engineering of Clostridium strains with superior tumor colonization properties with high success rates. This conjugation procedure was subsequently used to create a recombinant $C$. sporogenes over expressing the isolated NTR enzyme. Finally, analogous to a clinical setting situation, we have tested the effect of multiple consecutive treatment cycles, with antibiotic bacterial clearance between cycles. Importantly, this regimen demonstrated that intravenously administered spores of NTR-recombinant $C$. sporogenes produced significant antitumor efficacy when combined with

prodrug administration. 


\section{INTRODUCTION}

Tumor heterogeneity, particularly with regard to hypoxia and necrosis, can dramatically limit the effectiveness of anticancer therapies. Recent analysis has shown that even in small distant metastasis, large avascular regions are present which can constitute between 25 and $75 \%$ of the tumor mass [1]. The poorly vascularized, hypoxic cells adjacent to these areas are difficult to eradicate with conventional treatments and can also negatively influence the efficacy of novel treatment strategies. In that context, the limited success of initially exciting oncolytic adenoviral vectors may be attributed to hypoxia, as the hypoxia-induced G1 arrest of celis is responsible for lack of viral replication, thereby rendering these vectors less effective for anticancer therapy $[2,3]$.

Similarly, retroviral vectors might also be less effective in hypoxic conditions, since upon activation of the PERK kinase under hypoxia, eIF2a gets phosphorylated, leading to overall inhibition of translation [4]. This defense mechanism against viral infection and the fact that hypoxic cells do not proliferate can negatively influence retroviral efficiency under hypoxic conditions. Perversely, the very existence of these hypoxic/necrotic regions may provide the solution. This is because they provide rather ideal environments for the growth and proliferation of obligate, anaerobic bacteria. Thus, while intravenously injected clostridial spores are dispersed throughout the body, only those that encounter the hypoxic environment of a solid tumor go on to germinate and multiply $[5,6]$. Delivery is exquisitely selective, and has led to the suggestion that clostridia could be used as tumor-specific vectors for therapeutic gene delivery [7-10]. During the past decade, several recombinant clostridial species that can express therapeutic proteins specifically in tumors have been generated $[9,11-13]$. Although these reports established the feasibility of this delivery system and showed some antitumoral promise, the properties of the strains used were suboptimal, particularly with respect to tumor colonization. So far, clostridial strains able to more effectively colonize tumors, typified by Clostridium sporogenes, have proven largely recalcitrant to DNA transfer.

Until now, the principal therapeutic proteins delivered using clostridial spores have been prodrug converting enzymes [14]. These enzymes are characterised by their bystander effect and form the basis of the Clostridium directed-enzyme-prodrug therapy (CDEPT). In this context, the nitroreductase (NTR) class of enzymes is of particular interest because their small size increases the likelihood of efficient clostridial expression. Nitroreductase converts the 4-nitrogroup of the prodrug CB1954 (5-aziridinyl-2,4-dinitrobenzamide) to its 10000 -fold more toxic 4-hydroxylamine $(4 H X)$ derivative, which can be further metabolized to form a DNA-DNA cross linking and apoptosis-inducing agent [15]. Interestingly, both proliferating and nonproliferating cells, as they are often present in tumor areas with gradients of hypoxia, are killed [16]. The initially detected rat enzyme (DT-diaphorase), has been superseded by an enzyme (NTR-B) isolated from Escherichia coli $B$, due to its increased activity against CB 1954. However, unlike the rat enzyme, NTR-B also reduces the 2-nitrogroup to produce the relatively nontoxic 2-hydroxylamine $(2 \mathrm{HX})$ derivative. 
Our goal was to substantially improve the prospects of clostridia by several ways. Firstly, we aimed to improve the enzymatic conversion of the CB1954 prodrug by isolating a new NTR enzyme with equivalent or better kinetic parameters to NTR-B, but which produced only the $4 H X$ derivative of $C B$ 1954. Secondly, we sought to increase the levels of bacteria, and inherently of therapeutic protein, in the tumor. This required the development of a method that allowed efficient gene transfer to strains with enhanced tumor colonizing capacities such as C. sporogenes. Finally, we intended to evaluate in a quantitative way the ability of the therapeutic protein delivered by the recombinant clostridia to convert sufficient levels of prodrug to produce in vivo antitumor efficacy. To this end, we limited the period of active prodrug conversion by the metabolically active vegetative recombinant clostridia in the tumor to a 2-week period by administration of antibiotics. Analogous to a clinical setting situation, we used this approach to test the effect of multiple consecutive treatment cycles.

\section{MATERIALS AND METHODS}

\section{Bacteria and plasmids}

C. sporogenes NCIMB 10696 was obtained from the National Collection of Industrial and Marine Bacteria (NCIMB Ltd, Aberdeen, Scotland). The strain was grown in TYG media ( $30 \mathrm{~g}$ $\mathrm{I}^{-1}$ tryptone, $20 \mathrm{~g} \mathrm{l}^{-1}$ yeast extract powder, $1 \mathrm{~g} \mathrm{I}^{-1}$ sodium thioglycollate supplemented with 250 mgml_1 D-cycloserine (to select for C. sporogenes)) at 371C in an Mkll anaerobic workstation (Don Whitley, Shipley, UK) with $80 \% \mathrm{~N} 2,10 \% \mathrm{H} 2,10 \% \mathrm{CO} 2$ atmosphere. For general cloning, E. coli TOP10 (Invitrogen, Paisley, UK) was used. The host employed for expression studies was NovaBlue (DE3). Strains were grown in Luria-Bertani media at $371 \mathrm{C}$. Media were supplemented, when applicable, with erythromycin (500 $\mathrm{mgml}^{-1}$ in E. coli or 10 $\mathrm{mgml}^{-1}$ in C. sporogenes), ampicillin (100 $\left.\mathrm{mgml}^{-1}\right)$, tetracycline (15 $\left.\mathrm{mgml}^{-1}\right)$ or 5-bromo-4chloro-3-indolyl-b-galactoside (X-Gal; $\left.40 \mathrm{mgml}^{-1}\right)$. Plasmids used in this study are listed in Table 1. 
Table 6.1 Plasmids used in this study

\begin{tabular}{lll}
\hline Plasmid & Features & Reference \\
\hline pMTL20E & Source of ermB & (Oultram et al, 1988) \\
pMTL4 & Shuttle vector backbone & (Chambers et al, 1988) \\
pET21b & Expression vector & Novagen \\
plMP1 & plM13 replicon & (Mermelstein et al, 1992) \\
pMTL6341aLS2 & Clostridial expression cartridge & (Carter et al, 2005) \\
pMTL20 & Cloning vector and source of LacZa & \\
pMTL30 & Source of OriT & (Williams et al, 1990) \\
pCR2.1-TOPO & TA PCR cloning vector & Invitrogen \\
pCR-Blunt II- & Blunt PCR cloning vector & Invitrogen \\
TOPO & Source of fac2 promoter & Entelechon GmBH \\
pCR4- & Vector backbone - ColEl Gram-negative & This study \\
TOPO::fac2 & replicon+ermB & This study \\
pMTL4-Em & pMTL4E+pIM13 replicon & This study \\
pMTL552 & pMTL552+expression cartridge & This study \\
pMTL553 & pMTL553+OriT & This study \\
pMTL554 & OriT from pMTL30 & This study \\
pEOriT & pMTL554+LacZalpha & \\
pMTL555 & & \\
\hline
\end{tabular}

\section{Isolation of NTR enzymes}

Homologues to the previously isolated $[17,18]$ bacterial NTRs of $E$. coll $(N f n B)$ and Bacillus amyloliquefaciens (YwrO) were identified in bacterial genomes using BLASTP. A total of 10 NfnB-like proteins and five YwrO-like proteins were selected for further study. DNA encompassing each encoding gene was amplified from the relevant genomic DNA of the target organism by PCR using appropriate oligonucleotide primers and cloned into the expression vector $\mathrm{PET} 21 \mathrm{~b}$. In each case, the 50-primer was designed so that it incorporated an Ndel restriction site (CATATG), whereby the ATG corresponded to the translational start codon of the gene. Each gene was inserted into pET21b at the Ndel site such that translational start codon was placed at the optimal distance from the vector encoded ribosomebinding site (RBS). To purify the enzyme, E. coli NovaBlue (DE3) cells carrying the wild-type (wt) gene were grown overnight at $37^{\circ} \mathrm{C}$ following induction with IPTG. Recombinant NTR enzymes were purified to homogeneity as previously described [18].

\section{NTR assays}

Quantitative assays using CB 1954 substrate were carried out at $37^{\circ} \mathrm{C}$ by HPLC as previously described [18]. When qualitative assays were used to identify column fractions, the standard conditions were $1 \mathrm{mM}$ prodrug, $2 \mathrm{mM} \mathrm{NAD(P)H,4 \%} \mathrm{DMSO} \mathrm{in} 100 \mathrm{mM}$ sodium phosphate buffer $\mathrm{pH} 7,37^{\circ} \mathrm{C}$. Incubation times varied according to the enzyme activity being studied. Assays using menadione as substrate were carried out spectrophotometrically as previously described [19] using cytochrome $\mathrm{c}$ as terminal electron acceptor. Similar procedures were used to assay flavin reductase activity with FMN and FAD as substrate and with cofactors $\mathrm{NADH}$ and/or NADPH. Kinetic parameters with respect to CB 1954 were determined by HPLC 
assay using $10 \mathrm{ml}$ of the final product in $500 \mathrm{ml}$ assay mix containing 100-1000 mM CB 1954, $500 \mathrm{mM} \mathrm{NADPH}$ and incubating the mixture at $37^{\circ} \mathrm{C}$ for $10 \mathrm{~min}$. Reduction of $\mathrm{CB} 1954$ was determined by comparison of peak areas at $325 \mathrm{~nm}$ in standard and enzyme tubes. Enzyme kinetics was only undertaken on those enzymes found in qualitative assay to produce predominantly the 4-hydroxlamine derivative.

\section{In vitro cytotoxicity of CB1954}

Microtitre plates (96 well) were obtained preseeded with $V 79$ cells at 10000 cells $\mathrm{ml}^{-1}$ (European Collection of Animal Cell Cultures, ECACC) in DMEMp10\% FCS. CB 1954 was dissolved in DMSO (Sigma, Gillingham, Dorset SP84XT, UK, tissue culture grade) so that the appropriate concentrations could be dispensed by adding $5 \mathrm{ml}$ per well. $\mathrm{NAD}(\mathrm{P}) \mathrm{H}$ was dissolved in sterile PBS to give the appropriate final concentration by adding $10 \mathrm{ml}$ per well. Enzymes were diluted in sterile PBS. The cells were exposed for $3 \mathrm{~h}$ to CB 1954 or SN 23862 (3.9-500 $\mathrm{mM}$ in doubling dilutions) alone or in combination with cofactor (NAD(P)H 125 or $250 \mathrm{mM}$ ) and enzyme (4 mg) and subsequently left to incubate at $37^{\circ} \mathrm{C}$ and $5 \% \mathrm{CO} 2$ for $3-4$ days. Cytotoxicity was quantified by sulpharhodamine $B$ (SRB) assay. Briefly, cells were fixed by adding cold $10 \%$ TCA for $30 \mathrm{~min}$ and washed before adding $0.4 \%$ dye in $1 \%$ acetic acid and incubating at room temperature for $30 \mathrm{~min}$. After washing and air drying at room temperature the dye was solubilized by adding $100 \mathrm{ml}$ of $10 \mathrm{mM}$ Tris to each well. The plates were read at $492 \mathrm{~nm}$ in a Titertek plate reader. Cytotoxicity towards treated cells was expressed as \% of A492 of untreated controls and statistical analysis was performed using the Mann-Whitney test. ED50s were calculated using probit analysis.

\section{Construction of the clostridial expression vectors}

The erythromycin resistance gene (ermB) from pMTL2OE was PCR amplified using the primers ermBF (50-ATGACTGATATCACT GATGCTAGCGAAATGATACACCAATCAG-30) and ermBR (50-CTTAGTGTTAACACAGCTGTAGGCGCTAGGGACCTC-30), and cloned into pMTL4 digested with ECoRV to generate PMTL4E. The Gram-positive replicon from pIMP1 was cloned between the blunt-ended $\mathrm{BspHI}$ sites of PMTL4E, deleting the bla gene in the process. The plasmid obtained was designated pMTL552. The expression cartridge was obtained from pMTL9341aLS2 and modified encompassing an altered ferredoxin promoter (fac2) in which the sequence preceding the ATG start codon had been replaced with AGGAGGTTAGTCAT, such that the RBS (AGGAGG) was 8 bp away from the ATG start. The entire modified expression cartridge was then cloned into the EcoRV site of pMTL552, to give PMTL553. For conjugative mobilisation of the plasmid, a Smal/ EcoRV fragment carrying the RK2 OriT region was isolated from the plasmid pEOriT and inserted into the Pvull site of PMTL553 yielding PMTL554. To enable blue/white selection for cloning purposes, LacZ alpha was cloned in PMTL554 to yield the final expression vector, PMTL555.

The most effective NTR enzyme identified was YC78_HAEIN of Haemophilus influenzae, accession Q57431, annotated as a putative NAD(P)H NTR. A synthetic gene encoding this 
protein was synthesised (Entelechon Gmbh, Germany), incorporating typical Clostridium codons. In parallel, the wt gene was amplified from the $\mathrm{H}$. influenzae chromosome using the primers HinNTRF (50-GAGGAAATCATATGACTCAAC-30) and HinNTRR (50CTGCAGGCCTTTTTTAAT-30). Both the wt and synthetic gene were inserted into pMTL555 between the Ndel and Pstl sites to yield pOJP10 and pOJP11, respectively.

\section{Conjugation procedure}

Plasmids were introduced into $C$. sporogenes NCIMB 10696, M-55 and Clostridium novyi-NT (Dang et al, 2001) using a modification of the protocol previously described by Purdy et al [20]. Briefly, cells harvested from a $1 \mathrm{ml}$ overnight culture of the $\mathrm{E}$. coli donor were washed in PBS before being resuspended in $200 \mathrm{ml}$ of an overnight culture of $C$. sporogenes or $C$. novyi-NT grown in TYG broth. The $200 \mathrm{ml}$ mating mix was spotted onto a TYG $+0.5 \%$ glucose $\left(v v^{-1}\right)$ agar plate and incubated anaerobically for $7 \mathrm{~h}$. The mating mixture was subsequently resuspended in $500 \mathrm{ml}$ of sterile PBS before plating onto selective agar (TYG + erythromycin). E. coli donors were counter selected by the addition of D-cycloserine (250 $\mathrm{mgml}^{-1}$ ) to the media. Recombinant colonies of C. sporogenes NCIMB 10696 were screened for the presence of the plasmid by PCR and also by retransforming the plasmid back into $E$. coli followed by restriction digestion verification of the plasmid.

In vivo evaluation of antitumor effect

Human colorectal carcinoma (HCT116) were injected subcutaneously $\left(1.5 \times 10^{6}\right.$ cells) in the abdominal flank of female adult NMRI nu/nu mice. Tumors were measured at least twice/week in three orthogonal diameters and volumes calculated according the formula $\mathrm{AxBxC} \times \pi / 6$. All experiments were conducted in accordance with local institutional guidelines, approved by the Animal Ethics Committee of the University and procedures were according to the guidelines defined by the UKCCCR.

When tumors reached an average volume of $400 \mathrm{~mm}^{3}$, treatment was started. Tumor colonization was allowed for 5 days before initiation of prodrug and sham treatment, while selection antibiotics (erythromycin at $60 \mathrm{mg} \mathrm{l}^{-1}$ ) were added to the drinking water. CB1954 prodrug (15 mg kg-1) was prepared as previously described [21] and administrated intraperitoneally (i.p.) for 5 consecutive days. Animals were subsequently treated with $200 \mathrm{mg}$ $\mathrm{kg}^{-1}$ Flagyls i.p. twice daily for 9 days. During this period, the drinking water was also supplemented with Flagyls. Body weight measurements were used as a parameter for treatment toxicity. At the end of the follow-up period, or when tumors outranged the ethically allowed maximal volume, animals were killed by cervical dislocation. Tumors and normal tissues (liver, spleen) were excised, grinded and examined for colonization levels at different time points using a procedure described previously [10]. 


\section{Statistics}

All statistical analyses were performed with SPSS 12.0.1 for Windows (SPSS Inc., 2003, Chicago, IL, USA). Mixed models linear regression was used to determine the statistical significance of differences between two independent groups of variables.

\section{RESULTS}

\section{Isolation of novel NTR enzyme}

Recombinant procedures were used to produce purified protein from 10 bacterial homologues of the E. coli NfnB (NTR-B) enzyme [17] and five homologues of YwrO of B. amyloliquefaciens [18]. Qualitative assays showed that only one of the YwrO-like enzymes and four of the NfnB homologues produced predominantly the $4 \mathrm{HX}$ derivative of CB1954. These enzymes were, therefore, subjected to quantitative analysis and their $\mathrm{Km}$ and kcat with CB1954 determined (Table 2).

Table 6.2 Characteristics of purified bacterial nitroreductases

\begin{tabular}{|c|c|c|c|c|}
\hline Enzyme & Product & $K_{\mathrm{m}}(\ldots=\mathrm{M})$ & $\left.\boldsymbol{k}_{\text {cat }}\left(\mathbf{s}^{-1}\right)\right)$ & $\begin{array}{l}\mathrm{ED}_{50} \mathrm{CB} 1954 \\
(\mu \mathrm{M})\end{array}$ \\
\hline NfnB & $4 H X+2 H X$ & 682 & 6 & 6.3 \\
\hline YwrO BAM & $4 H X$ & 617 & 8.2 & 137.1 \\
\hline Ydgl & $4>2 \mathrm{HX}$ & 3863.9 & 30.3 & 15.3 \\
\hline YodC & $4>2 H X$ & 552.2 & 58 & 20.3 \\
\hline Haemophilus influenzae NfnB & $4 H X$ & 690 & 56.2 & 4.7 \\
\hline Campylobacter jejuni NfnB & $4 H X$ & 217 & 6.1 & 55.8 \\
\hline Porphyromonas gingivalis YwrO & $4 H X$ & 1200 & 3.2 & 252.3 \\
\hline
\end{tabular}

The enzyme NTR-H isolated from $H$. influenzae (Accession no. YP_249310) possessed the most favourable properties. In addition to producing only the $4 \mathrm{HX}$ derivative from CB1954, it had a $\mathrm{Km}$ and kcat for this substrate of $690 \mathrm{mM}$ and $56.2 \mathrm{~s} \_1$, respectively. This compares to the previously isolated bacterial enzymes of E. coli B (NTR-B) and B. amyloliquefaciens (YwrO) which possess a respective $\mathrm{Km}$ of 862 and $618 \mathrm{mM}$ and a kcat of 6.0 and $8.2 \mathrm{~s} .1$. Thus, while the affinity of NTR-H and NTR-B for the prodrug substrate (Km) is broadly equivalent, the rate at which it is turned over (kcat) is an order of magnitude greater in the case of NTR-H. Moreover, the entire reaction product is the toxic $4 \mathrm{HX}$ derivative, as opposed to NTR-B where $50 \%$ of the reaction results in the nontoxic $2 \mathrm{HX}$ derivative.

The benefits of these improved properties on cytotoxicity were demonstrated in a set of experiments in which equivalent quantities of purified NTR enzyme were incubated with V79 cells in the presence of varying concentrations of CB1954 (Figure 1). The greatest degree of killing was observed in the case of NTR-H. In general, with all the enzymes tested (Table 2), ED50 appeared to be more highly related to kcat as opposed to Km, with NTR-H proving to be the most potent. 


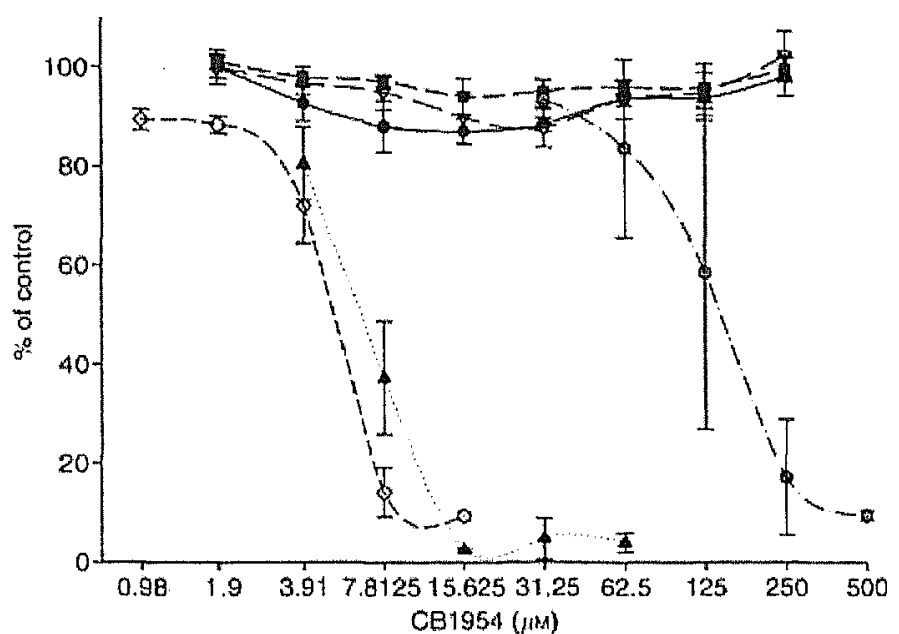

Flgure 6.1. Assessment of CB1954 cytotoxicity. Cytotoxicity of CB 1954 was assessed in 96-well plates seeded with V79 cells $\left(10^{4}\right.$ per $\left.\mathrm{ml}\right)$ by incubating them with $\mathrm{CB} 1954$ alone $(3.9 .500 \mu \mathrm{M})$, prodrug+NAD $\left.\mathrm{P}\right) \mathrm{H}(250 \mu \mathrm{M})$, or prodrug, cofactor and enzyme $\left(4 \mathrm{Kg}\right.$ we $\left.\mathrm{ll}^{-1}\right)$ for $3 \mathrm{~h}$ in serum free DMEM. The medium was replaced and the cells grown for $72-96$ h post-treatment in DMEM $+10 \%$ FCS until control (untreated) cells had achieved confluence. The cells were flxed, stained with SRB and the plates read at $492 \mathrm{~nm}$. Results are expressed as \% of control (untreated cells). Key: - , prodrug alone; $\boldsymbol{U}$, prodrug +NADH; $\boldsymbol{\Delta}$, prodrug+NADPH; $\mathbf{D}$, HinNTR+NAPDH+Prodrug; $\square$ $\mathrm{NfnB}+\mathrm{NADH}+$ prodrug, and; $\bullet$ YwrO+NADPH+prodrug.

\section{Transformation of Clostridium spp with superior tumor colonizing properties}

Having established the superiority of the NTR-H, we sought to introduce an expression plasmid carrying the gene into the Clostridium strains with the best tumor colonizing properties. A method of transforming the selected species, C. sporogenes, has previously been described [12]. However, repeated attempts to obtain transformants with this method of two different $C$. sporogenes strains and of $C$. novyi-NT in our laboratories over a period of 2 years were unsuccessful. We therefore explored the use of a conjugative procedure, initially developed for the introduction of plasmids into Clostridium difficile [20].

In our initial experiments we utilized C. sporogenes ATCC 13732 as the recipient, and we were able to show that plasmids could be consistently introduced at appreciable frequencies. The rate of transfer varied between $1.5 \times 10^{-7}$ and approaching $1.0 \times 10^{-4}$ transconjugants per recipient, dependant on the plasmid employed (Table 3). Significantly, for those plasmids tested (Table 3) this method also proved to be applicable to $C$. sporogenes M-55 [22] and C. novyi-NT $[1,23]$ which had previously proven recalcitrant to all transformation attempts. With this conjugation method, we obtained success rates of $70-90 \%$, depending on the strain being used. In all cases, the plasmid could be reisolated by transformation into $E$. coli, and its authenticity established through analysis of suitably restricted samples on agarose gels. 
Table 6.3 Transfer frequencies of various plasmids from $E$. coll donors into three different clostridial strains

\begin{tabular}{llll}
\hline Plasmid (replicon) & \multicolumn{2}{l}{$\begin{array}{l}\text { Conjugation efficiency (transconjugants per recipient } \\
\text { strain) }\end{array}$} \\
\cline { 2 - 4 } & $\begin{array}{l}\text { C. sporogenes } \\
\text { ATCC 13732 }\end{array}$ & $\begin{array}{l}\text { C. sporogenes } \\
\text { M55 }\end{array}$ & C. novyi-NT \\
& & & \\
\hline pMTL555 (p|M13) & $1.44 \times 10^{-7}$ & $1.84 \times 10^{-7}$ & ND \\
pMTL9501/pCTC41 & $1.18 \times 10^{-6}$ & $1.27 \times 10^{-6}$ & $1.80 \times 10^{-7}$ \\
(pAMbeta1) & $8.86 \times 10^{-5}$ & ND & ND \\
pMTL9401 (pCB102) & $8.3 \times 10^{-6}$ & ND & ND \\
pMTL9611 (p|P404) & $4.00 \times 10^{-5}$ & ND & \\
\hline
\end{tabular}

Having derived an efficient gene transfer procedure, we constructed a purpose built expression vector, pMTL555, in which two different genes encoding NTR-H were independently cloned (Figure 2). The first represented the wt gene; the second was a synthetic gene, in which the codons were changed to match the Clostridium codon usage. Following the introduction of the two recombinant plasmids (pOJP10 and pOJP11, wt and synthetic NTR-H, respectively), verification of the transconjugants indicated no structural change to either pOJP10 or pOJP11. The levels of NTR in both recombinant derived samples were significantly higher compared to wt control samples. As the lysate derived from cells carrying pOJP11 produced slightly higher levels than cells harbouring pOJP10, we chose the NTR-H expressing $C$. sporogenes strain carrying pOJP11 to evaluate its ability to produce antitumor activity.

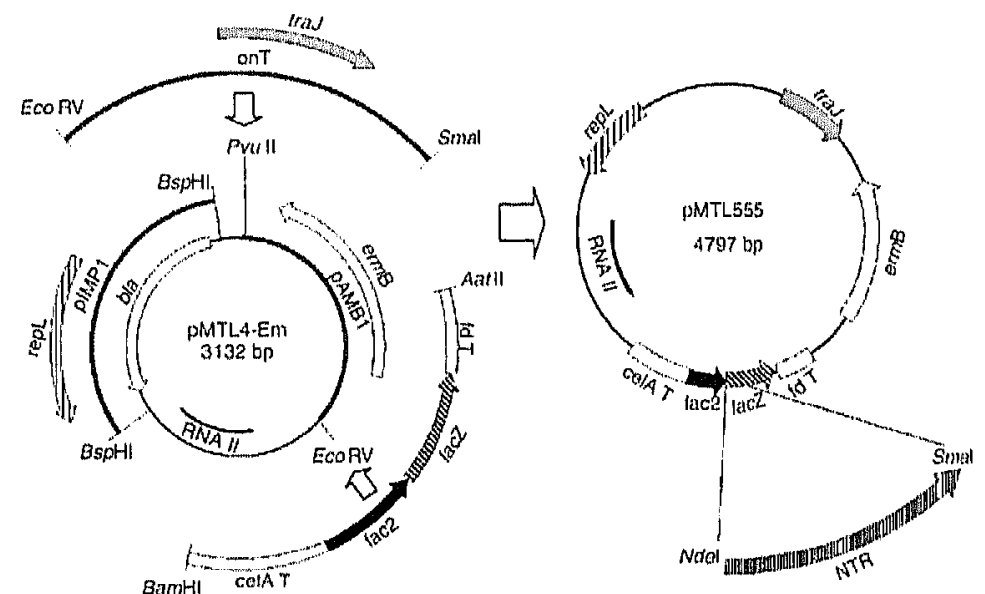

Figure 6.2. Construction of plasmids over expressing NTR. The derivation of DNA fragments used to assemble the expression vector PMTL555 is as indicated. For a detalled description see Materials and Methods. Key: repL, replication protein of pIM13, taken from the derivative plasmid pIMP1, bla, 3 -lactamase of pMTL4; ormB, erythromycin resistance gene from plasmid pAM $31 ;$ traJ, transfer protein from the 'origin of transfer' (oriT) of plasmld RK2; RNAll, replication region of ColE1, taken from the derivative plasmid PMTL4; celA T, transcriptlonal terminator RK2; RNAll, replication region of ColE1, taken from the derivative plasmid pMTL4; celA T, transcriptlonal terminator
of the Clostridium thermocellum celA gene; fac2, the promoter of the Clostridium pasteurianum ferredoxin gene, derivatised to include an $E$. coll lac operator; lacz, $\beta$-galactosidase alpha fragment; fd $T$, transcriptional terminator of the C. pasteurianum ferredoxin gene. Gene fragments encompassing NTR enzymes (NRase) are cloned into the lacZ region using the $\mathrm{Ndel}$ site adjacent to the fac2 RBS and an appropriate site (e.g., Smal) in the pMTL20 polylinker region present in lacZ. 
In vivo antitumor activity following systemic administration of recombinant $C$. sporogenes

Our aim was to determine whether the levels of NTR-H delivered by the recombinant $C$. sporogenes were sufficiently high to cause enough prodrug conversion to result in measurable antitumor efficacy. A tumor regrowth delay assay was used to quantify the magnitude of this effect. Nu/nu mice xenografted with HCT116 were injected with NTR-H expressing $C$. sporogenes spores when tumors reached an average volume of $400 \mathrm{~mm} 3$. In order to be potentially useful for the treatment of disseminated or inaccessible tumors, injections were given systemically rather than through local injection. Animals were divided into four groups that received (1) no treatment, (2) CB1954 prodrug alone (15 mg kg-1, five times a week), (3) recombinant spores (at a concentration of $5.10^{7} \mathrm{cfu}$ in a volume of $100 \mathrm{ml}$ saline via the tail vein) followed by prodrug vehicle only (sham treatment) or (4) recombinant spores followed by CB1954 prodrug solution, respectively. To allow tumor colonization to take place, prodrug or sham treatment started at day 5 after spore injection. Although the in vivo feasibility of the CDEPT approach has been investigated in the past, it has been difficult to discriminate between the specific effect of prodrug conversion and the effect of the bacteria only. The main reason is the continuous presence of recombinant bacteria during the entire follow-up and consequently, their potential contribution to the observed antitumor effects. Therefore, in order to quantitatively evaluate the CDEPT approach, we eradicated the $C$. sporogenes form the tumor following the daily prodrug injections by an antibiotic treatment course (Flagyls, $200 \mathrm{mg} \mathrm{kg}^{-1}, 2 x$ daily, for 9 days). This allowed us to specifically separate the effects of the recombinant bacteria alone from the effects of the bacteria in combination with the prodrug. Tumor colonization following recombinant spore administration but before the onset of antibiotic treatment was quantified by performing dilution series of randomly selected tumors from spore-treated animals. All tumors investigated showed colonization levels of $10^{8}$ $10^{9} \mathrm{cfu} \mathrm{g}^{-1}$ tumor tissue. As expected, viable clostridia could not be detected in normal tissues. Importantly, tumor colonization levels decreased below the detection limit following antibiotic treatment, indicating the efficacy of the Flagyls therapy. As already well established using other NTR directed gene therapy approaches [24], CB1954 administration alone had no effect on tumor volumes (Figure $3 A$ ). Administration of spores alone caused a moderate, but significant tumor growth delay $(P=0.0001$, mixed linear regression analysis) (Figure $3 A)$. This was a consequence of modest tumor lysis and the appearance of haemorrhagic necrosis, an observation also made when using other clostridial species such as $C$. sporogenes M55 and C. novyj-NT [1]. When combined with $\mathrm{CB} 1954$ administration, the antitumor effect significantly increased $(P=0.0001$, mixed linear regression analysis) (Figure $3 A$ ), thereby establishing the in vivo treatment efficacy of the NTR CDEPT approach. During the treatment, animals in both treatment arms showed a transient weight loss. This effect was not significantly different between the two groups. Most importantly, the observed weight loss was totally reversible and the animals recovered completely following the antibiotic treatment (Figure 3B). 

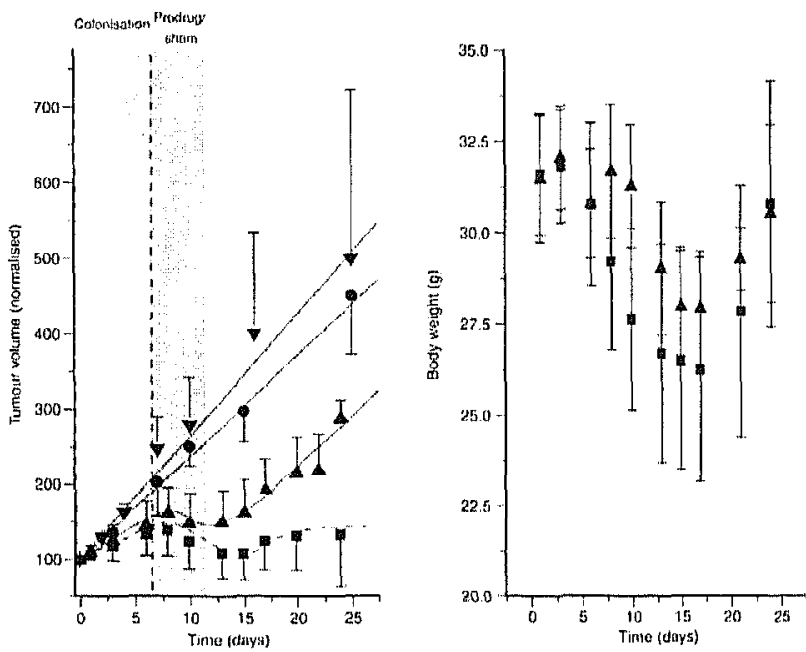

Figure 6.3. Antitumour effect following systemic administration of NTR.recombinant C. sporogenes spores to nu/nu mice bearing HCT116 tumors. (A) Tumor growth after one cycle of recombinant $\mathrm{C}$. sporogenes treatment with CB1954 prodrug ( $)$ or vehicle only (sham) ( $\mathbf{A}$ ) treatment. Control animals received no treatment ( $)$ or CB1954 alone $(\nabla)$. (B) Representative body weight evolution during a treatment cycle. Data are from at least five mice per group with error bars showing standard deviations for each group. Tumor volumes are normalised to 100 arbitrary units at the start of the treatment, allowing comparison of tumor growth within and across groups.

\section{In vivo efficacy of repeated CDEPT treatment cycles}

In a clinical setting, chemotherapy is typically given in multiple cycles in order to maximize its effects. Analogous to this situation, we questioned whether clostridial therapy could be given repeatedly. A treatment cycle started at the day of spore injection (day 1), followed 5 days later (day 6) by prodrug or vehicle treatment for 5 days. Each treatment cycle was then followed by antibiotic treatment during 9 days. Eventually animals were allowed to recover for an additional period of 5-7 days. Sham treated animals were given two consecutive identical cycles. The tumor growth delay caused by each of the two (sham) treatment cycles was very similar (Figure 4). This result indicates not only that the bacteria can effectively recolonize the tumor to result in an antitumor effect, but also that the tumor microenvironment following the first treatment cycle did not fundamentally change. Despite the observed growth delay within the sham-treated group, the animals in this group had to be killed for ethical reasons by the end of the second treatment cycle because their tumor volumes became too high. In contrast, and more importantly, a highly significant and much bigger antitumor effect were observed in animals that were treated twice with recombinant spores combined with CB1954 prodrug (Figure 4). This allowed application of an additional third treatment cycle. Throughout the three cycles, the treatment resulted in sustained growth delay effects. 


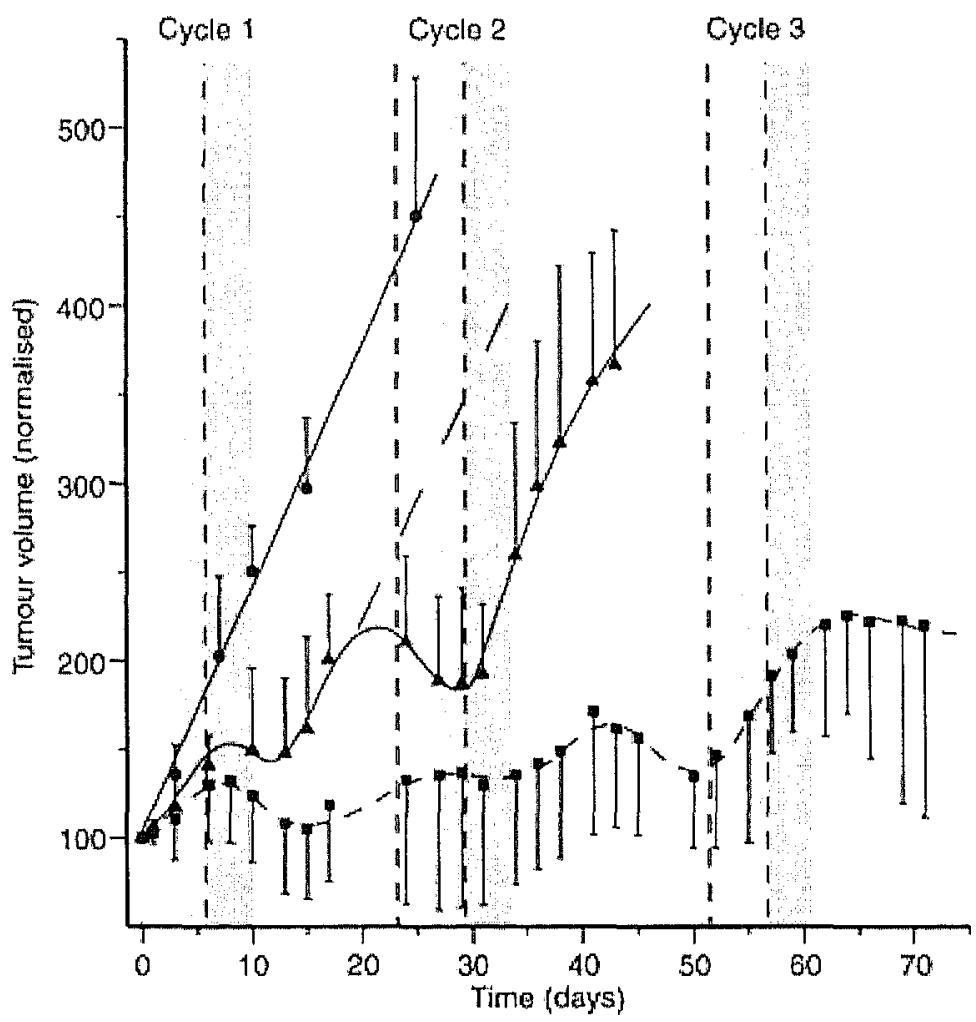

Figure 6,4. Anttimor effect following repeated treatment cycles of NRase-recombinant $C$. sporogenes in combination with $\mathrm{CB} 1954$ administration. Groups were recombinant $C$. sporogenes treatment with CB1954 prodrug (D) or vehicle only (sham) ( $\Delta$ ) treatment and control animals, receiving no treatment ( $)$. The dashed line indicates the expected tumour growth following one treatment cycle (based on results shown in Figure $3 \mathrm{~A}$ ). A single treatment cycle consisted of bacterial spore administration at day 0 , followed by CB1954/vehicle administration at day 6 , during 5 days. Each treatment cycle was followed by antibiotic therapy and an additional recovery period for the 6 , during 5 days. Each treatment cycle was followed by antibiotic therapy and an additional recovery period for the
animals (for more details, see legend Flgure 3 and text). Sham-treated animals received two treatment cycles before animals (for more details, see legend Flgure 3 and text). Sham-treated animals received two treatment cycles before
tumor volumes outranged the ethically allowed maximum. The CB1954 treated group was given an additional third treatment cycle. Tumor volumes are normalized to 100 arbitrary units at the start of the treatment, allowing comparison of tumor growth within and across groups. 


\section{DISCUSSION}

In the current paper, we report significant progress in the use of clostridia to deliver prodrugconverting enzymes specifically to tumors. As a first step to improve the system, we isolated a novel NTR enzyme with better characteristics than NTR enzymes used so far. The NTR-H enzyme was demonstrated to be the best out of 15 tested bacterial NTR homologues. The enzyme produced only the toxic $4 \mathrm{HX} \mathrm{CB} 1954$ derivative and showed the best kinetic parameters of all the enzymes tested. As expected, the superior enzyme properties translated into an enhanced toxicity profile in vitro. To evaluate the in vivo efficacy of this novel enzyme, transfer of the NTR-H enzyme to a Clostridium strain with enhanced tumor colonization properties was absolutely necessary. Indeed, although previous CDEPT work undoubtedly established the safety and feasibility of the approach, proof of in vivo antitumor efficacy has so far been limited $[9,12,25]$. The major reason for this failure has been attributed to the low tumor colonization efficiency of the employed strains.

Until recently, the best tumor colonizing strains, such as $C$. sporogenes or $C$. novyi-NT, could not be transformed. Thus, the reported development a few years ago of a transformation system based on electroporation for $C$. sporogenes, was encouraging [12]. Unfortunately, the reported transformation procedure could never be reproduced in our laboratories. As exogenous endonucleases represent a major impediment to DNA transfer, we therefore devised a procedure based on conjugative transfer from $\mathrm{E}$. coli donors. Here, we demonstrate that this procedure can be used to introduce recombinant plasmids into superior tumor colonizing strains such as $C$. sporogenes, $C$. oncolyticum and $C$. novyi-NT at high frequencies and with high success rates. Thanks to this breakthrough, it will now be possible to express essentially any heterologous gene of interest in these clostridial vectors. As shown here for NTR-H, the adaptation of the heterologous gene codons to the codon usage in the clostridial host, characterized by its low $\mathrm{G}+\mathrm{C} \%$ content, might further increase therapeutic protein yield. Finally, we evaluated if the recombinant $C$. sporogenes strain could deliver enough NTR-H to tumors in vivo to convert sufficient levels of prodrug to produce antitumor efficacy. Although in vivo antitumor effects using a CDEPT strategy have already been demonstrated with recombinant clostridia, it has been difficult to attribute the observed effects specifically to prodrug conversion, since the bacteria remain present in the tumor. As the bacteria have antitumor effects in their own right, as demonstrated in our work, it is not clear how much of the effect is due to their continuous presence. We therefore devised a way to quantify the magnitude of the antitumor effect due to prodrug conversion by giving pulse treatment cycles, followed by antibiotic treatment. Clearance of the bacteria from the animal not only allowed recovery after the treatment cycle, it also enabled a precise and direct quantification of the antitumor effect. In order to minimize all secondary effects that could be potentially involved in mediating the antitumor effect, we chose immunocompromised mice as a model, although there is no evidence for an immune response as shown earlier in immunocompetent rats [25]. Our results clearly demonstrate that intravenously administered spores of $C$. sporogenes expressing NTR-H produce significant antitumor efficacy when combined with prodrug 
administration. Most importantly, highly significant and prolonged antitumor efficacy could be obtained following repeated cycles. As we observe such a striking antitumor response, it must mean that not only the hypoxic but also aerobic cells are being killed as a result of an additional bystander effect. Such a phenomenon has indeed been described for NTR in combination with CB1954 $[21,26]$. Therefore, the use of a prodrug activating enzyme not only is a further safeguard to the system (compared to expression of a direct cytotoxic protein which might produce host toxicity if it comes in circulation), but also provides considerable potential for treatment amplification.

To our knowledge, this is the first demonstration of a sustained antitumor effect following multiple cycles of recombinant clostridia treatment. Overall, this indicates that maturation of inactive spores into vegetative rods following a first cycle does not eliminate the activity of subsequent administrations. Our data are in line with our own previously reported results [11] and with the observations of Liu et al [12] showing no reduction in numbers of vegetative cells $\mathrm{g}^{-1}$ tumor occurring between 7 and 14 days after a single spore injection. This is not limited to animals with an immunocompromised immune system since it was demonstrated some 25 years ago that repeated clostridial spore administration could be performed in tumor bearing rats [27]. This is likely due to the lack of immunogenicity of the applied clostridial spores. Moreover, transition from spores to the vegetative reproductive state only occurs in the severe hypoxic and necrotic region of the tumor, considered to be an immune privileged site.

Although the observed effects of the therapy were significant, additional efficacy would be predicted when combined with radiotherapy and/or conventional chemotherapy. Other potential combined treatment modalities include specific targeting of the structurally abnormal tumor blood vessels with vascular targeting agents as we [25] and others [1] have aiready successfully reported. In addition, more soluble derivatives of CB1954 that cause more effective tumor regression have recently been cescribed [26] and since 5-FU and CB1954 have been shown to act synergistically [15], the combinatorial use of prodrug activating enzymes (CDase and NTR) might be a promising option for CDEPT.

\section{ACKNOWLEDGEMENTS}

We thank Kim Paesmans for technical assistance. The work was financially supported by the QLK3-CT-2001-01737 grant of the European Community. Ludwig Dubois is a PhD student supported by the LSCH-CT-2003-502932/EUROXY Grant. 


\section{REFERENCES}

1. Dang, L.H., Bettegowda, C., Huso, D.L., Kinzler, K.W. and Vogelstein, B. (2001) Combination bacteriolytic therapy for the treatment of experimental tumors. Proc Nat Acad Sci U S A, 98, 15155-60.

2. Pipiya, T., Sauthoff, H., Huang, Y.Q., Chang, B., Cheng, J., Heitner, S., Chen, S., Rom, W.N. and Hay, J.G. (2005) Hypoxia reduces adenoviral replication in cancer cells by downregulation of viral protein expression. Gene Ther, 12, 911-7.

3. Shen, B.H. and Hermiston, T.W. (2005) Effect of hypoxia on Ad5 infection, transgene expression and replication. Gene Ther, 12, 902-10.

4. Koumenis, C., Naczki, C., Koritzinsky, M., Rastani, S., Diehl, A., Sonenberg, N. Koromilas, A. and Wouters, B.G. (2002) Regulation of protein synthesis by hypoxia via activation of the endoplasmic reticulum kinase PERK and phosphorylation of the translation initiation factor elF2alpha. Mol Cell Biol, 22, 7405-16.

5. Mose, J.R., Mose, G., Propst, A. and Heppner, F. (1967) [Oncolysis of malignant tumors by Clostridium strain M 55]. Med Klin, 62, 189-93.

6. Carey, R. (1967) Clostridial oncolysis in man. . European J. Cancer 3(1967) 37-46, $37-46$.

7. Minton, N.P., Mauchline, M.L., Lemmon, M.J., Brehm, J.K., Fox, M., Michael, N.P., Giaccia, A. and Brown, J.M. (1995) Chemotherapeutic tumour targeting using clostridial spores. FEMS Microbiol Rev, 17, 357-64.

8. Fox, M.E., Lemmon, M.J., Mauchline, M.L., Davis, T.O., Giaccia, A.J., Minton, N.P. and Brown, J.M. (1996) Anaeroblc bacteria as a delivery system for cancer gene therapy: in vitro activation of 5-fluorocytosine by genetically engineered clostridia. Gene Ther, 3, 173-8.

9. Lemmon, M.J., van Zijl, P., Fox, M.E., Mauchline, M.L., Giaccia, A.J., Minton, N.P. and Brown, J.M. (1997) Anaerobic bacteria as a gene delivery system that is controlled by the tumor microenvironment. Gene Ther, 4, 791-6.

10. Lambin, P., Theys, J., Landuyt, W., Rijken, P., van der Kogel, A., van der Schueren, E., Hodgkiss, R., Fowler, J., Nuyts, S., de Bruijn, E., Van Mellaert, L. and Anne, J. (1998) Colonisation of Clostridium in the body is restricted to hypoxic and necrotic areas of tumours. Anaerobe, 4, 183-8.

11. Theys, J., Landuyt, W., Nuyts, S., Van Mellaert, L., Bosmans, E., Rijnders, A., Van Den Bogaert, W., van Oosterom, A., Anne, J. and Lambin, P. (2001) Improvement of Clostridium tumour targeting vectors evaluated in rat thabdomyosarcomas. FEMS Immunol Med Microbiol, 30, 37-41.

12. Liu, S.C., Minton, N.P., Giaccla, A.J. and Brown, J.M. (2002) Anticancer efficacy of systemically delivered anaerobic bacteria as gene therapy vectors targeting tumor hypoxia/necrosis. Gene Ther, 9, 291-6.

13. Barbe, S., Van Mellaert, L., Theys, J., Geukens, N., Lammertyn, E., Lambin, P. and Anne, J. (2005) Secretory production of biologically active rat interleukin-2 by Clostridium acetobutylicum DSM792 as a tool for anti-tumor treatment. FEMS Microbiol Lett, 246, 67-73.

14. Minton, N.P. (2003) Clostridia in cancer therapy. Nat Rev Microbiol, 1, $237-42$.

15. Palmer, D.H., Milner, A.E., Kerr, D.J. and Young, L.S. (2003) Mechanism of cell death induced by the novel enzyme-prodrug combination, nitroreductase/CB1954, and identification of synergism with 5-fluorouracil. $\mathrm{Br} J$ Cancer, 89, 944-50.

16. Cui, W., Gusterson, B. and Clark, A.J. (1999) Nitroreductase-mediated cell ablation is very rapid and mediated by a p53-independent apoptotic pathway. Gene Ther, 6, 764-70.

17. Michael, N.P., Brehm, J.K., Anlezark, G.M. and Minton, N.P. (1994) Physical characterisation of the Escherichla coli $B$ gene encoding nitroreductase and its overexpression in Escherichia coll K12. FEMS Microbiol Lett, 124, 195-202.

18. Anlezark, G.M., Vaughan, T., Fashola-Stone, E., Michael, N.P., Murdoch, H., Sims, M.A., Stubbs, S., Wigley, S. and Minton, N.P. (2002) Bacillus amyloliquefaciens orthologue of Bacillus subtilis ywrO encodes a nitroreductase enzyme which activates the prodrug CB 1954. Microbiology, 148, 297-306.

19. Knox, R.J., Boland, M.P., Friedlos, F., Coles, B., Southan, C. and Roberts, J.J. (1988) The nitroreductase enzyme in Walker cells that activates 5-(aziridin-1-yl)-2,4- 
dinitrobenzamide (CB 1954) to 5-(aziridin-1-y)-4-hydroxylamino-2-nitrobenzamide is a form of NAD(P)H dehydrogenase (quinone) (EC 1.6.99.2). Biochem Pharmacol, 37 , 4671-7.

20. Purdy, D., OKeeffe, T.A., Elmore, M., Herbert, M., McLeod, A., Bokori-Brown, M., Ostrowski, A. and Minton, N.P. (2002) Conjugative transfer of clostridial shuttle vectors from Escherichia coli to Clostridium difficile through circumvention of the restriction barrier. Mol Microbiol, 46, 439-52.

21. Djeha, A.H., Hulme, A., Dexter, M.T., Mountain, A., Young, L.S., Searle, P.F., Kerr, D.J. and Wrighton, C.J. (2000) Expression of Escherichia coli B nitroreductase in established human tumor xenografts in mice results in potent antitumoral and bystander effects upon systemic administration of the prodrug CB1954. Cancer Gene Ther, 7, 721-31.

22. Mose, J.R., Mose, G., Propst, A. and Heppner, F. (1967) [Oncolysis of malignant lumors through the M 55 clostridium strain. II]. Med Klin, 62, 220-5.

23. Bettegowda, C., Dang, L.H., Abrams, R., Huso, D.L., Dillehay, L., Cheong, I., Agrawal, N., Borzillary, S., McCaffery. J.M., Watson, E.L., Lin, K.S., Bunz, F., Baidoo, K., Pomper, M.G., Kinzler, K.W., Vogelstein, B. and Zhou, S. (2003) Overcoming the hypoxic barrier to radiation therapy with anaerobic bacteria. Proc Natl Acad Sci U S $A, 100,15083-8$.

24. Djeha, A.H., Thomson, T.A., Leung, H., Searle, P.F., Young, L.S., Kerr, D.J., Harris, P.A. Mountain, A. and Wrighton, C.J. (2001) Combined adenovirus-mediated nitroreductase gene delivery and CB1954 treatment: a well-tolerated therapy for established solid tumors. Mol Ther, 3, 233-40.

25. Theys, J., Landuyt, W., Nuyts, S., Van Mellaert, L., van Oosterom, A., Lambin, P. and Anne. J. (2001) Specific targeting of cytosine deaminase to solid tumors by engineered Clostridium acetobutylicum. Cancer Gene Ther, 8, 294-7.

26. Wilson, W.R., Pullen, S.M., Hogg, A., Helsby, N.A., Hicks, K.O. and Denny, W.A. (2002) Quantitation of bystander effects in nitroreductase suicide gene therapy using three-dimensional cell cultures. Cancer Res, 62, 1425-32.

27. Gericke, D., Dietzel, F., Konig, W., Ruster, I. and Schumacher, L. (1979) Further progress with oncolysis due to apathogenic clostridia. Zentralb/ Bakteriol [Orig A], $243,102-12$. 


\section{CHAPTER 7}

\section{Functional antibodies produced by oncolytic clostridia}

Arjan J. Groot, \#, Asferd Mengesha, "Elsken van der Wall , Paul J. van Diest, Jan Theys, Marc Vooijs,

Biochem Biophys Res Commun. 2007 Dec 28;364(4):985-9.

\# These authors contribute equally 


\begin{abstract}
Hypoxia is a hallmark of solid cancer and characterized by regions of low oxygen and necrosis due to insufficient blood perfusion. Intratumoral hypoxia triggers the transcription of genes responsible for cell survival. The transcription factor hypoxia-inducible factor 1alpha (HIF-1a) is a key regulator of this response. HIF activation is associated with resistance to radio-and chemotherapy and poor clinical outcome, and may therefore provide an attractive therapeutic target. Clostridium-based oncolysis is a promising therapeutic strategy for the treatment of hypoxic tumors where these microorganisms naturally home. Here, we report for the first time the isolation of transconjugants of two excellent tumor colonizing Clostridium strains, C. novyi-NT and C. sporogenes, expressing single chain antibodies specific for human HIF-1a. This is a first step towards Clostridium-directed antibody therapy (CDAT) that holds promise as a carrier of cancer therapeutics targeting the most resistant regions in
\end{abstract} human solid cancer.

\title{
INTRODUCTION
}

When solid tumors outgrow their vasculature, reglons of very low oxygen concentrations (hypoxia) develop, which leads to necrotic areas [1]. Hypoxic tumor cells are resistant to chemotherapy and radiotherapy and their presence is thereby indicative of poor clinical outcome [2]. Furthermore, hypoxia increases mutation rate, local angiogenesis, motility, and invasion leading to aggressive local tumor behavior and increased predisposition to metastases $[3,4]$. Hypoxia is therefore a hallmark of solid tumor development and strategies targeting hypoxia have thus evolved as a conceptual strategy for anti-cancer treatment by utilizing hypoxia-specific delivery of pro-drugs and small molecules [5] (reviewed in [6]) targeting the hypoxia-inducible factor 1alpha (HIF-1a), the key regulator of the hypoxia response in many solid cancers [7,8]. Delivery of cancer therapeutics to hypoxic tumors is hampered by their limited perfusion due to poor vascularization. Non-pathogenic strains of the obligate anaerobic bacterium clostridia produce spores that naturally colonize and lyse hypoxic tumor areas [9-11]. Since oncolysis in these experimental models never completely eradicated tumor growth, improved non-toxic bacteriolytic clostridia strains have been generated suitable for producing cancer therapeutic proteins (reviewed in [12]). The efficacy of Clostridium-based cancer therapy has been demonstrated in experimental models as a vehicle for tumor-specific delivery of pro-drug converting enzymes $[13,14]$ and to enhance radio-and chemotherapy [15-17]. Antibody-based therapeutics have several advantages over cytotoxic agents; most importantly their high affinity and specificity for tumor antigens. Their application, however, is hampered by tumor heterogeneity and the difficulty to obtain high specificity antibodies against tumor antigens that can be coupled to tumor selective carriers. VHH are small (15 kDa), naturally occurring, single chain antibodies from camelids with full antigen-binding capacity and specificity [18]. Because of size, specificity, low toxicity, and immunogenicity, and ease of molecular engineering, $\mathrm{VHH}$ have the potential to act as therapeutic antibodies [19-21]. We have generated VHHs against HIF-1a that, when 
expressed in mammalian cells, bind and inhibit HIF activity [22] and unpublished results). Here, we show for the first time heterologous gene expression of $\mathrm{VHH}$ antibodies targeting HIF-1a by the non-pathogenic Clostridium strain C. novyi-NT. Clostridium directed antibody therapy (CDAT) combines the oncolytic properties of Clostridium and the target selectivity of antibody therapeutics and has the potential to target the most resistant parts in human solid tumors.

Materials and methods

Construction of a universal VHH expressing Clostridial vector

VHHAG2 CDNA (a gift from Unilever Research Vlaardingen, The Netherlands) was amplified by standard PCR with primers from Sigma-Genosys Ltd, restriction sites are underlined, (Cambridge, UK) forward primer 50GGGTGCGCAAAGGCCCAGCCGGCCATGGCCGATGT GCAGCTG-GT-30 and reverse primer 50-GGGCTCGAGCGCGAA TTCCTATGCGGCCCCATGGTG-ATG-30 introducing an Mstl site to fuse the $\mathrm{VHH}$ with the eglA signal sequence exactly as described $[23,24]$. This plasmid was used as a template to generate the SSeglA VHH fusion using PCR with primers forward 50-ATATACATATGATGT TGTTTACAGTATTAGGAACAAATACTTATAAAGC-30 and reverse 50-TATACCCCGGGCTACTATGCGGCCCCATGGTGATG-30 introducing an Ndel and Smal site and ligated in the Ndel and Smal digested PMTL-555 shuttle vector [14] generating pMTL-555-VHH. Cloning was controlled by restriction analysis and verified by sequencing. With the restriction sites Sfil and BstEll any $\mathrm{VHH}$ cDNA can be cloned as an egIA fusion with Myc and HIS6 tags.

\section{Clostridial conjugation procedure}

Conjugation of the Escherichia coli donor strain CA434 (HB101 carrying the IncPb conjugative plasmid, R702) carrying pMTL-555-VHH with C. novyi-NT [15] or C. sporogenes NCIMB 10696 with pMTL-555-VHH was performed exactly as described [14]. Plasmids were isolated from erythromycin resistant clostridia and retransformed into $E$. coll followed by restriction digest and sequencing to verify their integrity.

\section{Isolation and characterization of VHH from strains}

Transformed clostridia were grown in a volume of $1 \mathrm{~L} \mathrm{BHI} \mathrm{media} \mathrm{under} \mathrm{strictly} \mathrm{anaerobic}$ conditions in a MACS Anaerobic Workstation (Don Whitley Scientific, Shipley, UK) overnight at $37^{\circ} \mathrm{C}$. Cells were harvested, resuspended in $25 \mathrm{ml}$ sonication buffer $(50 \mathrm{mM}$ Tris- $\mathrm{HCl}, 30$ $\mathrm{mM} \mathrm{NaCl}$, and $\mathrm{pH} \mathrm{8.0)}$ and lysed by sonication on ice. Unsoluble debris was spun down twice for $20 \mathrm{~min}$ at 12,000 rpm at 4 _C. Recombinant VHH was purified with immobilized metal ion affinity chromatography (IMAC) as previously described [25] and dialysed to PBS. Protein concentration was determined with a BCA_Protein Assay Kit (Pierce Co., Rockford, IL, USA). Isolated proteins were analysed by Western blot procedures (15\% SDS-PAGE gels). Gels were stained for protein content with either Simplyblue, according to manufacturer's 
instructions (Invitrogen, Carlsbad, CA, USA), or proteins were transferred onto PVDF membranes (Millipore Co., Bedford, MA, USA). Protein detection was subsequently performed with a HRP conjugated mouse anti-6.HIS monoclonal antibody (BD Biosciences, San Diego, CA, USA). ECL (Amersham Biosciences, Buckinghamshire, UK) was used for visualization as described by the manufacturer.

\section{Identification of recombinant strains}

To identify colonies of C. sporogenes, NCIMB 10696 and C. novyi-NT, harbouring PMTL-555$\mathrm{VHH}$, we performed colony PCR. We used primers for the $\mathrm{VHH}$, forward 50 GGGCTGCAGATGGCCGATGTGCAGCTGGT-30, and reverse 50CGCTTGCGGCCGCTGAGGAGACGGTGACCTG-30 (385 bp). Primers specific for $\mathrm{C}$. novyi flagellin (filA) gene: forward 50-AACAAATGTACAAAAAGAAATAGC-30 and reverse 50CTAATCTATTTTGGATAGCTCC-30. Primers specific for $E$. coli thymidine kinase (TK) gene: forward 50-TGATGAAAAGTAGAACAGTCG-30 and reverse 50ATCAAGACGCAGCACCATG-30 with expected fragment sizes of 305 and $770 \mathrm{bp}$. respectively. PCR fragments were resolved by agarose gel electrophoresis.

ELISA. NUNC MAXISORP (NUNC, Roskilde, Denmark) plates were absorbed O/N at 4 _C with $5 \mathrm{lg}$ per well of HIS6-purified VHH from C. novyj-NT and C. sporogenes or with control VHH (AG2, AG4) isolated from E. coli or left empty. Wells were blocked with $2 \%$ BSA in PBS/0.1\% Tween 20 (BSAT) for $2 \mathrm{~h}$ in a TERMOstar incubator (BMG LABTECH, Offenburg, Germany) shaking at 25 _C. All following incubation steps were performed under these conditions in this incubator. Next, after two washes, the wells were incubated with $5 \mathrm{lg}$ of recombinant HIF-1a fragment $E$ (aa375-455) or $C$ (aa543-605) for $2 \mathrm{~h}$ (recombinant proteins carry an N-terminal T7 and C-terminal HIS6 tag [22]). Wells were washed 8 times with PBST (PBS, 0.1\% Tween 20) and incubated with a HRP-conjugated mouse anti-T7 (1:5000, Novagen, Madison, WI, USA) in BSAT for $30 \mathrm{~min}$, and washed 7 times with PBST and 1 time with PBS, followed by staining using ImmunoPure TMB Substrate kit (Pierce) according to the manufacturer's instructions. The signal intensities were measured using an ELISA reader (BioRad, Hercules, CA, USA) at $450 \mathrm{~nm}$. Coating of the VHHs in the wells was detected with a HRP-conjugated anti-Myc antibody (Invitrogen) and rabbit anti-Llama serum (a kind gift of Dr. M. El Khattabi) in combination with HRP conjugated goat anti-rabbit IgG $(H+L)$ antibodies (Bio-Rad). 


\section{Results}

\section{Clostridial VHH expression}

To enable Clostridium-specific expression of VHH-AG2, an anti-HIF-1a VHH, [22] we modified pMTL-555 to drive $V H H$ expression from the constitutive ferrodoxin fac2 promoter. To enable secretion of $\mathrm{VHH}$ into the microenvironment, we made an N-terminal fusion of $A G 2$ with the secretion signal of eglA. To allow detection and purification of $\mathrm{VHH}$ from clostridia, we added C-terminal Myc and HIS6 epitope tags (Fig. 1). By including Sfil and BstEll restriction sites, any $\mathrm{VHH}$ cDNA can be cloned and expressed by clostridia.

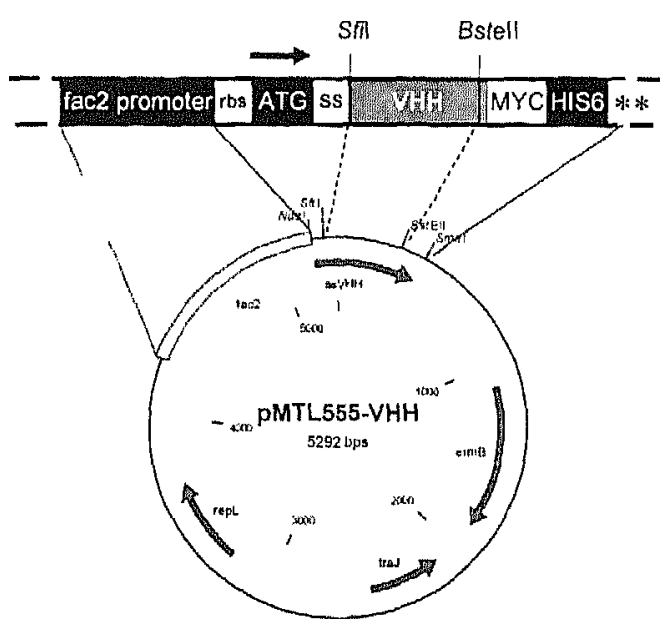

Figure 7.1. Schematic representation of the universal shuttle vector pMTL-555-VHH. Indicated are restriction sites and important motives and highlighted from the vector are the promoter, ribasomal binding site (rbs), ATG start codon, the N-terminal secretion signal (SS), VHH, and Myc and HIS6 tags followed by a double stop codon ("*).

\section{Identification of transconjugants}

Strain-specific PCR was employed to ascertain that upon transfer of the PMTL-555-VHH construct the obtained erythromycin-resistant colonies of C. sporogenes NCIMB 10696 and C. novyi-NT were pure. Especially, contamination by the E. coli donor strain used for transconjugation should be avoided, as the fac2 promoter is also active in E. coli. Both Clostridium strains were negative for the E. coli-specific TK gene and positive for presence of the shuttle plasmid $(\mathrm{VHH})$. To ensure C. novyi-NT-specific transformation, we performed PCR amplification for the filA gene (Fig. 2). Single pure colonies from both $\mathrm{C}$. sporogenes and $\mathrm{C}$. novyi-NT were expanded under anaerobic conditions and used throughout this study. These results demonstrate for the first time transformation of bacteriolytic $\mathrm{C}$. novyi-NT with heterologous gene sequences. 


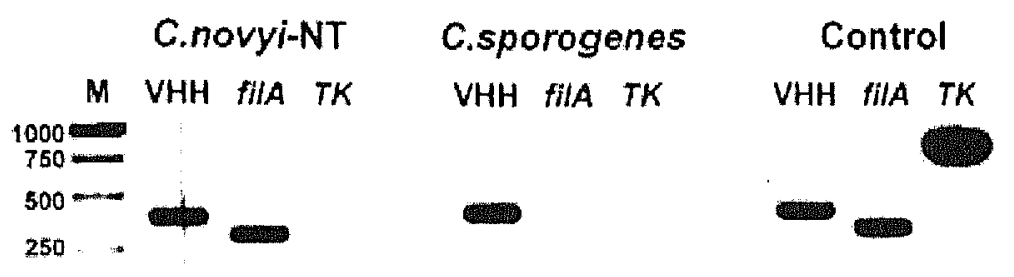

Figure 7.2. Characterization of Clostridium conjugates. Single colony PCR with primers specific for the VHH-AG2. filA, and TK genes for both C. novyi-NT and C. sporogenes. Both strains carry the PMTL-555-VHH shuttle vector and are free of the $E$. coli donor strain shown by absence of TK amplification. The filA gene is specific for C. novyi-NT.

Isolation and characterization of VHH from Clostridium strains

Lysates from AG2 containing $C$. sporogenes and $C$. novyi-NT grown under anaerobic conditions were analysed for the presence of the VHH by immunoblotting with HIS and Myc antibodies. In both strains two distinct bands could be detected at 18 and $16 \mathrm{kDa}$, respectively. The predicted

unprocessed $\mathrm{VHH}$ form with the signal peptide (ssVHH) has a calculated molecular weight of $18 \mathrm{kDa}$ and the cleaved form of the $\mathrm{VHH}$ has a mass of $16 \mathrm{kDa}$. Purification of HIS6 tagged VHH directly from whole Clostridium lysate, yielded $130 \mathrm{lg}$ of protein per liter culture. Purified fractions were analysed and visualized by PAGE. Both 16 and $18 \mathrm{kDa}$ forms could be isolated and confirmed by Simply-blue staining and HIS immunoblot. Although affinity purified isolated fractions from both strains were not $100 \%$ pure, there was significant enrichment of $\mathrm{VHH}$ in both cases (Fig. 3). 


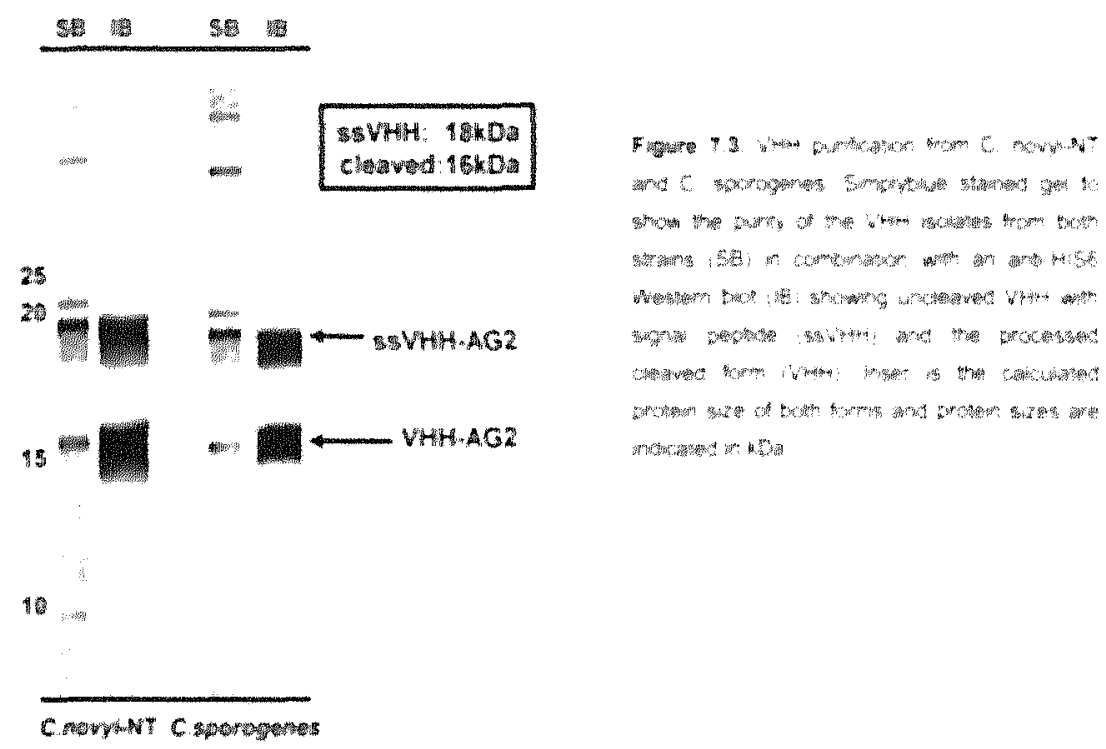

VHH produced by Chostridium are functional

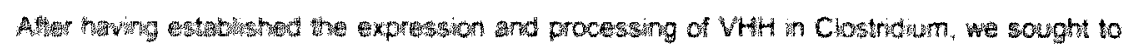

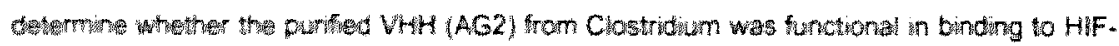
13. To to so we conducted ELISA with the MF-1a antigen fragment C (HIF543-605) and a control HF-1a hragment $E$ (HIF 375-455). VHH-AG4 specific for fragment $E$ isclated from $E$

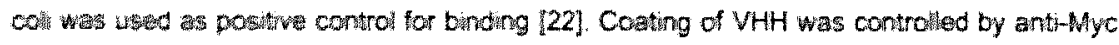
and wh ant-Lama antibodics (data not shown. AG2 isolated from both C. nowy-NT and C sporogenes spectucatury bound to HIF-1a tragment $C$ and not $E$ (Fig. 4). We could not delemine which of the VHH isotorms (cleaved or undeaved) were binding. However, we determined that the undeawed form, $5 \mathrm{VHHH}$, is asso functional when isolated from $\mathrm{E}$. con, where a not clawed (data not shown) 


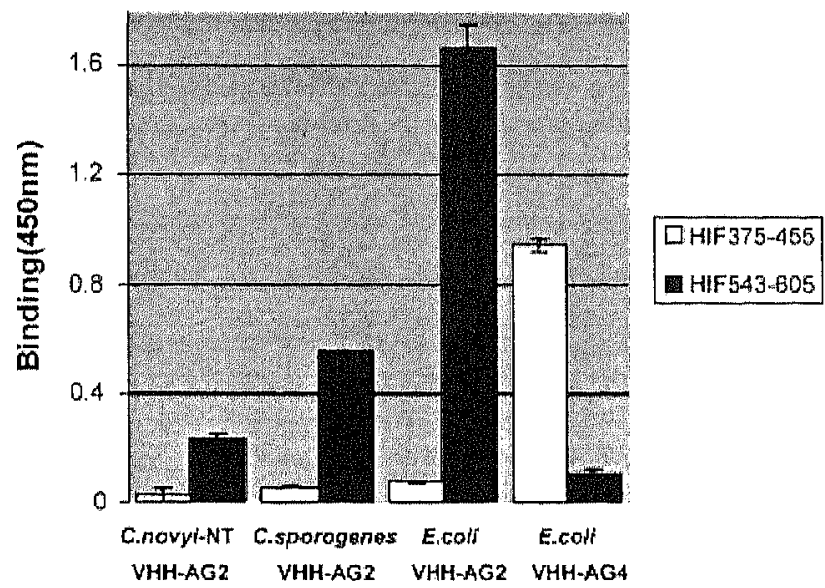

Discussion
Figure 7.4. HIF-1a antibodies produced by clostridia are functional. Isolated VHH-AG2 from C. novyi-NT, $C$. sporogenes, and $E$. coli bind specifically T7-tagged HIF543605 (black bars) and not HIF375455 (open bars). Control VHHAG4 binds HIF375-455 fragment only demonstrating speciflcity. Binding is expressed as absorbance at $450 \mathrm{~nm}$ and corrected for amount of $\mathrm{VHH}$ plated and background signals. Data represent the means \pm standard deviation of three experiments.

Here, we demonstrate for the first time heterologous gene transfer into the obligate anaerobic C. novyi-NT strain. We show that HIF-1a targeting VHH antibodies isolated from clostridia retained their binding capacity and specificity for the HIF-1a antigen. With the current methodology we demonstrate cleavage of the anti-HIF-1a VHH, suggesting that $\mathrm{VHH}$ is being secreted. For therapeutic use several improvements can be envisaged. First, the high AT content of C. novyi-NT [26] suggests that molecular engineering of VHH codon usage that is GC rich may improve translation of GC rich VHH. In addition, with the complete C. novyi-NT genome sequence available, new promoters may be explored to obtain high-level expression of therapeutic antibodies in Clostridium. The ease of $\mathrm{VHH}$ antibody design and selection using phage display makes this an attractive strategy to explore antibody-based therapeutics. We envisage that expression and secretion of antagonistic $\mathrm{VHH}$ targeting mutant cell surface receptors may further enhance CDAT approaches [21]. Altogether, this study demonstrates the feasibility of Clostridium-based antibody therapy against HIF-1a, the key regulator of the hypoxic response, by showing successful conjugation, expression, and functionality of therapeutic antibodies. Since the secreted antibodies may target the hypoxic rim of tumor cells surrounding the necrotic areas, which provides a haven for Clostridium species, this may have an additive or synergistic therapeutic effect. We expect that further improvements in $\mathrm{VHH}$ antibody design and expression by anaerobic bacteria may lead to novel approaches in cancer treatment that, when used in combination with existing therapies targeting aerobic tumor growth, may lead to improved clinical outcome. 


\section{Acknowledgments}

The authors acknowledge the members of the Pathology Department and Dr. Shibin Zhou at Johns Hopkins University School of Medicine for his helpful discussion and suggestions and providing us with primer sequences. This work was supported by The Dutch Cancer Society, Grant No.: UU2003-2825, and in part by the 2nd AEGON international Scholarship in Oncology.

\section{References}

1. A.L. Harris, Hypoxia-a key regulatory factor in tumour growth, Nat. Rev. Cancer 2 (2002) 38-47.

2. J. Pouyssegur, F. Dayan, N.M. Mazure, Hypoxia signalling in cancer and approaches to enforce tumour regression, Nature 441 (2006) 437-443.

3. R. Bos, P. van der Groep, A.E. Greijer, A. Shvarts, S. Meijer, H.M. Pinedo, G.L. Semenza, P.J. van Diest, E. van der Wall, Levels of hypoxia-inducible factor-1alpha independently predict prognosis in patients with lymph node negative breast carcinoma, Cancer 97 (2003) 1573-1581.

4. U. Woelfle, J. Cloos, G. Sauter, L. Riethdorf, F. Janicke, P. Van Diest, R. Brakenhoff, $\mathrm{K}$. Pantel, Molecular signature associated with bone marrow micrometastasis in human breast cancer, Cancer Res. 63 (2003) 5679-5684.

5. G.U. Dachs, A.V. Patterson, J.D. Firth, P.J. Ratcliffe, K.M. Townsend, I.J. Stratford, A.L. Harris, Targeting gene expression to hypoxic tumor cells, Nat. Med. 3 (1997) $515-520$.

6. J.M. Brown, W.R. Wilson, Exploiting tumour hypoxia in cancer treatment, Nat. Rev. Cancer 4 (2004) 437-447.

7. G.L. Semenza, HIF-1, O(2), and the 3 PHDs; how animal cells signal hypoxia to the nucleus, Cell 107 (2001) 1-3.

8. R. Bos, H. Zhong, C.F. Hanrahan, E.C. Mommers, G.L. Semenza, H.M. Pinedo, M.D. Abeloff, J.W. Simons, P.J. van Diest, E. van der Wall, Levels of hypoxiainducible factor-1 alpha during breast carcinogenesis, J. Nall. Cancer Inst. 93 (2001) 309-314.

9. R.A. Malmgren, C.C. Flanigan, Localization of the vegetative form of Clostridium tetani in mouse tumors following intravenous spore administration, Cancer Res. 15 (1955) 473-478.

10. J.R. Moese, G. Moese, Oncolysis by clostridia. I. Activity Of Clostridium butyricum (M-55) and other nonpathogenic clostridia against the ehrlich carcinoma, Cancer Res. 24 (1964) 212-216.

11. R. Carey, J. Holland, E. Whang, E. Neter, B. Bryant, Clostridial oncolysis in man, Eur. J. Cancer 3 (1967) 37-46.

12. L. Van Mellaert, S. Barbe, J. Anne, Clostridium spores as antitumour agents, Trends Microbiol. 14 (2006) 190-196.

13. S.C. Liu, N.P. Minton, A.J. Giaccia, J.M. Brown, Anticancer efficacy of systemically delivered anaerobic bacteria as gene therapy vectors targeting tumor hypoxia/necrosis, Gene Ther. 9 (2002) 291-296.

14. J. Theys, O. Pennington, L. Dubois, G. Anlezark, T. Vaughan, A. Mengesha, W. Landuyt, J. Anne, P.J. Burke, P. Durre, B.G. Wouters, N.P. Minton, P. Lambin, Repeated cycles of Clostridium-directed enzyme prodrug therapy result in sustained antitumour effects in vivo, Br. J. Cancer 95 (2006) 1212-1219.

15. L.H. Dang, C. Bettegowda, D.L. Huso, K.W. Kinzler, B. Vogelstein, Combination bacteriolytic therapy for the treatment of experimental tumors, Proc. Natl. Acad. Sci. USA 98 (2001) 15155-15160.

16. C. Bettegowda, L.H. Dang, R. Abrams, D.L. Huso, L. Dillehay, I. Cheong, N. Agrawal, S. Borzillary, J.M. McCaffery, E.L. Watson, K.S. Lin, F. Bunz, K. Baidoo, M.G. Pomper, K.W. Kinzler, B. Vogelstein, S. Zhou, Overcoming the hypoxic barrier to radiation therapy with anaerobic bacteria, Proc. Natl. Acad. Sci. USA 100 (2003) 15083-15088. 
17. L.H. Dang, C. Bettegowda, N. Agrawal, I. Cheong, D. Huso, P. Frost, F. Loganzo, L. Greenberger, J. Barkoczy, G.R. Pettit, A.B. Smith 3rd, H. Gurulingappa, S. Khan, G. Parmigiani, K.W. Kinzler, S. Zhou, B. Vogelstein, Targeting vascular and avascular compartments of tumors with C. novyi-NT and anti-microtubule agents, Cancer Biol. Ther. 3 (2004) 326-337.

18. C. Hamers-Casterman, T. Atarhouch, S. Muyldermans, G. Robinson, C. Hamers, E.B. Songa, N. Bendahman, R. Hamers, Naturally occurring antibodies devoid of light chains, Nature 363 (1993) 446-448.

19. P. Verheesen, A. Roussis, H.J. de Haard, A.J. Groot, J.C. Stam, J.T. den Dunnen R.R. Frants, A.J. Verkleij, C. Theo Verrips, S.M. van der Maarel, Reliable and controllable antibody fragment selections from Camelid non-immune libraries for target validation, Biochim. Biophys. Acta 1764 (2006) 1307-1319.

20. U. Rothbauer, K. Zolghadr, S. Tillib, D. Nowak, L. Schermelleh, A. Gahl, N. Backmann, K. Conrath, S. Muyldermans, M.C. Cardoso, H. Leonhardt, Targeting and tracing antigens in live cells with fluorescent nanobodies, Nat. Methods 3 (2006) 887889 .

21. R.C. Roovers, T. Laeremans, L. Huang, S. De Taeye, A.J. Verkleij, H. Revets, H.J. de Haard, P.M. van Bergen En Henegouwen, Efficient inhibition of EGFR signalling and of tumour growth by antagonistic anti-EGFR nanobodies, Cancer Immunol. Immunother. (2006) 303-317.

22. A.J. Groot, P. Verheesen, E.J. Westerlaken, E.H. Gort, P. van der Groep, N. Bovenschen, E. van der Wall, P.J. van Diest, A. Shvarts, Identification by phage display of singledomain antibody fragments specific for the ODD domain in hypoxia-inducible factor 1alpha, Lab. Invest. 86 (2006) 345-356.

23. S. Barbe, L. Van Mellaert, J. Theys, N. Geukens, E. Lammertyn, P.Lambin, J. Anne, Secretory production of biologically active rat interleukin-2 by Clostridium acetobutylicum DSM792 as a tool for anti-tumor treatment, FEMS Microbiol. Lett. 246 (2005) 67-73.

24. J. Theys, S. Barbe, W. Landuyt, S. Nuyts, L. Van Mellaert, B. Wouters, J. Anne, P. Lambin, Tumor-specific gene delivery using genetically engineered bacteria, Curr. Gene Ther. 3 (2003) 207-221.

25. S. van Koningsbruggen, H. de Haard, P. de Kievit, R.W. Dirks, A. van Remoortere, A.J. Groot, B.G. van Engelen, J.T. den Dunnen, C.T. Verrips, R.R. Frants, S.M. van der Maarel, Llama-derived phage display antibodies in the dissection of the human disease oculopharyngeal muscular dystrophy, J. Immunol. Methods 279 (2003) 149161.

26. C. Bettegowda, X. Huang, J. Lin, I. Cheong, M. Kohli, S.A. Szabo, X. Zhang, L.A. Diaz Jr., V.E. Velculescu, G. Parmigiani, K.W. Kinzler, B. Vogelstein, S. Zhou, The genome and transcriptomes of the anti-tumor agent Clostridium novyi-NT, Nat. Blotechnol. 24 (2006) 1573-1580. 
CHAPTER 8

GENERAL DISCUSSION AND FUTURE PERSPECTIVES 


\section{GENERAL DISCUSSION AND FUTURE PERSPECTIVES}

Of the various ways to treat cancer today, chemotherapy and radiotherapy are the most common options for patients. However, these conventional treatment options for advanced or metastatic tumors are limited $[1,2]$. On the other hand, gene therapy represents a potential new modality for the treatment of cancer [3]. Although, technical problems still prevent the full exploitation of the approach. The major hurdle remains the specific transfer of the gene encoding the therapeutic protein to the tumor site. The key to a successful gene therapy is the vector system. Various vectors have been developed with unique features, including viral and non-viral based therapy systems [4-6] with the replication-competent oncolytic viral vectors as the most promising [7]. However, due to the complex nature of cancers, these vectors suffer from several deficiencies. Firstly, the majority of vectors currently in use require intratumoral injection to elicit a therapeutic effect. While this might be useful in some cases, it has limited applicability and, in fact, far from ideal as many tumors are inaccessible and treating distant metastasis become difficult. Secondly, most vectors do not have the capacity to efficiently enter and kill every tumor cell. Consequently, a proportion of the tumor mass is left unaffected, from which tumor regrowth could occur. It is thus, fair to say that cancer gene therapy has yet to realize its full potential. Of all cancer diagnosed, $90 \%$ of these are solid tumors. Recent understanding of the unique pathophysiology of solid tumors has shed light on the disappointing nature of these new therapies and now demands rational and novel design of vectors. All solid tumors undergo angiogenesis that results in biological changes and adaptive metabolisms with the formation of defective vessels, appearance of hypoxic/necrotic areas, and emergency of hetereneous tumor cell pulations [8]. These poorly vascularized tumor areas are a major hindrance in cancer gene therapy as they inhibit the effective delivery of therapeutics and hence, limit treatment efficacy [9-11]. The presence of hypoxia in solid tumors on the other hand, may also be an advantage and is potentially exploitable $[12,13]$. This tumor microenvironment provides a haven for specific anaerobic and facultative anaerobes. In animals, these bacteria target and multiply selectively within the hypoxic/necrotic area in tumors. In some cases the microbes also exhibited inherent tumor suppressing activities [14-17].

In recent years, a number of novel approaches in developing oncopathic bacteria have been described, including attenuated Salmonella [18]. Although attenuated Salmonella possess properties of targeting multiple tumors and selective replication within tumors, the mechanisms contributing to its initial infection to tumors, followed by preferential accumulation to high levels relative to normal tissues, are not completely understood.

We used attenuated $S$. typhimurium recombinant for cytosine deaminase (TAPET-CD) for our first study. With the aim to investigate the success of the TAPET-CD/5-FC cancer therapy system, we introduced real time non-invasive MRS to monitor the efficacy of treatment on an individual basis. The study clearly demonstrated the dynamic 5-FC/5-FU conversion In the human colorectal HCT116 tumor xenograft following systemic injection of TAPET-CD. 5-FC 
could be monitored using in wiw "F-MRS. Interestingly. Whth the study populaton. a ciear distinction could be made between responders (showng antitumon uffect upon tratmant) and non-responders (showing no anti-tumor effect upon treatmemt) The fact that 5-FC/5-FU conversion occurred when adding fresh growth media to a tumct extract of non-fesponders in the absence of variation in morphological phistcogical heterogenety, level of bacterial colonzation, and CD protein expression among tumors, indwate that a necessary yet unidentified tumoral factor in a subgroup of tumors may play a prvotat role for efficitun $C D$ enzymatic activity. As such, this study clearly demonstrated the advantage for incorporating a real-tme non-invasive imaging method such as "F-MRS a tool for mividualized patuent treatment as it helps to predict antitumor efficacy when using TAFET-CD/5.FC therapy. This study could be viewed in a wide range of an enzyme based therapeutics such that possible tumoral factors should be considered while assessing treatment out come.

In parallel to maximizing therapeutic efficacy, minimizing undesired systernic side effect is of major importance in any treatment modahty. Therefore, specificity of a delivery vector is a key for better treatment outcome. So far studies that used salmonella as a delivery vector employed a constitutive promoter to drive the therapeutic gene of interest (19). However. since attenuated Salmonella vectors also colonize normal tissues (abbeit to a lesser extent as tumor tissue) untargeted cytotoxic therapeutic gene expression, using such promoters could potentially lead to undesired side effects. Therefore, when using salmonella for therapeutic purposes, strategies which allow precise control of gene transcription are likely to play a crucial role in the future pre-cinical and clinical development of cancer gene therapy, in this context the molecular differences between tumor and normal cells to yield therapeutic benefits can be potentially exploitabie.

The abjective of the work described in chapters 4 and 5 was to combine the salmonella mediated gene transfer with controlled gene expression via inducible promoter systems thereby increasing the specificity of the approach. We first assessed the use of hypoxia inducible promoter to drive reporter gene expression. All studies published so far concerning the use of hypoxia induced promaters to control gene expression, were based on eukaryotic promoters [20]. Analogous to the eukaryotic context in which the hypoxia response element (HRE) is the recognition site for the hypoxia-inducible factor-1 (HIF-1), an oxygen-responsive global transcription factor (FNR) induces the expression of a number of bacterial genes during anaerobic growth following binding to a consensus FNR recognition site at the target genes [21]. We thus reasoned that FNR responsive promoter would be an attractive candidate to exploit for restricting therapeutic gene expression specifically to the tumor. in this study, we demonstrate that attenuated Samonella can be genetically engineered to spatially control gene expression using a hypoxia-inducible promoter. A -40 -fold increase in reporter gene activity was observed using HIF-1 promoter within three hours of hypoxic treatment. Genetic engineering of the regulatory sequence allowed fine tuning of gene induction up to 200-fold. We further demonstrated that HIP-1 can drive hypoxia mediated gene expression in bacteria which have colonized human tumor xenografts in mouse model. Expression of reporter genes 
under the control of HIP-1 demonstrated a 15-fold increase relative to a constitutive promoter when tumors were made hypoxic. Consistent with the necessity of hypoxia for activation of HIP-1, our in vivo data confined the HIP-1 driven signal to the tumor. Indeed, no signals in normai tissues could be detected when the reporter was driven off by the hypoxia-inducible promoter. Moreover, we have shown that engineering of the HIP-1 promoter can be used to maximize the inducibility and/or vary the absolute gene expression levels that may be necessary to achieve optimal expression levels of the therapeutic gene. In proposing the use of highly regulated promoters in Salmonella vectors so that therapeutic gene expression is minimal in normal tissues, the ultimate success of each proposed promoter depends on a selected promoter and therapeutic protein. For instance genes that are very toxic needs to be driven with promoter that are less leaky (but highly induced) and for genes where their expression needed to be in a very high level, a promoter with higher level of absolute gene expression could be used. In that context the use of proposed promoter rests on the type of therapeutic genes employed.

We subsequently sought to further increase the applicability of an inducible gene delivery system in salmonella since inducible promoters would be tools to reduce expression of bacteria outside the tumor, and thus reduce side effects. We therefore, further explored the gene induction profile of the whole genome of attenuated salmonella following either external or internal stimuli and performed a microarray to determine if we could select highly induced genes differentially expressed following hypoxia or radiation. Interestingly, we found an extensive list of genes that were induced following hypoxia exposure as well as genes that were upregulated after irradiating saimonella at low doses. Reporter assays using promoters of selected genes from these arrays yielded, however, lower than expected induction levels. One of the possible reasons that might account for this discrepancy that the reporter system is plasmid-based, while the mlcro-array data originate from endogenous, genomic signals. Furthermore, some crucial elements (such as enhancer binding sites) needed for the transcripts could have lost while constructing transcriptional fusions. In any case, the microarray analysis revealed an interesting and extensive set of data, and promoters of the most highly induced genes definitely have promise when they can be used to drive therapeutic gene expression form a single copy integrated into the Salmonella genome. Unfortunately, standard procedures to successfully insert recombinant constructs into the Salmonella genome are currently not available. We are therefore developing novel approaches to accomplish this task, which will eventually allow the proper evaluation of the applicability of the selected hypoxia- and radiation-inducible promoters to drive therapeutic gene expression.

In addition to promoters that are induced upon application or external stimuli such as hypoxia or radiation, we investigated whether we could detect Salmonella genes that were only upregulated within the tumor and not in normal tissues. If we could find such genes, not only would the promoters be useful to drive gene expression, but Identification of such genes might also help us to understand the mechanisms that explain the preferential tumor 
accumulation of attenuated Salmonella strains. Indeed, although it is well established that avirulent mutants of Salmonella prefer tumors over normal tissues at ratios that vary between $250: 1$ and $10,000: 1$, the underlying mechanisms are poorly understood. so far, it has been speculated that it is predominantly the hypoxic and relatively acidic environment compared with normal tissues that might explain the tumor specific colonization phenomenon, but obviously, other mechanisms might be involved. Interestingly, it is known that the gene expression profile of bacteria changes during host invasion [22]. We did find several transcripts that were preferentially expressed in human tumors in nude mice. The obvious next step will be to isolate and identify these genes. It can be speculated that at least part of the active genes within the tumors are hypoxia-regulated. It will be interesting to see, however, whether other genes can be identified as well. Overall, our work described in chapter 4 to 5 , indicate that new promoter systems that can be induced by either external or internal stimuli have high potential within attenuated Salmonella delivery vectors. Most importantly, application of such promoter system allows the delivery of a therapy that can be highly controlled in both time and space.

The second part of this thesis described the use of strictly anaerobic bacteria to deliver therapeutic proteins. Unlike salmonella, clostridium $s p$. are obligate anaerobic, spore-forming bacteria. In the past few years, several Clostridium species have been studied for anti-tumor potential. Since the introduction of the idea to use non-pathogenic clostridia as protein delivery vehicles by Martin Brown about 15 years ago [23], C. sporogenes has generally been recognized as the strain with the best tumor colonizing capacities. More recently, Vogelstein and colleagues developed another strain with similar tumor colonizing properties. This novel strain, C. novyi-NT, was shown to germinate within the avascular regions of tumors and destroy the surrounding tumor cells in mice $[24,25]$. Very recently, the same group showed that treatment of mice bearing large tumors with $C$. novyi-NT plus a single dose of liposomal doxorubicin led to eradication of the tumors. C. sporogenes have also been extensively studied in our lab and proven for its enhanced tumor colonizing properties $[26,27]$. However, for a long time, both strains could not be genetically engineered due to the lack of reproducible transformation methods. As such, the superior tumor colonization properties of both strains could not be fully exploited. Therefore, with the aim to substantially improve the use of clostridia in cancer therapy, we firstly sought to develop a method that allowed efficient gene transfer. Using this method, we were the first to endow both strains with heterologouse proteins. The existence of a reliable and efficient transformation method for these strains can be considered a real breakthrough, as it allowed the subsequent evaluation of their full therapeutic potential. Firstly, we sought to test the efficacy of $C$. sporogenes, recombinant for nitroreductase. Since the ultimate goal of our research is to test the potential of clostridia in a clinical trial, we delivered therapy with our recombinant bacteria in a way we would eventually like to treat cancer patients. Following repeated cycles of therapy, we could observe a sustained anti-tumor effect. The fact that repeated administrations are possible, is probably 
due to the lack of immunogenicity of the clostridial spores $[28,29]$ and the immune privileged nature of the hypoxic/necrotic region of solid tumors.

In our second approach in using clostridial vectors, we proposed to use both $C$. sporogenes and C. novyi-NT to deliver a therapeutic antibody to hypoxic tumors. As described in chapter 7, we explored the potential of the clostridial-mediated delivery approach for immunotherapy: clostridum-directed antibody therapy (CDAT). The underlying aim in this research was to combine the specificity of an antibody targeted against a key player within the hypoxic response of cells with the efficacy of Clostridium to target hypoxic tumors. To proof the principle of this approach, we chose anti-HIF-1alpha VHH-AG2, since it is well known that HIF-Talpha is highly expressed in hypoxic tumors. In this study, for the first time, we demonstrated the production of a recombinant single-domain $\mathrm{VHH}$ antibody fragment against HIF-1a in both clostridial strains with superior tumor colonizing properties. We showed that HIF-1a targeting $\mathrm{VHH}$ antibodies isolated from clostridia retained their binding capacity and specificity. Furthermore, $\mathrm{VHH}$ is being secreted evidenced by the presence of its cleaved fragment. Unfortunately, significant amounts could not be detected in culture medium, indicating the necessity for further optimization. Obviously, higher secreted VHH levels might be obtained by improving the secretion of the therapeutic protein by using strong promoter, signal peptide and by optimlzing the codon usage. In that context, the promoter and secretion signal sequence of the recently identified lipase gene from $C$. novyi-NT, would be a good candidate [22]. We suggest combining the latter with the use of $\mathrm{VHH}$ with nanomolar affinity, displaying strong therapeutic effects preferentially on cell surface markers such as EGFR [30], in order to obtain significant anti-tumor effects. Over all, the ease of VHH antibody design and selection using phage display makes this an attractive strategy to explore antibody-based therapeutics. We expect that further improvements in VHH antibody design and expression by clostridia may lead to novel approaches in cancer treatment that, when used in combination with existing therapies that target aerobic rim of the tumor, may lead to further improved clinical outcome. Altogether, this study clearly demonstrated the feasibility of Clostridium-based antibody therapy which can be extended to wide potential target antigens in cancer therapy.

The antibody directed treatment strategy represents one of a number of approaches, designed to improve the effectiveness and tumor cell specificity of cancer treatment, through the use of monoclonal antibodies directed against a tumor specific antigen. CDAT however, serve as a dual approach - enhanced specificity and increased tumoral concentration of therapeutic antibody (as the protein is synthesized locally with in clostridial host) leading to better therapeutic effects. This approach could also circumvent the problem encountered when using antibody alone such as systemic side effects and a rapid clearance from the circulation.

In comparison, one of the advantages of clostridium as a cancer therapeutic is that they are an obligate anaerobe that germinates only in hypoxic regions of tumors, and cannot target nonhypoxic areas. Another advantage of clostridium is that they must be administered as 
spores, which requires that the bacteria germinate only in tumors that are sufficiently hypoxic. On the contrary, facultative anaerobes, such as $S$. typhimurium do not solely target hypoxic regions and are attracted to smail molecules released by quiescent and apoptotic cancer cells, which are present in many small tumors [31,32]. Facultative anaerobes can be administered as active motile bacteria that can penetrate tumor tissue in the process of localizing to quiescent and apoptotic tumor regions. As the selectivity of salmonella for tumor tissue is based on their auxotrophic nature, they can be considered to be less tumor-specific compared to Clostridium. This difference implies that the targeting mechanisms of facultative anaerobes can be tuned using inducible system, whereas the mechanism of obligate anaerobe targeting is fixed. These different targeting mechanisms are complementary, suggesting that obligate and facultative anaerobic bacterial cancer therapies should be developed in parallel. It is likely that each bacterial genus will be better suited for a different tumor type and location. A facultative anaerobe, such as S. typhimurium, might be used to prevent metastases, whereas clostridium might be deployed to eradicate large, untreatable and inoperable tumors. Overall, engineered bacteria have great promise as cancer therapeutics. 


\section{REFERENCE:}

1. Marples, B., Greco, O., Joiner, M.C. and Scott, S.D. (2002) Molecular approaches to chemo-radiotherapy. Eur J Cancer, 38, 231-9.

2. Marples, B., Greco, O., Joiner, M.C. and Scott, S.D. (2003) Radiogenetic therapy: strategies to overcome tumor resistance. Curr Pharm Des, 9, 2105-12.

3. Hingorani, M., White, C.L., Agrawal, V.K. Vidal, L., Melcher, A. and Harrington, K.J. (2007) Combining radiation and cancer gene therapy: a potential marriage of physical and biological targeting? Curr Cancer Drug Targets, 7, 389-409.

4. Seth, P. (2005) Vector-mediated cancer gene therapy: an overview. Cancer Biol Ther, 4, 512-7.

5. Woo, C.Y., Osada, T., Clay, T.M., Lyerly, H.K. and Morse, M.A. (2006) Recent clinical progress in virus-based therapies for cancer. Expert Opin Biol Ther, 6, 1123-34.

6. Wolff, J., Lewis, D.L., Herweijer, H., Hegge, J. and Hagstrom, J. (2005) Non-viral approaches for gene transfer. Acta Myol, 24, 202-8.

7. Tai, C.K. and Kasahara, N. (2008) Replication-competent retrovirus vectors for cancer gene therapy. Front Biosci, 13, 3083-95.

8. Vaupel, P. and Harrison, L. (2004) Tumor hypoxia: causative factors, compensatory mechanisms, and cellular response. Oncologist, 9 Suppl 5, 4-9.

9. Hay, J.G. (2005) The potential impact of hypoxia on the success of oncolytic virotherapy. Curr Opin Mol Ther, 7, 353-8.

10. Pipiya, T., Sauthoff, H., Huang, Y.Q., Chang, B., Cheng, J., Heitner, S., Chen, S., Rom, W.N. and Hay, J.G. (2005) Hypoxia reduces adenoviral replication in cancer cells by downregulation of viral protein expression. Gene Ther, 12, 911-7.

11. Durand, R.E. (1994) The influence of microenvironmental factors during cancer therapy. In Vivo, 8, 691-702.

12. Greco, O., Marples, B., Joiner, M.C. and Scott, S.D. (2003) How to overcome (and exploit) tumor hypoxia for targeted gene therapy. J Cell Physiol, 197, 312-25.

13. Kizaka-Kondoh, S., Inoue, M., Harada, H. and Hiraoka, M. (2003) Tumor hypoxia: a target for selective cancer therapy. Cancer Sci, 94, 1021-8.

14. Agrawal, N., Bettegowda, C., Cheong, I., Geschwind, J.F., Drake, C.G., Hipkiss, E.L., Tatsumi, M., Dang, L.H., Diaz, L.A., Jr., Pomper, M., Abusedera, M., Wahl, R.L., Kinzler, K.W., Zhou, S., Huso, D.L. and Vogelstein, B. (2004) Bacteriolytic therapy can generate a potent immune response against experimental tumors. Proc Nat Acad Sci U S A, 101, 15172-7.

15. Theys, J., Landuyt, A.W., Nuyts, S., Van Mellaert, L., Lambin, P. and Anne, J. (2001) Clostridium as a tumor-specific delivery system of therapeutic proteins. Cancer Detect Prev, 25, 548-57.

16. Pawelek, J.M., Low, K.B. and Bermudes, D. (1997) Tumor-targeted Salmonella as a novel anticancer vector. Cancer Res, 57, 4537-44

17. Van Mellaert, L., Barbe, S. and Anne, J. (2006) Clostridium spores as anti-tumour agents. Trends Microbiol, 14, 190-6.

18. Lee, C.H., Wu, C.L. and Shiau, A.L. (2005) Systemic administration of attenuated Salmonella choleraesuis carrying thrombospondin-1 gene leads to tumor-specific transgene expression, delayed tumor growth and prolonged survival in the murine melanoma model. Cancer Gene Ther, 12, 175-84.

19. Tjuvajev, J., Blasberg, R., Luo, X., Zheng, L.M., King, I. and Bermudes, D. (2001) Salmonella-based tumor-targeted cancer therapy: tumor amplified protein expression therapy (TAPET) for diagnostic imaging. $J$ Control Release, 74, 313-5.

20. Shibata, T., Giaccia, A.J. and Brown, J.M. (2000) Development of a hypoxiaresponsive vector for tumor-specific gene therapy. Gene Ther, 7, 493-8.

21. Kiley, P.J. and Beinert, H. (1998) Oxygen sensing by the global regulator, FNR: the role of the iron-sulfur cluster. FEMS Microbiol Rev, 22, 341-52.

22. Bettegowda, C., Huang, $X$., Lin, J., Cheong, I., Kohli, M., Szabo, S.A., Zhang, $X$ Diaz, L.A., Jr., Velculescu, V.E., Parmigiani, G., Kinzler, K.W., Vogelstein, B. and Zhou, S. (2006) The genome and transcriptomes of the anti-tumor agent Clostridium novyi-NT. Nat Biotechnol, 24, 1573-80.

23. Minton, N.P., Mauchline, M.L., Lemmon, M.J., Brehm, J.K., Fox, M., Michael, N.P. Giaccia, A. and Brown, J.M. (1995) Chemotherapeutic tumour targeting using clostridial spores. FEMS Microbiol Rev, 17, 357-64. 
24. Dang, L.H., Bettegowda, C., Huso, D.L., Kinzler, K.W. and Vogelstein, B. (2001) Combination bacteriolytic therapy for the treatment of experimental tumors. Proc Natl Acad SciU S A, 98, 15155-60.

25. Dang, L.H., Bettegowda, C., Agrawal, N., Cheong, I., Huso, D., Frost, P., Loganzo, F., Greenberger, L., Barkoczy, J., Pettit, G.R., Smith, A.B., 3rd, Gurulingappa, H., Khan, S., Parmigiani, G., Kinzler, K.W., Zhou, S. and Vogelstein, B. (2004) Targeting vascular and avascular compartments of tumors with $C$. novyi-NT and antimicrotubule agents. Cancer Biol Ther, 3, 326-37.

26. Theys, J., Landuyt, W., Nuyts, S., Van Mellaert, L., van Oosterom, A., Lambin, P. and Anne, J. (2001) Specific targeting of cytosine deaminase to solid tumors by engineered Clostridium acetobutylicum. Cancer Gene Ther, 8, 294-7.

27. Lambin, P., Theys, J., Landuyt, W., Rijken, P., van der Kogel, A., van der Schueren, E., Hodgkiss, R., Fowler, J., Nuyts, S., de Bruijn, E., Van Mellaert, L. and Anne, J. (1998) Colonisation of Clostridium in the body is restricted to hypoxic and necrotic areas of tumours. Anaerobe, 4, 183-8.

28. Theys, J., Landuyt, W., Nuyts, S., Van Mellaert, L., Bosmans, E., Rijnders, A., Van Den Bogaert, W., van Oosterom, A., Anne, J. and Lambin, P. (2001) Improvement of Clostridium tumour targeting vectors evaluated in rat rhabdomyosarcomas. FEMS Immunol Med Microbiol, 30, 37-41.

29. Gericke, D., Dietzel, F., Konig, W., Ruster, I. and Schumacher, L. (1979) Further progress with oncolysis due to apathogenic clostridia. Zentralb/ Bakteriol [Orig A], $243,102-12$.

30. Omidfar, K., Rasaee, M.J., Modjtahedi, H., Forouzandeh, M., Taghikhani, M. and Golmakani, N. (2004) Production of a novel camel single-domain antibody specific for the type III mutant EGFR. Tumour Biol, 25, 296-305.

31. Kasinskas, R.W. and Forbes, N.S. (2006) Salmonella typhimurium specifically chemotax and proliferate in heterogeneous tumor tissue in vitro. Biotechnol Bioeng, $94,710-21$.

32. Kasinskas, R.W. and Forbes, N.S. (2007) Salmonella typhimurium lacking ribose chemoreceptors localize in tumor quiescence and induce apoptosis. Cancer Res, 67, 3201-9. 


\section{Samenvatting}

Ondanks de vooruitgang die wordt gemaakt in de ontwikkeling van nieuwe medicijnen en ondanks verbeterde bestralingstherapieën, kan worden vastgesteld dat de effectiviteit van deze conventionele behandelingswijzen voor tumorcontrole door diverse fatoren wordt gelimiteerd. Dat heeft geleid tot interesse voor en ontwikkeling van alternatieve strategieën in kankertherapie, zoals het gebruik van bacteriën die selectief tumorcellen zouden kunnen vernietigen. Het gebruik van prokaryote vectoren als selectieve kankerbehandeling is een relatief nieuw onderzoeksgebied, en de klinische effectiviteit ervan moet nog worden aangetoond. De specificiteit van de vectoren is gebaseerd op de unieke fysiologie van vaste tumoren, die vaak gekarakteriseerd wordt door de aanwezigheid van hypoxie en necrose. Er is voor verschillende niet-pathogene prokaryote stammen aangetoond dat ze na systemische toediening selectief in deze hypoxisch/necrotische regio's infiltreren en repliceren. Voor zowe Clostridium als Salmonella vectoren werd bewezen dat ze veilig kunnen worden toegediend en dat ze kunnen gebruikt worden om therapeutische eiwitten naar tumoren te transporteren. In dit werk wordt onderzoek beschreven met twee verschillende prokaryote anti-kanker vectoren. In het eerste gedeelte komt het gebruik van geattenueerde Salmonella spp. als vector aan bod. In het tweede gedeelte wordt het onderzoek met Clostridium beschreven. In het eerste gedeelte van het Salmonella werk, werd het potentieel bestudeerd van in vivo ${ }^{19} \mathrm{~F}$-MRS om het succes van het TAPET-CD/5-FC kankertherapie systeem te voorspellen. We hebben er aangetoond dat deze techniek inderdaad kan gebruikt worden om het resultaat van dit prokaryote-gemedieerde transfersysteem te voorspellen, en dat het nuttig is om met een niet-invasieve beeldvormingstechniek de behandeling op te volgen. Daarnaast hebben we onderzocht of het mogelijk was de specificiteit van het systeem te verhogen door gebruik te maken van een induceerbaar systeem. In de eerste plaats werd een hypoxie-induceerbare promoter (HIF-1, gebaseerd op de endogene pepT promoter) geselecteerd op basis van beschikbare literatuurgegevens. Dit resulteerde in vitro in een $\sim 40$-voudige inductie onder hypoxische condities. Bovendien hebben we met behulp van een reporterconstruct ook in een tumormodel in vivo deze hypoxie-inductie gevalideerd. Vervolgens hebben we deze promoter genetisch gewijzigd om de induceerbaarheid en de flexibiliteit van het systeem te maximaliseren. Ten tweede hebben we microarray experimenten uitgevoerd met als doel genen te identificeren die in hoge mate geinduceerd werden na blootstelling aan hypoxie of bestraling. Zo werden o.a. meer dan 45 genen geïdentificeerd die $>10$-voudig geïnduceerd werden in hypoxische condities. Dezelfde microarray technologie werd tenslotte ook gebruikt voor de identificatie van genen die specifiek in de tumor geïnduceerd werden, door het genomisch expressieprofiel van de Salmonella bacteriën geïsoleerd uit tumoren te analyseren. Onze waarnemingen tonen aan dat het gebruik van een induceerbaar systeem de selectiviteit van de Salmonella-gemedieerde transfer van therapeutische moleculen verbetert. Zulk een systeem kan dan ook een zinvolle uitbreiding vormen voor het klinisch gebruik van deze prokaryote vector. 
In het tweede gedeelte van deze thesis, wordt het onderzoek beschreven dat we hebben uitgevoerd om het Clostridium-gemedieerde vectorsysteem substantieel te verbeteren. In de eerste plaats hebben we een methode ontwikkeld, gebaseerd op conjugatie, die het voor het eerst mogelijk maakt on de Clostridium stammen met de beste tumorkoloniserende eigenschappen (e.g. C. sporogenes), op een efficiënte manier genetisch te wijzigen. Ten tweede, hebben we onderzocht of het mogelijk is, naar analogie met de situatie in een klinische setting, om meerdere consecutieve behandelingscycli met NTR-recombinante $C$. sporogenes bacteriën uit te voeren. In combinatie met toediening van een niet-toxische prodrug resulteerde dit in een veelbelovend aanhoudend anti-tumor effect. Tenslotte hebben we Clostridium ook gebruikt als vector om, naast de reeds beschreven prodrugconverterende enzymes en cytokines, antilichamen te produceren. We beschrijven dat het inderdaad mogelijk is om Clostridium genetisch te veranderen zodat ze een zogenaamd VHH tegen HIF-1 alpha tot expressie brengen. Deze VHH zijn afgeleid van een speciaal soort antilichaam, geïsoleerd uit kameelachtigen, waarvan de opbouw van de bindingscapaciteit wordt bepaald door één gen. Clostridium bracht dit VHH niet enkel tot expressie, er bleek ook dat de geproduceerde VHH's volledig functioneel waren. 


\section{Acknowledgement}

First of all, I owe my success and accomplishment to the almighty God, who helped me arod uphold me throughout my life. You have made my life more bountiful. May your wonderfut name be exalted, honored, and giorified.

After all those years, ive got quite a list of people who contributed in some way to this thesis. for which I would like to express thanks.

I would like to express my deep and sincere gratitude to my Promoter Professor Phlippe Lambin for giving me the opportunity to pursue my PhD study in his lab. My gratifude aiso goes to Prof Bradely G. Wouters for his wide knowledge and logical way of thinking have been of great value for me.

It is difficult to overstate my gratitude to my supervisor, Dr. Jan Theys, for his understanding and encouragement and also for his detailed and constructive comments, as well as his scientific guidance and support throughout this work have provided a good basis for the present thesis.

l owe my sincere gratitude to Professor Ming Wei, Head of the Department of Molecular Gene Therapy, Griffith University, Australia who gave me the opportunity to work in his lab in last months of my research work. I warmly thank for his valuable advice and friendly help. His discussions around my work have been very helpful.

My sincere thanks are due to the member of the evaluation committee Prof. dr. F.C.S Ramaekers, Prof. dr. C.A. Bruggeman, prof. dr. V. Tjan-Heijnen, Prof. dr. M. Vooujs for taking their time to read the manuscript.

My thanks are to all present and past colleagues in the lab of Maastricht radiation oncology (MAASTRO) for their good companionship and for their help in my stay in the lab and thank you all. Special thanks are due to Kim paesmans and Ludwig where we shared a lot of ideas in the same Gene therapy project.

During this work I have collaborated with many colleagues for whom I have great regard, and I wish to extend my warmest thanks to all those who have helped me with my work in the Department of Microbiology (IFT), Norwich, UK, and Department of Molecular Gene Therapy, Griffith University, Gold coast, Australia.

I am blessed with the support and encouragement from many people in my stay in Maastricht. W/o Merdia, Rahel, W/O Etetu and others made my stay in Maastricht easier and comfortable. Thank you all for your support in one way or another.

I would also like to use this opportunity to thank, Dr Fetene Bekele and Mihiret Anteneh (1 thank God for you guys being in The Netherlands after I left as you were my "liaison"- thanks Prof.), Ayenew melese and Yemariyamwork, Dr Hibru kelemu and Sable, Ato Getachew and Tsehay, Gash Gebeyaw and Amele and the rest of the Ethiopian Community members in Belgium for their continuous friendship, moral support and creating a home like atmosphere away from home particularly in my family's absence. I also cherished the prayers and support, 
and the friendships with my Christian brothers and sisters in Leuven and Antwerp. I treasured all precious moments we shared and would really like to thank you all.

I am thankful for my family and relatives back home for their love, encouragement,and moral supports.

Finally, I would like to thanks my wife Dr. Netsanet and my children for whom there are no words to express my love. Thank you HAYE for your love and constant encouragement. Without your moral support and patience which was tested to the utmost by a long period of separation, it would have been impossible for me to complete this work. LOVE you so much. Particularly, my gratitude goes to my dearer sons- Ammanuel and Bereket whom have lost my company a lot due to my research away from where they spend part of their precious childhood period. To them I dedicate this thesis. 


\section{Curriculum vitae}

Asferd Mengesha was born in November 10, 1969 in Negelle Borena, Ethiopia. He graduated from Gondar College of Medical Sciences, Addis Ababa University in 1993 as a Medical Doctor and served as general medical practitioner for more than six years before he did his first master degree at the Universite Lebre De Bruxelles (ULB) in public health in 1999-2000. After graduating with great distinction from ULB he joined an interuniversity program for "Master of Science in Molecular Biology" at Vrije Universiteit Brussel (VUB), Belgium. He did his master thesis at Rega Institute for Medical Research, Laboratory of Bacteriology under Prof. Anne with the title "Analysis of inducibility of RecA Promoter and Modification Thereof for Controlled Gene Expression In Cancer Gene Therapy". After his master he stayed at Katholieke Universitiet Leuven (KUL), Belgium as a pre-doctoral fellow for about two years and then moved to Maastricht. As of 2005 he was working as AlO (PhD student) at Maastricht Radiation Oncology Lab (MAASTRO), Grow-School for Oncology and Developmental Biology, University of Maastricht under the supervision of Dr. Jan Theys and his promoter Prof. Philippe Lambin. With in gene therapy group, he examined the use of non-pathogenic bacteria as vectors for treatment of solid tumors. 


\section{List of publications}

- Asferd Mengesha, Roy Bongaerts, Ludwig Dubois, Brad Wouters, Jay Hinton, Philippe Lambin and Jan Theys. Identification of highly induced Salmonella genes to increase the specificity of Salmonella mediated cancer therapy. 2008. In preparation

- Ming Q Wei, Asferd Mengesha, David Good, Jozef Anné: Bacterial targeted tumour therapy-dawn of a new era; Cancer Lett. 2008 Jan 18;259(1):16-27

- Asferd Mengesha*; Arjan J Groot*; Elsken van der Wall; Paul $J$ van Diest; Jan Theys;

Dear Dr. Vooijs. Functional antibodies produced by oncolytic Clostridia. Biochem Biophys Res Commun. 2007 Dec 28;364(4):985-9.

- Asferd Mengesha, Ludwig Dubois, Roland K. Chiu, Bradly G. Wouters ,Philippe Lambin and Jan Theys: Potential And Limitations Of Bacterial-Mediated Cancer Therapy. Frontiers of Bioscience. Front Biosci. 2007 May 1;12:3880-91.

* J. Theys, L. Dubois, A. Mengesha, K.C.I. Paesmans, W. Landuyt, B.G. Wouters en $P$. Lambin. Bacteriën als vector bij behandeling van kanker (Bacteria as vector in cancer treatment). Nederlands tijdeschrift voor oncologie. 2007: 4(2) 79-86.

- Theys J, Pennington O, Dubois L, Anlezark G, Vaughan T, Mengesha A, Landuyt W, Anne J, Burke PJ, Durre P, Wouters BG, Minton NP, Lambin P. Repeated cycles of Clostridium-directed enzyme prodrug therapy result in sustained antitumor effects in vivo. $\mathrm{Br} J$ Cancer. 2006 Nov 6;95(9):1212-9.

- Dubois L, Dresselaers T, Landuyt W, Paesmans K, Mengesha A, Wouters BG, Hecke PV, Theys J, Lambin P. Efficacy of gene therapy-delivered cytosine deaminase is determined by enzymatic activity but not expression. $\mathrm{Br} J$ Cancer.(2007) 96, 758 -761

- Mengesha A, Dubois L, Lambin P, Landuyt W, Chiu RK, Wouters BG, Theys J. Development of a flexible and potent hypoxia-inducible promoter for tumor-targeted gene expression in attenuated Salmonella. Cancer Biol Ther. 2006 Sep;5(9):1120-8. 
Book chapters:

- Asferd Mengesha, Ludwig Dubois, Kim Paesmans, Brad Wouters, Philippe Lambin and Jan Theys. (2009). Clostridia in anti-tumour therapy' in "Current Topics in the Molecular Biology of Clostrdia" (Horizon Scientific Press). In press.

- Wei MQ, Mengesha A, Anne J. The New Era for Bacterial Targeted Tumor Therapy. In: Gene Therapy and Cancer Research Focus. Rebecca N. Campbell, NOVA Science Publishers, New York; 293-307, 2008. 
Printed by PROCOPIA NV Ambachtenlaan 29 3001 Heverlee 0.16/38.36.34 info@procopia.be wWw.procopia.be 